ANALYSIS AND CONTROL OF COMPLEX FLOWS IN U-BENDS USING COMPUTATIONAL FLUID DYNAMICS

A THESIS SUBMITTED TO

THE GRADUATE SCHOOL OF NATURAL AND APPLIED SCIENCES $\mathrm{OF}$ MIDDLE EAST TECHNICAL UNIVERSITY

BY

YİĞİTCAN GÜDEN

IN PARTIAL FULLFILLMENT OF THE REQUIREMENTS FOR

THE DEGREE OF MASTER OF SCIENCE

IN

MECHANICAL ENGINEERING 

Approval of the thesis:

\section{ANALYSIS AND CONTROL OF COMPLEX FLOWS IN U-BENDS USING COMPUTATIONAL FLUID DYNAMICS}

submitted by YİĞITCAN GÜDEN in partial fulfillment of the requirements for the degree of Master of Science in Mechanical Engineering Department, Middle East Technical University by,

Prof. Dr. Canan Özgen

Dean, Graduate School of Natural and Applied Sciences

Prof. Dr. Suha Oral

Head of Department, Mechanical Engineering

Assoc. Prof. Dr. Mehmet Metin Yavuz

Supervisor, Mechanical Engineering Dept., METU

\section{Examining Committee Members:}

Assist. Prof. Dr. Merve Erdal

Mechanical Engineering Dept., METU

Assoc. Prof. Dr. Mehmet Metin Yavuz

Mechanical Engineering Dept., METU

Assist. Prof. Dr. Cüneyt Sert

Mechanical Engineering Dept., METU

Assist. Prof. Dr. Yiğit Yazıcıoğlu

Mechanical Engineering Dept., METU

Assoc. Prof. Dr. Murat Kadri Aktaş

Mechanical Engineering Dept., TOBB ETU

Date: $\quad 03 / 09 / 2014$ 
I hereby declare that all information in this document has been obtained and presented in accordance with academic rules and ethical conduct. I also declare that, as required by these rules and conduct, I have fully cited and referenced all material and results that are not original to this work.

Name, Last name: Yiğitcan Güden

Signature: 


\title{
ABSTRACT \\ ANALYSIS AND CONTROL OF COMPLEX FLOWS IN U-BENDS USING COMPUTATIONAL FLUID DYNAMICS
}

\author{
Güden, Yiğitcan \\ M. S., Department of Mechanical Engineering \\ Supervisor: Assoc. Prof. Dr. Mehmet Metin Yavuz
}

September 2014, 101 pages

Analysis and control of flow structure is crucial in the sense that the increase in the ratio of inertial and centrifugal forces to viscous forces destabilizes the flow and creates a three-dimensional complex flow consisting of stream wise parallel counterrotating vortices, so-called Dean vortices. In addition, due to the curvature in Ubends, in line with these vortices, a high level of turbulence is detected, which is quite critical in considering noise problems and structural failures.

In this thesis, computational fluid dynamic (CFD) models are developed using ANSYS FLUENT to analyze and to control these complex flows patterns in square sectioned U-bend with a radius of curvature $R_{c} / D=0.65$. The predictions of velocity profiles on different angular positions of the U-bend are compared against the experimental results available in the literature and previous numerical studies. The performances of six different turbulence models are evaluated, namely: the standard k- $\varepsilon$, the k- $\varepsilon$ Realizable, the k- $\varepsilon$ RNG, the k- $\omega$ SST, the Reynolds Stress Model (RSM) and the Scale-Adaptive Simulation Model (SAS), to propose the best numerical approach that has high accuracy with reduced computation time. Numerical results of the present thesis show improvements with respect to the previous numerical studies 
and very good agreement with the available experimental results. In addition, a flow control technique with using airfoils inside the bend is applied to regulate the flow inside the duct. With this control technique, the elimination of Dean vortices along with significant reduction in turbulence levels in different cross flow planes are successfully achieved.

Keywords: U-bend, Dean Vortex, Turbulence Intensity, Computation Time, Flow Control Strategy 


\title{
U-DİRSEKLERDE OLUŞAN KOMPLEKS AKIŞIN CFD MODELLEME KULLANILARAK ANALİZI VE KONTROLÜ
}

\author{
Güden, Yiğitcan \\ Yüksek Lisans, Makina Mühendisliği Bölümü \\ Tez Yöneticisi: Doç. Dr. Mehmet Metin Yavuz
}

Eylül 2014, 101 sayfa

Dirseklerde akış içerisindeki eylemsizlik ve merkezkaç kuvvetlerinin akışmazlık kuvvetine oranının artması akışı istikrarsızlaştııı ve içerisinde Dean vorteks olarak anılan akış yönünde ters dönüşlü vorteksleri barındıran üç boyutlu kompleks akış yapılarının oluşmasına sebep olur, bu yüzden akış yapısının analizi ve kontrolü kritik önem taşımaktadır. Buna ek olarak U-dirseklerdeki eğrilikten dolayı ses problemleri ve yapısal bozukluklarda kritik önem taşıyan yüksek türbülans değerleri oluşmaktadır.

$\mathrm{Bu}$ tez çalışmasında, eğrilik yarıçapı 0.65 olan kare kesitli bir U-dirsekte oluşan kompleks akış şekillerini analiz ve kontrol etmek için ANSYS FLUENT kullanarak CFD modeller geliştirilmiştir. U-dirsek içerisindeki farklı açısal pozisyonlarda elde edilen hız profili tahminleri literatürde bulunan deneysel sonuçlar ve daha önceki nümerik çalışmalar ile kıyaslanmıştır. Yüksek doğruluk ve düşük hesaplama zamanı kriterleri göz önünde bulundurularak en iyi nümerik yaklaşımı önerebilmek için altı değişik türbülans modelin performansı değerlendirilmiştir, bu modeller: the standard

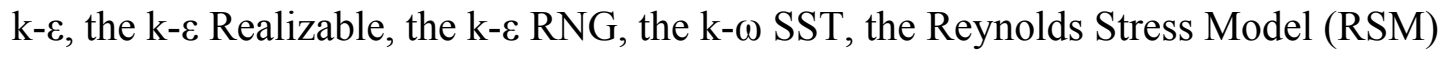
and the Scale-Adaptive Simulation Model (SAS). Bu tez çalışmasının sonuçları, 
literatürdeki nümerik çalışmalara göre ilerlemeler göstermekte ve deneysel sonuçlar ile çok iyi bir şekilde örtüşmektedir. Bunlara ek olarak, akış kontrol tekniği olarak dirsek içerisine yerleştirilen kanat profilleri ile kanaldaki akış düzenlenmiştir. $\mathrm{Bu}$ teknik ile Dean vortekslerin yok edilmesi ve buna bağlı olarak akış kesitlerindeki türbülans seviyelerinde dikkate değer bir düşüş başarıyla sağlanmıştır.

Anahtar Kelimeler: U-dirsek, Dean Vortex, Türbülans Yoğunluğu, Hesaplama Zamanı, Akış Kontrol Tekniği 
To My Parents 


\section{ACKNOWLEDGEMENTS}

I would like to express my sincere gratitude to my supervisor, Assoc. Prof. Dr. M. Metin Yavuz, for his invaluable supervision, advice, criticism and support that made the study possible.

I would like to thank Enis Dönmez, Kadir Ali Gürsoy, Mahmut Murat Göçmen, Nevin Spahieva and to all other for valuable their friendship and without them it is impossible for me to finish this study.

I would also like to thank Erkin Turgut, Chief Engineer of the Project and Technical Support Department in my former company and Kerem Ali Günbulut, Chief Engineer in my present company for their executive support, tolerance and trust.

I would like to thank my colleague Ufuk Yiğit for his support and guidance.

I would like to thank my family for their support and patience. 


\section{TABLE OF CONTENTS}

ABSTRACT

\section{CHAPTERS}

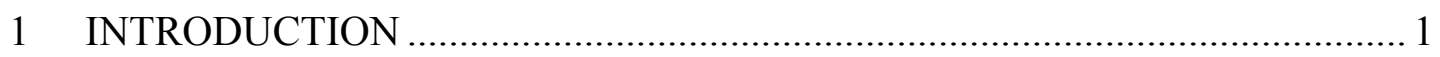

1.1 Motivation of the Study .................................................................. 1

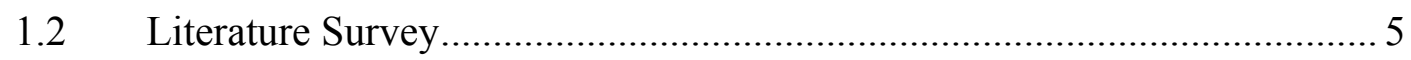

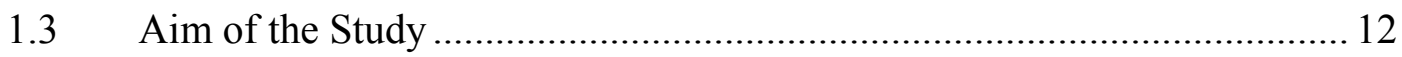

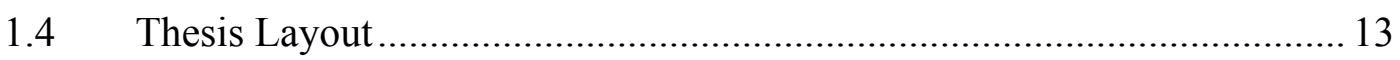

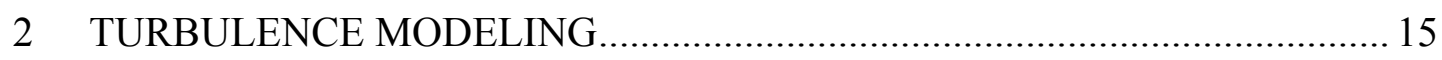

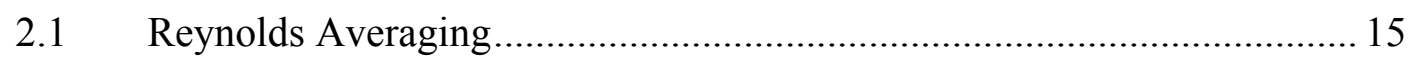

2.2 Boussinesq Approach and Reynolds Stress Transport Models................. 17

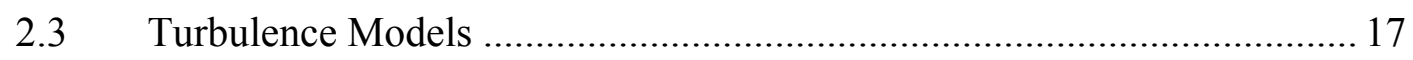

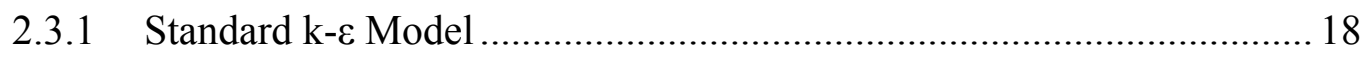




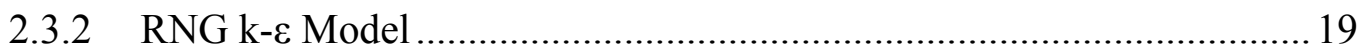

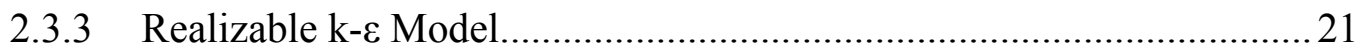

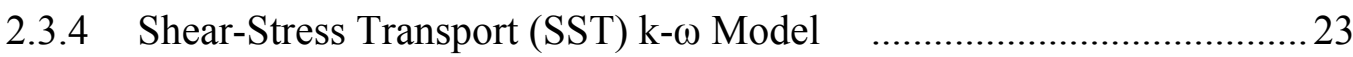

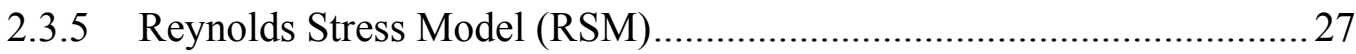

2.3.6 Scale-Adaptive Simulation (SAS) Model .............................................. 31

3 MODEL DEVELOPMENT AND MESH INDEPENDENCY …........................35

3.1 Description of the Test Case …….................................................... 35

3.2 Development of the CFD Model ............................................................ 37

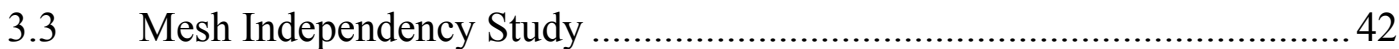

4 VERIFICATION AND COMPARISON OF DIFFERENT TURBULENCE

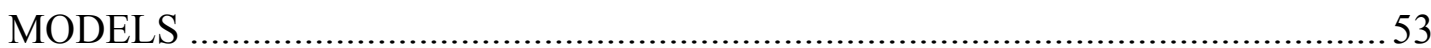

4.1 Velocity Profiles at Bend Sections ............................................................5 53

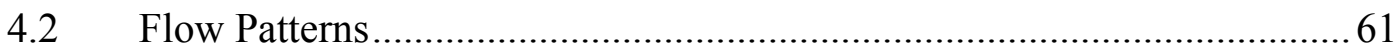

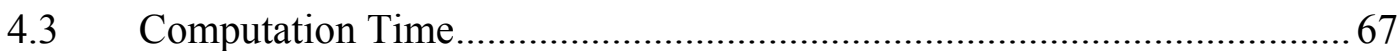

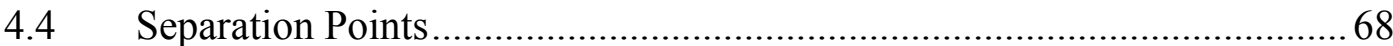

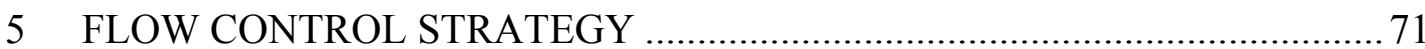

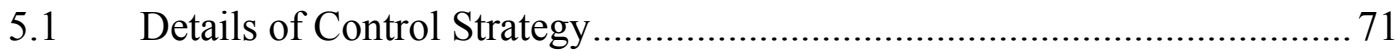

5.2 Flow Control Model Development ..................................................... 74

$5.3 \quad$ Results of Flow Control Strategy .......................................................... 76

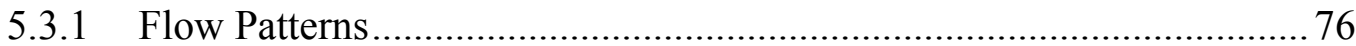




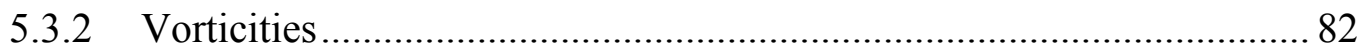

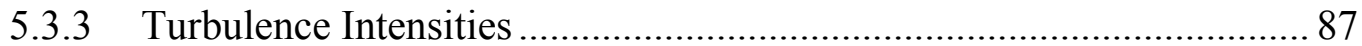

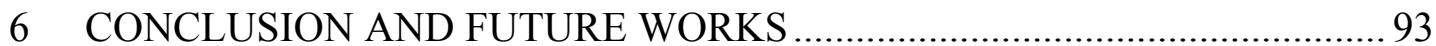

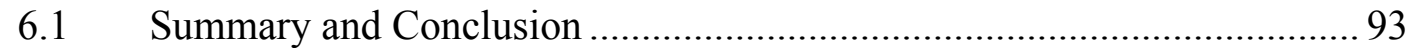

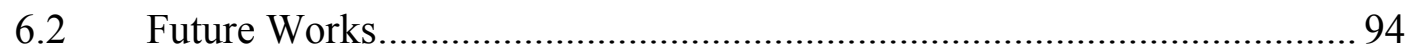

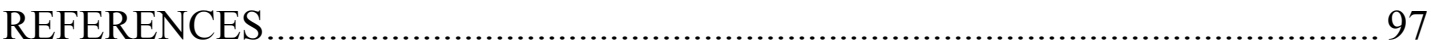




\section{LIST OF TABLES}

\section{TABLES}

Table 1.1 Experimental studies on bend flows

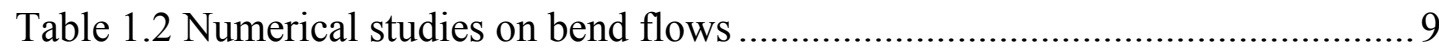

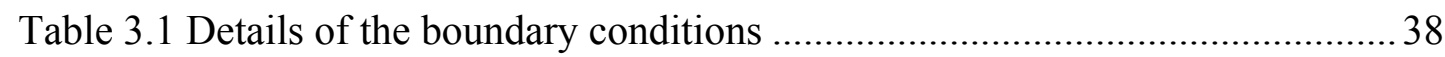

Table 3.2 The summary of the parameters used in mesh independency study 45

Table 3.3 Statistics of meshes used in the mesh independency study 47

Table 4.1 The computation requirements of different turbulence models 67

Table 4.2 The location of separation points 69

Table 5.1 Parameters and statistics of mesh used in the flow control 75

Table 5.2 The plane average vorticity levels of the base model and the controlled case 87

Table 5.3 The maximum and average turbulence intensity levels of the base model and the controlled case .92 


\section{LIST OF FIGURES}

\section{FIGURES}

Figure 1.1 Details of Ducret's experimental setup for 90 degree bends; (a) R/D =1.6;

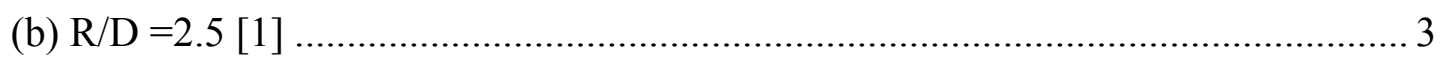

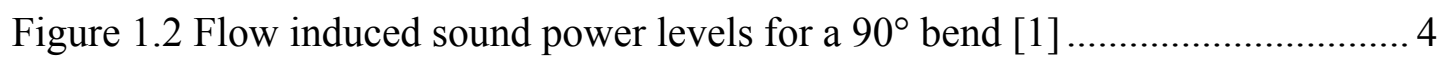

Figure 1.3 Details of the Azzola et al.'s experimental setup [7] ............................. 6

Figure 1.4 Schematic diagram of test bend used in Sudo et al's experiments [9] ....... 7

Figure 1.5 Axial velocity contours and secondary velocity vectors at 135 deg. (a) computed velocity vectors; (b) computed axial velocity contours; (c) measured axial

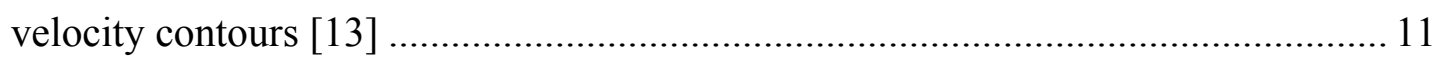

Figure 1.6 Schematic display of square sectioned $180^{\circ}$ U-bend duct flows used in Djebedjian et al's study; (a) $\mathrm{R}_{\mathrm{c}} / \mathrm{D}=3.357$; (b) $\mathrm{R}_{\mathrm{c}} / \mathrm{D}=0.65$ [16] .............................. 12

Figure 3.1 The schematic display of the fluid domain for the test case.................... 36

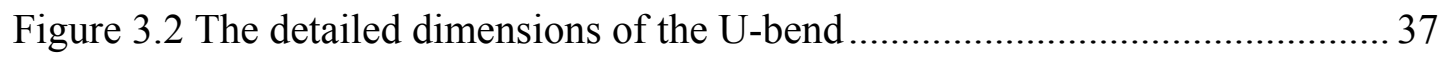

Figure 3.3 Solver residuals used for determining the convergence level of the

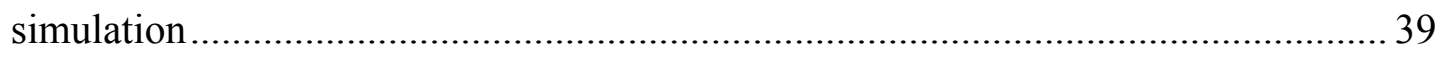

Figure 3.4 The location of the monitor points used for determining the convergence level of the simulations 40

Figure 3.5 Convergence results for the monitor points located in the inlet and exit sections 41

Figure 3.6 Convergence results for the monitor points located in the bend section .. 41 
Figure 3.7 The histogram of $\mathrm{y}^{+}$values 44

Figure 3.8 Contours of constant $\mathrm{y}^{+}$values in the bend .44

Figure 3.9 The coarsest mesh used in the mesh independency study .46

Figure 3.10 The finest mesh used in the mesh independency study 47

Figure 3.11 Mesh independency results on mean streamwise velocity 48

Figure 3.12 Mean streamwise velocity profiles at $180^{\circ}$ bend angle $2 \mathrm{y} / \mathrm{D}=0.25$ plane 49

Figure 3.13 Mean streamwise velocity profiles at $180^{\circ}$ bend angle $2 \mathrm{y} / \mathrm{D}=1$ plane $\ldots 49$

Figure 3.14 The preview of the selected mesh (Mesh 4) for numerical simulations . 50

Figure 3.15 The preview of the selected mesh at the bend section 50

Figure 3.16 The preview of the selected mesh at the 90 -degree bend section 51

Figure 4.1 The mean streamwise velocity profiles at $90^{\circ}$ in the bend; (a) $2 \mathrm{y} / \mathrm{D}=0.25$; (b) $2 \mathrm{y} / \mathrm{D}=1$ .54

Figure 4.2 The mean streamwise velocity profiles at $135^{\circ}$ in the bend; (a) $2 \mathrm{y} / \mathrm{D}=0.25$; (b) $2 \mathrm{y} / \mathrm{D}=1$ .55

Figure 4.3 The mean streamwise velocity profiles at $180^{\circ}$ in the bend; (a) $2 \mathrm{y} / \mathrm{D}=0.25$; (b) $2 y / D=1$ 56

Figure 4.4 The comparison of the experimental results, present analyses' standard k- $\varepsilon$ and k- $\omega$ SST model results, and the previous studies Djebedjian et al.'s best predictions (RSM model) at $90^{\circ}$ bend angle; (a) $2 \mathrm{y} / \mathrm{D}=0.25$; (b) $2 \mathrm{y} / \mathrm{D}=1$ .58

Figure 4.5 The comparison of the experimental results, present analyses' standard k- $\varepsilon$ and k- $\omega$ SST model results, and the previous studies Djebedjian et al.'s best predictions (RSM model) at $135^{\circ}$ bend angle; (a) $2 \mathrm{y} / \mathrm{D}=0.25$; (b) $2 \mathrm{y} / \mathrm{D}=1$ 59 
Figure 4.6 The comparison of the experimental results, present analyses' standard k- $\varepsilon$ and k- $\omega$ SST model results, and the previous studies Djebedjian et al.'s best predictions (RSM model) at $180^{\circ}$ bend angle; (a) $2 \mathrm{y} / \mathrm{D}=0.25$; (b) $2 \mathrm{y} / \mathrm{D}=1$ 60

Figure 4.7 The streamlines associated with secondary flow patterns predicted by the standard k- $\varepsilon$ model at; (a) $\theta=90^{\circ}$; (b) $\theta=135^{\circ}$; (c) $\theta=180^{\circ}$

Figure 4.8 The streamlines associated with secondary flow patterns predicted by the k- $\omega$ SST model at; (a) $\theta=90^{\circ}$; (b) $\theta=135^{\circ}$; (c) $\theta=180^{\circ}$ 63

Figure 4.9 The contours of constant turbulence intensity levels predicted by the standard k- $\varepsilon$ model at; (a) $\theta=90^{\circ}$; (b) $\theta=135^{\circ}$; (c) $\theta=180^{\circ}$ 64

Figure 4.10 The contours of constant turbulence intensity levels predicted by the k- $\omega$ SST model at; (a) $\theta=90^{\circ}$; (b) $\theta=135^{\circ}$; (c) $\theta=180^{\circ}$ 65

Figure 4.11 Demonstration of experimental resolution used in Cheah et al.'s study [11] 68

Figure 5.1 The schematic display of the fluid domain with airfoils at the 45-degree plane used as flow control technique .72

Figure 5.2 Airfoil nomenclature [33] 73

Figure 5.3 The preview of the mesh used for the simulations with airfoils. 74

Figure 5.4 The preview of the mesh inside the bend and on the airfoils 75

Figure 5.5 The contours of velocity at the simulation domain are shown in (a) for the base model and in (b) for the controlled case 76

Figure 5.6 The streamlines associated with secondary flow patterns at $\theta=90^{\circ}$ are shown in (a) for the base model and in (b) for the controlled case. 78

Figure 5.7 The streamlines associated with secondary flow patterns at $\theta=120^{\circ}$ are shown in (a) for the base model and in (b) for the controlled case..... .79 
Figure 5.8 The streamlines associated with secondary flow patterns at $\theta=150^{\circ}$ are shown in (a) for the base model and in (b) for the controlled case 80

Figure 5.9 The streamlines associated with secondary flow patterns at $\theta=180^{\circ}$ are shown in (a) for the base model and in (b) for the controlled case 81

Figure 5.10 The contours of constant vorticity levels at $\theta=90^{\circ}$ are shown in (a) for the base model and in (b) for the controlled case. 83

Figure 5.11 The contours of constant vorticity levels at $\theta=120^{\circ}$ are shown in (a) for the base model and in (b) for the controlled case. 84

Figure 5.12 The contours of constant vorticity levels at $\theta=150^{\circ}$ are shown in (a) for the base model and in (b) for the controlled case. 85

Figure 5.13 The contours of constant vorticity levels at $\theta=180^{\circ}$ are shown in (a) for the base model and in (b) for the controlled case 86

Figure 5.14 The contours of constant turbulence intensity levels at $\theta=90^{\circ}$ are shown in (a) for the base model and in (b) for the controlled case. 88

Figure 5.15 The contours of constant turbulence intensity levels at $\theta=120^{\circ}$ are shown in (a) for the base model and in (b) for the controlled case. 89

Figure 5.16 The contours of constant turbulence intensity levels at $\theta=150^{\circ}$ are shown in (a) for the base model and in (b) for the controlled case. 90

Figure 5.17 The contours of constant turbulence intensity levels at $\theta=180^{\circ}$ are shown in (a) for the base model and in (b) for the controlled case. 91 


\section{LIST OF SYMBOLS}

\begin{tabular}{|c|c|}
\hline$D$ & width of duct, or pipe diameter (m) \\
\hline $\mathrm{De}$ & Dean number \\
\hline$I$ & turbulence intensity, $(\%)$ \\
\hline$k$ & turbulent kinetic energy, $\left(\mathrm{m}^{2} / \mathrm{s}^{2}\right)$ \\
\hline$P_{\text {static }}$ & static pressure, $\left(\mathrm{N} / \mathrm{m}^{2}\right)$ \\
\hline $\bar{p}$ & mean pressure, $\left(\mathrm{N} / \mathrm{m}^{2}\right)$ \\
\hline$r^{\prime}$ & transverse distance measured from convex to concave wall, (m) \\
\hline$R_{c}$ & radius of curvature of U-bend, (m) \\
\hline $\operatorname{Re}$ & Reynolds number, \\
\hline$t$ & time, $(\mathrm{s})$ \\
\hline$u_{\text {wall }}$ & velocity at wall, $(\mathrm{m} / \mathrm{s})$ \\
\hline$U$ & mean streamwise velocity component, $(\mathrm{m} / \mathrm{s})$ \\
\hline$U_{0}$ & average inlet velocity, $(\mathrm{m} / \mathrm{s})$ \\
\hline$y^{+}$ & distance from pipe wall \\
\hline$y$ & distance from pipe wall, $(\mathrm{m})$ \\
\hline$\varepsilon$ & turbulence dissipation rate, $\left(\mathrm{m}^{2} / \mathrm{s}^{3}\right)$ \\
\hline$\omega$ & specific turbulence dissipation rate, $\left(\mathrm{s}^{-1}\right)$ \\
\hline$\theta$ & angle of turn, (deg) \\
\hline$\mu$ & laminar viscosity of fluid, (Pa.s) \\
\hline
\end{tabular}




$\begin{array}{ll}\mu_{t} & \text { turbulent viscosity, }(\mathrm{Pa} . \mathrm{s}) \\ v & \text { kinematic viscosity, }\left(\mathrm{m}^{2} / \mathrm{s}\right) \\ \rho & \text { density of fluid, }\left(\mathrm{kg} / \mathrm{m}^{3}\right) \\ \text { ASM } & \text { algebraic stress model } \\ \text { EWT } & \text { enhanced wall treatment } \\ \text { LDA } & \text { Laser Doppler Anemometer } \\ \text { RNG } & \text { re-normalization group } \\ \text { RSM } & \text { Reynolds stress model } \\ \text { SAS } & \text { scale-adaptive simulation } \\ \text { SPL } & \text { sound pressure level } \\ \text { SST } & \text { shear stress transport }\end{array}$




\section{CHAPTER 1}

\section{INTRODUCTION}

\subsection{Motivation of the Study}

Ducts with thin flexible vibrating walls are used in buildings for airflow transportation between the various locations for ensuring better living conditions. Ducts are generally made of thin aluminum or steel sheets. Although, the main purpose is the transportation of a fluid such as air, noise is also carried out along the duct. Various sources can be thought of, the most obvious one is the fan or fluid machine connected to the duct [1].

However, Marks [2] showed in his research on the calculation of generated noise in ducts that for the places which requires low noise levels as their nature such as theatres, concert halls and film studios, the main source of noise is not fan noise. He found that flow-generated noise within the duct system by fittings and control elements has higher sound levels than fan noise.

The magnitude of the sound can be shown in two different ways; sound power level and sound pressure level (SPL). Sound power level gives the total acoustic power emitted by the source and shows the power per unit area of the sound pressure wave. Sound pressure is measured via a single microphone and is depending on the location of the observer [3]. Sound pressure level measures the changes in pressure and is the most popular way to describe the human behavior across the sound. Distance of the receiver to the sound and the environment are the two main parameters that affect sound pressure level directly whereas sound power level is independent of both of these parameters [4]. 
Despite sound power shows acoustical energy exactly, it is impossible to measure sound power directly. It is calculated with the usage of a series of sound pressure measurements [4].

The cooling passages generally consist of bends with sharp turns. The flow inside these passages with a sharp turn shows strong secondary flow patterns, with the effect of the curvature, separation and reattachment. The interference between secondary flows and separation lead to complex flow patterns. When flow enters a curved section, high velocity fluid in the center part tends to move outwards whereas slow velocity fluid near to pipe sides travels inwards. This behavior creates C-shaped streamwise velocity patterns and induces two counter-rotating vortices, the so-called Dean vortices [5]. These vortices contribute to formation of turbulent flow and generate sound power inside the bend.

Ducret [1], focused on flow generated sound in bends in his study. He conducted experiments with different bend geometries. One of the bend geometries that he focused on is 90 -degree bends. For these bends, the angle separating the upstream and downstream sections is $90^{\circ}$. He conducted experiments for two different radius of curvature that ratios of curvature radius $\mathrm{R}$ to pipe diameter $\mathrm{D}$ to be of 1.6 and 2.5. Figure 1.1 shows the details of the Ducret's [1] experimental setup. Figure 1.1(a) shows the setup for the $R / D=1.6$ case and (b) for the $R / D=2.5$ case. In his analysis, flow induced sound power level of the straight pipe is subtracted from the sound power level measured for each bend to obtain the right sound power level increase for bends. He compared the results of two different bend curvatures with straight pipe results. 


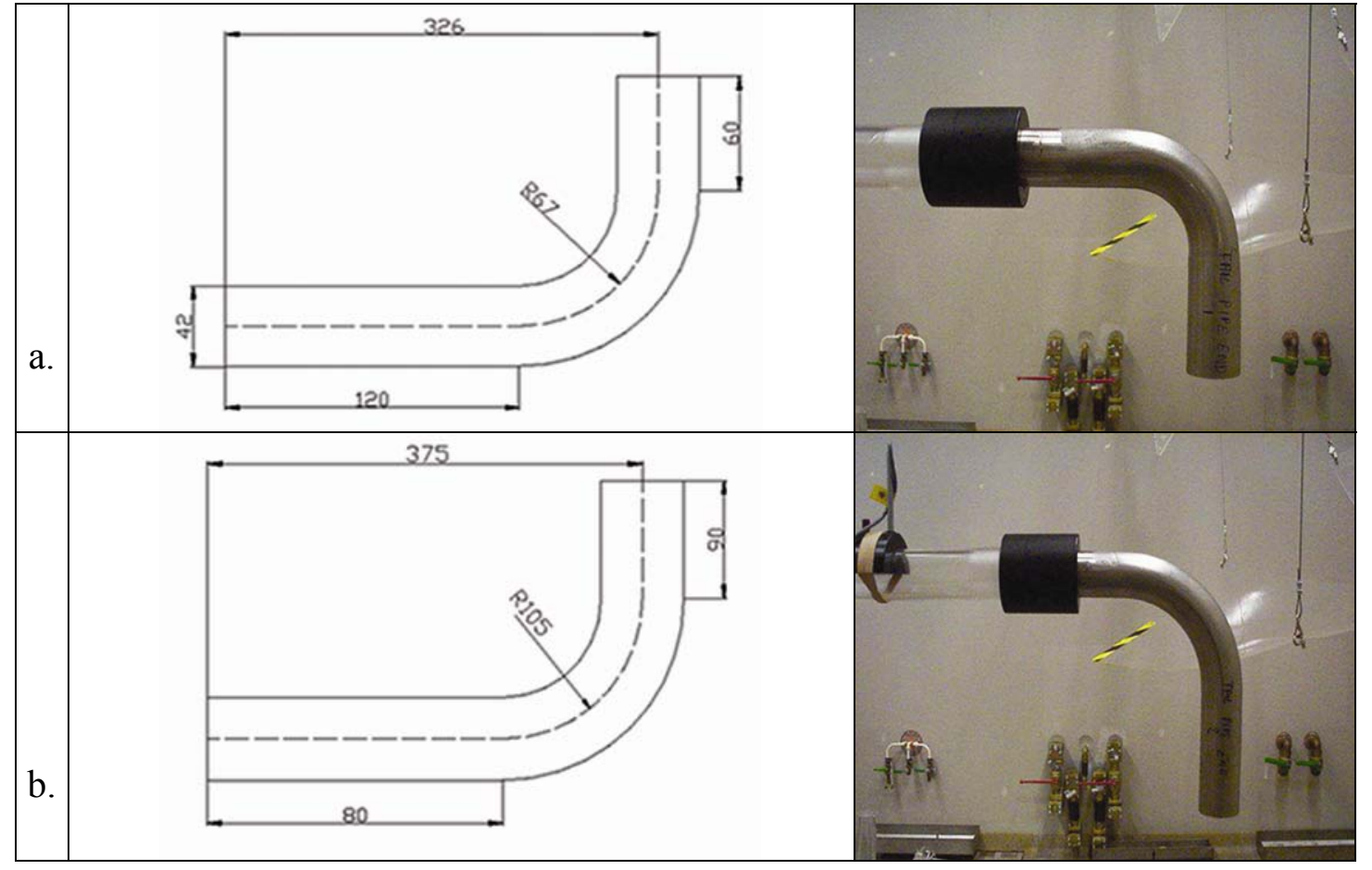

Figure 1.1 Details of Ducret's experimental setup for 90 degree bends; (a) R/D =1.6; (b) $\mathrm{R} / \mathrm{D}=2.5[1]$

Figure 1.2 shows the results of the Ducret's study for the 90 degree pipe bends [1]. In this figure the y-axis shows the sound power levels and $\mathrm{x}$-axis shows the sound frequencies. Straight pipe results are shown with the dashed lines whereas bends with different curvatures' results are shown with black and gray lines.

According to his study, sound power levels are higher for the pipe with bends than straight pipes. He also found that a 90 degree bend with a curvature $R / D=1.6$ causes a significant sound power level increase. Moreover, the decrease of the bend radius, which means sharper bends, causes higher sound power levels. 


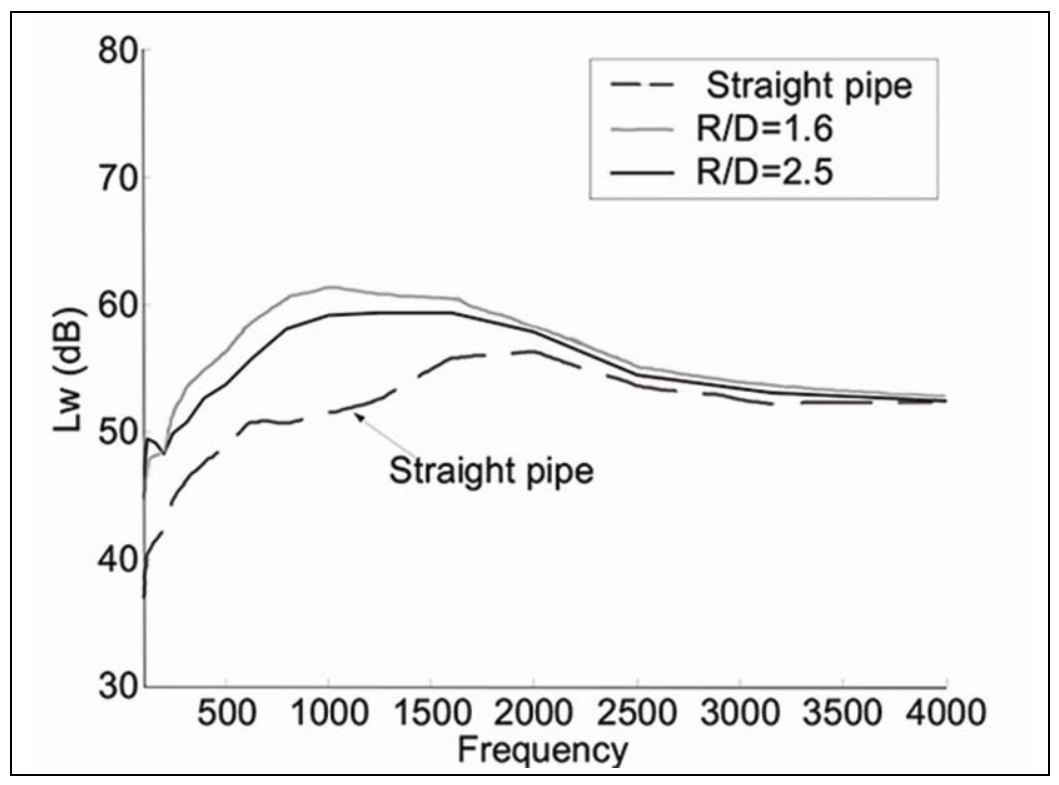

Figure 1.2 Flow induced sound power levels for a $90^{\circ}$ bend [1]

From Figure 1.2 it is easy to see that, especially at low frequencies, bend causes nearly $10 \mathrm{~dB}$ sound power level increase due to the complex flow inside the bend. This increase is significant because;

- A $1 \mathrm{~dB}$ change in the sound level cannot be recognized except laboratory conditions.

- Doubling the energy of a sound source causes a $3 \mathrm{~dB}$ increase in sound level.

- An increase in sound level of $6 \mathrm{~dB}$ means decreasing the distance of a sound source to the half.

- A $10 \mathrm{~dB}$ increase double the loudness and heard in a subjective manner.

Moreover, SPL (sound pressure level) of $140 \mathrm{~dB}$ is the threshold of pain [3]. To solve the flow induced sound problems in bends; it is important to resolve the turbulence characteristics of bend flow and try to minimize turbulence effects in bends. 
Before examining turbulence in bends in detail, it would be beneficial to investigate other studies in literature. Below, the review of the studies on turbulence in duct bends is presented.

\subsection{Literature Survey}

Turbulent flow characteristics in bends have been subjected to several experimental and numerical studies and particularly different bend angles, curvatures and cross sections have been investigated.

For the curved pipe flows, Rowe [6], Azzola et al. [7] and Anwer et al. [8] focused on circular cross sectioned bends while Sudo et al. [9], Chang et al. [10], Cheah et al. [11] focused on square sectioned bends, experimentally. In Table 1.1, the experimental studies found in the literature are tabulated and compared with each other.

Table 1.1 Experimental studies on bend flows

\begin{tabular}{|c|c|c|c|c|}
\hline Owner of the Study & $\mathbf{R}_{\mathbf{c}} / \mathbf{D}$ & $\mathbf{R e}$ & Bend Angle & Cross Section \\
\hline Rowe [6] & 12 & $2.36 \times 10^{5}$ & $180^{\circ}$ & Circle \\
\hline Azzola et al. [7] & 3.375 & $5.74 \times 10^{4}$ & $180^{\circ}$ & Circle \\
\hline Anwer et al [8] & 6.5 & $5 \times 10^{4}$ & $180^{\circ}$ & Circle \\
\hline Sudo et al. [9] & 4.0 & $4 \times 10^{4}$ & $90^{\circ}$ & Square \\
\hline Chang et al. [10] & 3.375 & $5.67 \times 10^{4}$ & $180^{\circ}$ & Square \\
\hline Cheah et al. [11] & 0.65 & $10^{5}$ & $180^{\circ}$ & Square \\
\hline
\end{tabular}


Rowe [6] conducted turbulent flow analyses with a $180^{\circ}$ bend at Reynolds number $2.36 \times 10^{5}$ with a radius of curvature $R_{c} / D=12$ where $D$ is the diameter of the pipe. An upstream tangent of length $\mathrm{X} / \mathrm{D}=69$ was used to provide a fully developed axisymmetric turbulent velocity profile at the bend inlet plane. He found that the secondary motion is greatest at $30^{\circ}$ from the inlet of the bend reducing afterwards its strength but still persisting until it reaches $90^{\circ}$.

Azzola et. al [7] used Laser-Doppler measurement technique to obtain the longitudinal and circumferential velocity components of a turbulent flow in a $180^{\circ}$ pipe bend. Figure 1.3 shows the basic components of the experimental test setup schematically. The results showed that the flow behavior for circular cross-sectioned U-bend is quite different than the square cross-sectioned U-bend. They revealed that the secondary flow patterns start at $45^{\circ}$ bend angle, which is not the case for square U-bends.

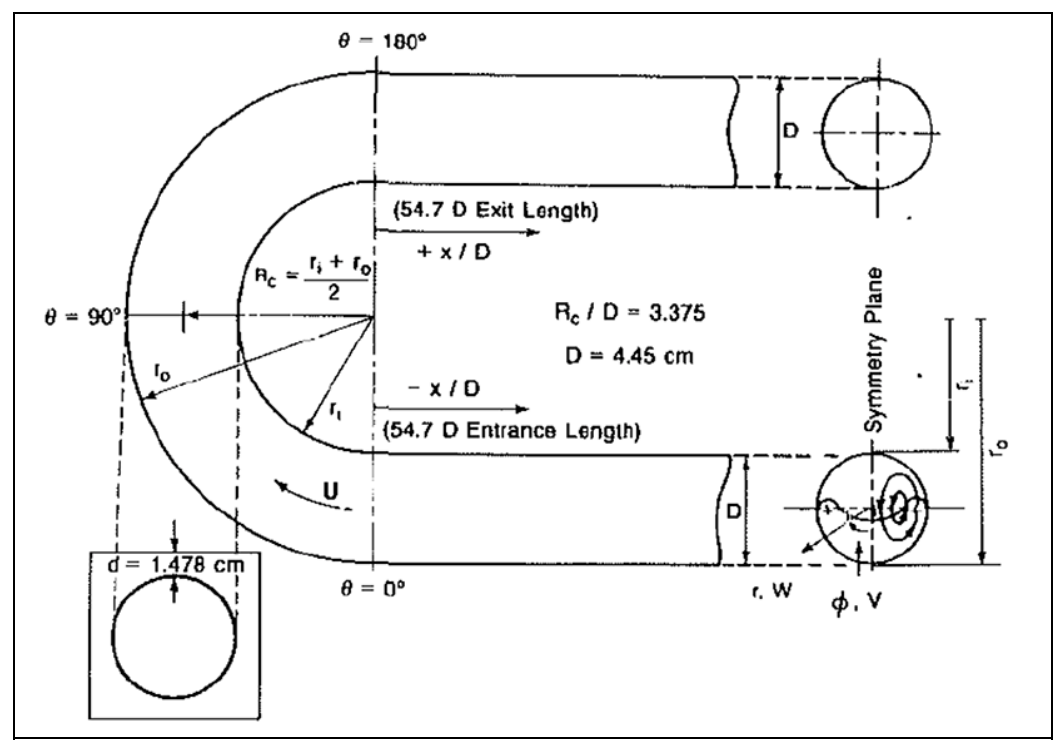

Figure 1.3 Details of the Azzola et al.'s experimental setup [7]

Anwer et al. [8] investigated flow and turbulence characteristics of the $180^{\circ}$ bend. They also investigated the flow development after the downstream tangent and they found that the flow reattaches 18 hydraulic diameters away from the bend exit. 
Sudo et al. [9] focused on the turbulent flow in a $90^{\circ}$ bend section of a square duct by using hot-wire anemometer. Details of the test bend are shown in Figure 1.4. They rotate an inclined hot-wire probe, inside the bend and measured the different velocity components and the Reynolds stresses. They found that the pressure difference between the outer and inner wall of the bend causes a secondary flow in the cross section and as a result a centrifugal force acts on the fluid. This centrifugal force accelerates the fluid near the inner wall and decelerates near the outer wall.

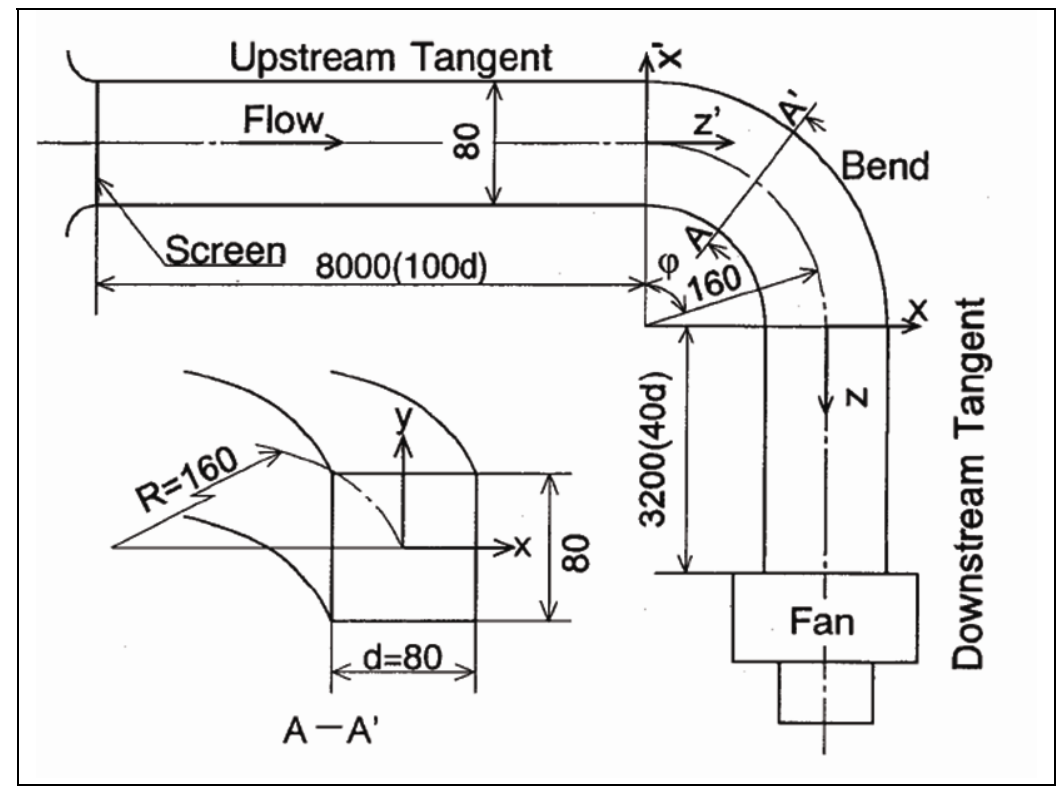

Figure 1.4 Schematic diagram of test bend used in Sudo et al's experiments [9]

Chang et al. [10] used a square sectioned bend in their researches and they increased the upstream section length to ensure the fully developed flow before the bend inlet and measured the Reynolds stresses from the bend inlet to the $180^{\circ}$ bend angle at periodic locations. They showed that the increase of the Reynolds stresses in the region between the inlet and the $90^{\circ}$ plane destabilizes the flow close to the concave wall. The measurements in between $90^{\circ}$ and $180^{\circ}$ planes showed intriguing changes in radial direction for the Reynolds stresses. 
Cheah et al. [11] measured the flow field in a strong curvature bend $\left(\mathrm{R}_{\mathrm{c}} / \mathrm{D}=0.65\right)$ with the Laser Doppler Anemometer (LDA) technique. They conducted experiments for three different cases; all have Reynolds number of $10^{5}$. These cases consist of; a stationary case, and cases with a positive and negative rotations with rotational numbers of 0.2 and -0.2 . They found the formation of a 3-D separation zone near the inner wall at the $90^{\circ}$ angle. This bubble elongates up to two diameters from the bend exit and generates the high level of turbulence along with it.

Numerical simulations of flow in U-bends have also been subject of many researches. Details of the numerical studies about bend flows are summarized in Table 1.2.

Azzola et al. [7] used the semi-elliptic k- $\varepsilon$ model to see how successfully predicts the flow behavior in a strongly curved $180^{\circ}$ pipe bend. They checked the accuracy of their numerical results by comparing numerical results with the experimental results. They used a simpler near wall treatment, PSL, which allows the inclusion of the very fine mesh needed to resolve the viscous sublayer without excessive computer storage. The results obtained with the semi- elliptic k- $\varepsilon$ model are reasonably good agreement with the experimental data. They found that the levels of secondary flow are on the whole lower than in the corresponding square duct flow that is observed by Chang et al. [10].

Chang et al. [10] formed their computational model based on a two equation linear k$\varepsilon$ model with a wall function to calculate flow patterns along with turbulence characteristics in U-bend. They made their numerical study with a semi-elliptic procedure to decrease computational power since the procedure requires only the storage of the pressure data over the whole domain. They compared their numerical results with the experimental results. Since they used an isotropic model, they could not represent the redistributive effects of the normal stresses. They also could not model the local separation and vortex formation close to the convex wall. 
Table 1.2 Numerical studies on bend flows

\begin{tabular}{|c|c|c|}
\hline Owner of the Study & Turbulence Model & Experiments \\
\hline Azzola et al. [7] & - Standard k- $\varepsilon$ model & [7] \\
\hline Chang et al. [10] & - Standard k- $\varepsilon$ model & {$[10]$} \\
\hline Choi et al. [12] & $\begin{array}{ll}\text { - } & \text { Standard k- } \varepsilon \text { model } \\
\text { - } & \text { Algebraic Stress Model } \\
& (\mathrm{ASM})\end{array}$ & {$[10]$} \\
\hline Iacovides et al. [13] & - $\mathrm{ASM}$ & {$[10]$} \\
\hline Münch and Métais [14] & - Large Eddy Simulation (LES) & {$[10]$} \\
\hline Suga [15] & $\begin{array}{l}\text { - Two-component-limit second } \\
\text { moment closure (TCL SMC) }\end{array}$ & {$[10],[11]$} \\
\hline Djebedjian et al. [16] & $\begin{array}{ll}\text { - } & \text { Standard k- } \varepsilon \text { model } \\
\text { - } & \text { Renormalization-group } \\
& (\mathrm{RNG}) \mathrm{k}-\varepsilon \text { model } \\
\text { - } & \text { Realizable k- } \varepsilon \text { model } \\
\text { - } & \mathrm{k}-\omega \text { model } \\
\text { - } & \text { Reynolds Stress Model } \\
& (\mathrm{RSM})\end{array}$ & {$[10],[11]$} \\
\hline
\end{tabular}

Choi et al. [12] used two different turbulence models in their numerical calculations that are; the k- $\varepsilon$ and Algebraic Stress (ASM) models. They focused on some modeling improvements in their numerical model such as; the replacement of wall functions with a fine mesh across sublayer, leaving the PSL approximation, which neglects pressure variations across the near-wall sublayer, and usage of the Algebraic Stress Model (ASM) as an alternative of the standard k- $\varepsilon$ model. These refinements 
lead to an appreciable improvement in the agreement between measurement and computation results. They also used Chang et al.'s [10] experimental results for validation. Although, the experimental data of the Chang et al. [10] were not detailed enough to compare numerical with; their results showed significant improvements.

Iacovides et al. [13] focused on the square sectioned U-bend that has a upstream length of only 6 hydraulic diameters before the bend inlet. They used Chang et al.'s [10] LDA data to compare their numerical model. Chang et al. [10] used 30 hydraulic diameters of straight duct to provide boundary layers fill the duct. Computations of the flow using a three-dimensional finite-volume solver employing an ASM turbulence model are in generally close agreement with the experimental data. However, five vortices on both side of the mid-plane are shown on the secondary flow contours at $135^{\circ}$ bend section. This means that the flow breaks down into more complex flow patterns despite the low Reynolds stress anisotropy. Figure 1.5 shows the computed velocity vectors, the computed and the measured axial velocity contours of the Iacovides et al.'s [13] study at $135^{\circ}$ location. In Figure 1.5(a) five vortices located on the one side of the symmetry plane can be seen from velocity vector distribution directly.

Münch and Métais [14] used Large Eddy Simulations (LES) for three different curvature radius that are $R_{c} / D=3.5,6.5$ and 10.5 to investigate the effect of the curvature radius $\mathrm{R}_{\mathrm{c}}$ on curved duct flows. They also used Chang et al. [10] experimental results to validate their computations. They indicate that the increase in the strength of secondary flow intensities in bends is caused due to the decrease of the radius of curvature.

Suga [15] used mild and strong curvature U-bends in his study and he observed the turbulence and heat transfer characteristics in U-bends. He compared the numerical results of his study with the Chang et al.'s [10] and Cheah et al.'s [11] experiments for the mild and strong curvature cases, respectively. He used the wall-reflection free low-Reynolds number second moment closure (TCL SMC) second moment 
closure turbulence model which is developed by Batten et al. [17]. He found that the TCL SMC can be used for both type of curvature ratios and gives reliable results.

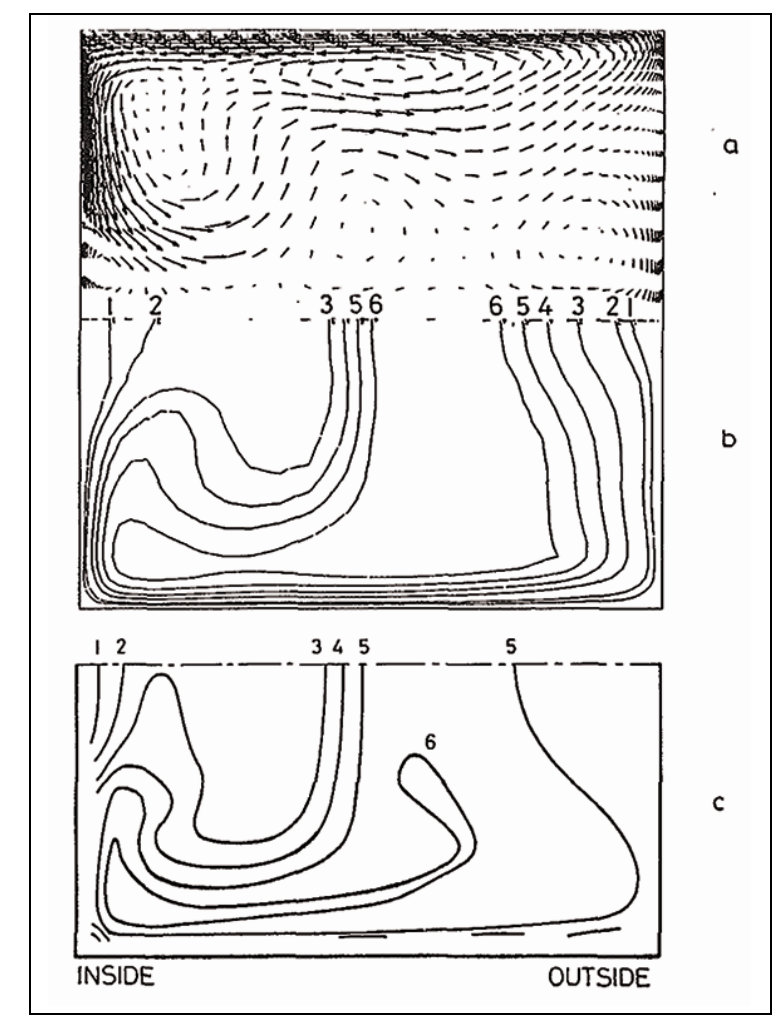

Figure 1.5 Axial velocity contours and secondary velocity vectors at $135 \mathrm{deg}$. (a) computed velocity vectors; (b) computed axial velocity contours; (c) measured axial velocity contours [13]

Djebedjian et al. [16] used five different turbulence models in their numerical simulations and investigated the 2-D and 3-D flows through two types of square sectioned bends, as illustrated in Figure 1.6. The turbulence models that are used in Djebedjian et al's [16] study can be listed as; Standard k- $\varepsilon$ model, Renormalizationgroup (RNG) k- $\varepsilon$ model, Realizable k- $\varepsilon$ model, k- $\omega$ model and Reynolds stress model $(\mathrm{RSM})$. They used a mild curvature bend $\left(\mathrm{R}_{\mathrm{c}} / \mathrm{D}=3.357\right)$ and a strong curvature bend $\left(\mathrm{R}_{\mathrm{c}} / \mathrm{D}=0.65\right)$, which were also used in the experiments of Chang et al. [10] and Cheah et al. [11]. They concluded that more advanced turbulence models give more reliable results for separation point detection and 3-D simulation results were more 
reliable compared to the results of 2-D simulations. Moreover, their numerical simulation results showed that the RSM model gives better results when it is compared with the k- $\omega$ turbulence model.

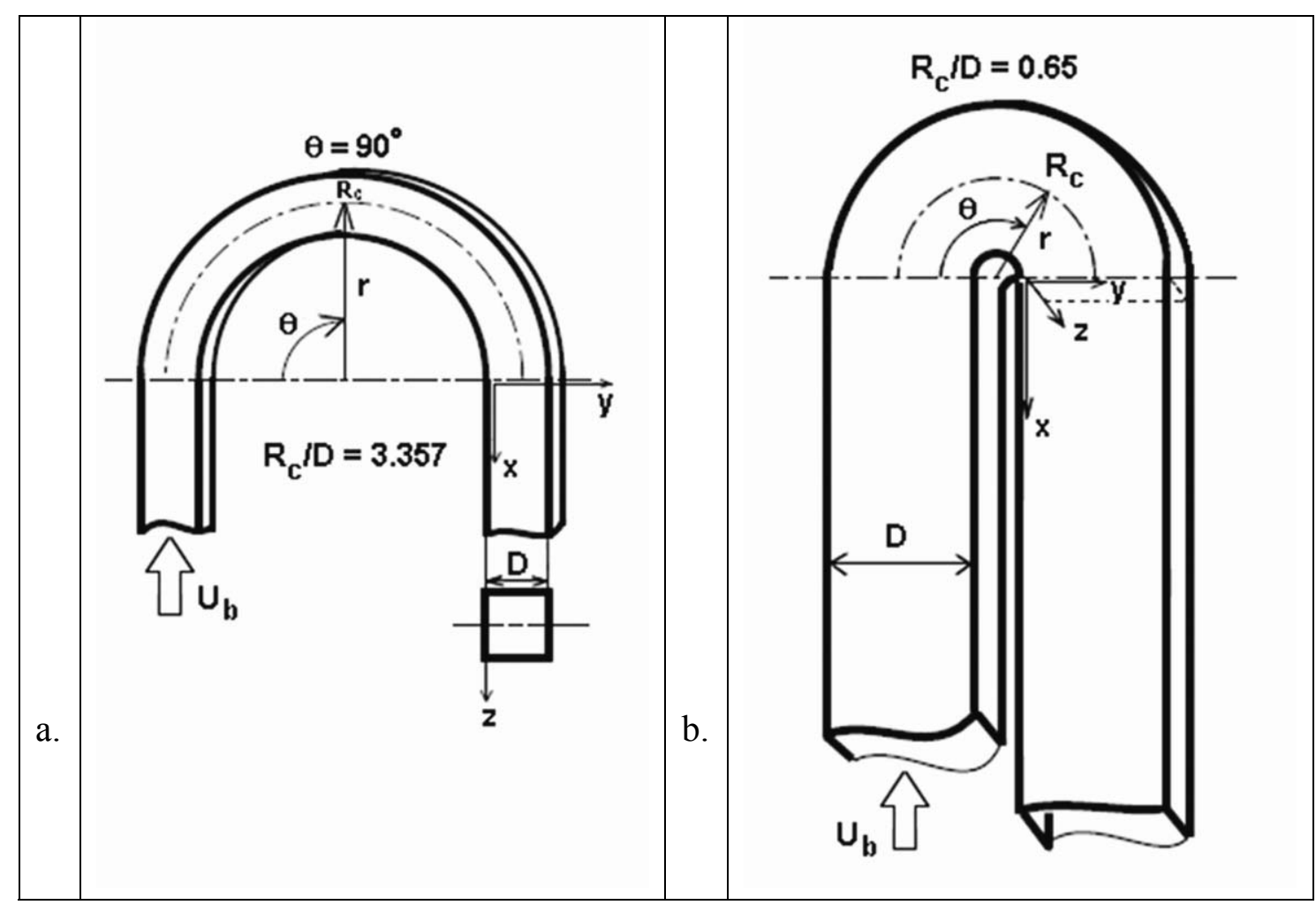

Figure 1.6 Schematic display of square sectioned $180^{\circ} \mathrm{U}$-bend duct flows used in Djebedjian et al's study; (a) $R_{c} / D=3.357$; (b) $R_{c} / D=0.65$ [16]

\subsection{Aim of the Study}

Proposal of the best numerical approach for U-bend with a specific radius of curvature and the elimination of Dean vortices along with significant reduction in turbulence levels in different cross planes are the main objectives of this thesis. For this purpose, computational fluid dynamic (CFD) models are developed to analyze and to control complex flows patterns in square sectioned U-bend with a radius of curvature $\mathrm{R}_{\mathrm{c}} / \mathrm{D}=0.65$. 
A detailed mesh independency study followed by the detailed comparison of numerical predictions with the experimental results of Cheah et al. [11] and numerical results of Djebedjian et al. [16] are performed. Velocity profiles at different angular positions, turbulence intensities and flow separation points are compared for six different turbulence models.

The best numerical approach is proposed for U-bend with a specific radius of curvature considering the accuracy of the results and computation time. In addition, a flow control technique with using airfoils inside the bend is applied to regulate the flow inside the duct. With this control technique, the elimination of Dean vortices along with significant reduction in turbulence levels in different cross planes are successfully achieved.

\subsection{Thesis Layout}

This thesis study is composed of six chapters. In Chapter 1, experimental and numerical studies on turbulent curved bend flow listed and explained in detail. Motivation and aim of this thesis study are clarified.

In Chapter 2, detailed information about Reynolds averaging, two different methods of closing the Reynolds-Averaged Navier Stokes (RANS) equations and the theory behind the six different turbulence models used in this study are presented.

In Chapter 3, test case used in this study is described and development of the CFD model is explained in detail. Parameters used in the mesh independency study are tabulated and results of five different meshes used for the mesh independency are compared.

In Chapter 4, the numerical results, obtained from the simulations in ANSYS FLUENT software for different turbulence models, are compared with appropriate experimental and numerical results on literature for the verification. 
In Chapter 5, details of the flow control applied in the bend to decrease turbulence levels and eliminate Dean vortices are explained. Development of the CFD model for the flow control analyses is discussed and details of the model are tabulated. Here, results of the flow control strategy as flow patterns, vorticity values and turbulence intensities are compared with the base model.

In Chapter 6, the thesis study is summarized and the points in order to improve the present study are shared as future studies. 


\section{CHAPTER 2}

\section{TURBULENCE MODELING}

In this chapter, detailed information about Reynolds averaging, two different methods of closing the Reynolds-Averaged Navier Stokes (RANS) equations and the theory behind the six different turbulence models used in this study are presented.

\subsection{Reynolds Averaging}

The present study uses the numerical simulation tool FLUENT 14.0 for the flow analysis inside the duct bend. FLUENT uses The Reynolds-Averaged Navier Stokes (RANS) equations for the computations. The mean and fluctuating components of the solution variables which can be velocity or other scalar quantities are used in Reynolds averaging. For the velocity components:

$$
u_{i}=\overline{u_{i}}+u_{i}^{\prime}
$$

where $\bar{u}_{i}$ is the mean and $u_{i}^{\prime}$ is the fluctuating velocity components.

In the same way, other scalar quantities such as pressure and energy can be expressed as:

$$
\phi=\bar{\phi}+\phi^{\prime}
$$

The time average of the continuity and the momentum equations should be taken after substituting the flow variables to obtain the ensamble-averaged momentum equations. Then, Reynolds-Averaged conservation of mass and momentum equations can be written as: 
Conservation of mass:

$$
\frac{\partial \rho}{\partial t}+\frac{\partial}{\partial x_{i}}\left(\rho \overline{u_{i}}\right)=0
$$

where $\rho$ is fluid density, $t$ is time and $\bar{u}_{i}$ is the time average of velocity.

Conservation of momentum:

$$
\begin{aligned}
\frac{\partial}{\partial t}\left(\rho \overline{u_{i}}\right)+\frac{\partial}{\partial x_{j}}\left(\rho \overline{u_{i}} \overline{u_{j}}\right)= & -\frac{\partial \bar{p}}{\partial x_{i}}+\frac{\partial}{\partial x_{j}}\left[\mu\left(\frac{\partial \overline{u_{i}}}{\partial x_{j}}+\frac{\partial \overline{u_{j}}}{\partial x_{i}}-\frac{2}{3} \delta_{i j} \frac{\partial \overline{u_{k}}}{\partial x_{k}}\right)\right] \\
& +\frac{\partial}{\partial x_{j}}\left(-\rho \overline{u_{i}^{\prime} u_{j}^{\prime}}\right)
\end{aligned}
$$

where $\bar{p}$ is the mean pressure, $\mu$ is the dynamic viscosity, $\delta_{i j}$ is the Kronecker delta and $-\rho \overline{u_{i}^{\prime} u_{j}^{\prime}}$ is the unknown Reynolds stress tensor.

Fluctuating velocity fields characterizes the turbulent flows. These fluctuations cause other fluctuations on transported quantities such as momentum and energy. Since these fluctuations can be small scale, the simulation of them is expensive computationally. The time averaging, ensemble-averaging or otherwise manipulations can be used on the instantaneous governing equations to eliminate the small scale effects and obtain a set of equations (Equations (2.3) and (2.4)). These equations are less expensive to solve computationally. However, the unknown Reynolds stresses, which are introduced by the averaging procedure, are required for the Reynolds-Averaged approach. These stresses must be modeled to close the system of governing equation. The turbulence models are used to convert these unknown variables to the known quantities. FLUENT provides various turbulence models to model Reynolds stresses, $-\rho \overline{u_{i}^{\prime} u_{j}^{\prime}}$. 


\subsection{Boussinesq Approach and Reynolds Stress Transport Models}

For completing the Reynolds Averaging approach and closing the system of governing equations, the Reynolds stresses in Equation (2.4) must be modeled appropriately. Boussinesq approach is a widespread method to relate the Reynolds stresses to the mean velocity gradients.

$$
-\rho \overline{u_{i}^{\prime} u_{j}^{\prime}}=\mu_{t}\left(\frac{\partial \overline{u_{i}}}{\partial x_{j}}+\frac{\partial \overline{u_{j}}}{\partial x_{i}}\right)-\frac{2}{3}\left(\rho k+\mu_{t} \frac{\partial \overline{u_{k}}}{\partial x_{k}}\right) \delta_{i j}
$$

The Spalart-Allmaras model, the k- $\varepsilon$ models and the k- $\omega$ models uses the Boussinesq hypothesis. This approach requires low computation power when comparing with computation of the turbulent viscosity, $\mu_{t}$. Only one extra transport equation for turbulent viscosity calculation is solved by the Spalart-Allmaras model. When using the k- $\varepsilon$ and k- $\omega$ models two additional transport equations are solved; one for the turbulent kinetic energy, $k$, the other for the turbulence dissipation rate, $\varepsilon$, or the specific dissipation rate, $\omega$. Then, $\mu_{t}$ is calculated in terms of the turbulent kinetic energy and the dissipation rate either turbulence or specific.

The other approach for modeling the Reynolds stresses is solving transport equations for the terms located in the Reynolds stress tensor matrix. The turbulence models which use this method are called as Reynolds Stress Transport Models. Moreover, an additional equation is required in terms of $\varepsilon$ or $\omega$ to determine the scale of the equations. This means for 2-D flows five additional and for 3D flows seven additional transport equations must be solved.

\subsection{Turbulence Models}

FLUENT provides various turbulence models to model Reynolds stresses. The following turbulence models are used in the present study; the standard k- $\varepsilon$ model, the Renormalization-group (RNG) k- $\varepsilon$ model, the Realizable k- $\varepsilon$ model, the Shear- 
Stress Transport (SST) k- $\omega$ model, the Reynolds Stress Model (RSM) and the ScaleAdaptive Simulation (SAS) model. This section describes the theory behind these models.

\subsubsection{Standard k- $\varepsilon$ Model}

Turbulent length and time scales are determined by solving two separated transport equations in two equation turbulence models. The standard $\mathrm{k}-\varepsilon$ model is a two equation turbulence model which was developed by Launder and Spalding [18]. It is robust, economical for computing and applicable for wide range of flows with its reasonable accuracy.

Two transport equations for the turbulence kinetic energy $(k)$ and its dissipation rate $(\varepsilon)$ is solved for the standard k- $\varepsilon$ model [18]. The k- $\varepsilon$ model assumes the flow is fully turbulent and it does not take into account the effects of molecular viscosity. As a consequence of this assumption; this model can only be used for fully turbulent flows.

The following transport equations are solved for the turbulence kinetic energy, $k$, and its rate of dissipation, $\varepsilon$, in the standard $\mathrm{k}-\varepsilon$ model:

$$
\frac{\partial}{\partial t}(\rho k)+\frac{\partial}{\partial x_{i}}\left(\rho k \overline{u_{i}}\right)=\frac{\partial}{\partial x_{j}}\left[\left(\mu+\frac{\mu_{t}}{\sigma_{k}}\right) \frac{\partial k}{\partial x_{j}}\right]+G_{k}+G_{b}-\rho \varepsilon-Y_{M}+S_{k}
$$

and

$$
\begin{aligned}
\frac{\partial}{\partial t}(\rho \varepsilon)+\frac{\partial}{\partial x_{i}}\left(\rho \varepsilon \overline{u_{i}}\right) & =\frac{\partial}{\partial x_{j}}\left[\left(\mu+\frac{\mu_{t}}{\sigma_{\varepsilon}}\right) \frac{\partial \varepsilon}{\partial x_{j}}\right]+C_{1 \varepsilon} \frac{\varepsilon}{k}\left(G_{k}+C_{3 \varepsilon} G_{b}\right) \\
& -C_{2 \varepsilon} \rho \frac{\varepsilon^{2}}{k}+S_{\varepsilon}
\end{aligned}
$$

In these equations, $G_{k}$ and $G_{b}$ indicates the production of the turbulence kinetic energy with the effect of the mean velocity gradients and the buoyancy, respectively. 
The fluctuating dilatation in compressible turbulence to the overall dissipation rate is shown with the term $Y_{M}$ and model constants are shown with the terms $C_{1 \varepsilon}, C_{2 \varepsilon}$ and $C_{3 \varepsilon}$. Turbulent Prandtl numbers for $k$ and $\varepsilon$ are shown with $\sigma_{k}$ and $\sigma_{\varepsilon}$, respectively. User-defined source terms are indicated with $S_{k}$ and $S_{\varepsilon}$ terms.

The equation given below shows computation of the turbulent (eddy) viscosity, $\mu_{t}$ :

$$
\mu_{t}=\rho C_{\mu} \frac{k^{2}}{\varepsilon}
$$

where $C_{\mu}$ is a constant.

\subsubsection{RNG k-E Model}

The RNG k- $\varepsilon$ model uses a statistical technique called renormalization group theory. The form of the model is similar to the standard k- $\varepsilon$ model but it has some refinements. Effect of the swirl flow is implemented into the RNG model and accuracy of the model to swirl flows is increased. In addition, the standard k- $\varepsilon$ model uses constant Prandtl numbers whereas the RNG model has its own analytical formula for turbulent Prandtl.

An additional $R_{\varepsilon}$ term is embedded into the $\varepsilon$ equation of the RNG model and this term improves the accuracy of the model for the rapidly strained flows.

A more accurate and reliable turbulence model is obtained with the additional refinements made on the RNG k- $\varepsilon$ model.

FLUENT uses the Yakhot and Orszag's [19] RNG k- $\varepsilon$ model. This model uses a mathematical technique called "renormalization group" (RNG) method. The analytical derivation of Yakhot and Orszag [19] results with additional terms in the transport equations and different model constants than the standard k- $\varepsilon$ model.

Transport equations for the RNG k- $\varepsilon$ model can be written as: 


$$
\frac{\partial}{\partial t}(\rho k)+\frac{\partial}{\partial x_{i}}\left(\rho k \overline{u_{i}}\right)=\frac{\partial}{\partial x_{j}}\left[\alpha_{k} \mu_{e f f} \frac{\partial k}{\partial x_{j}}\right]+G_{k}+G_{b}-\rho \varepsilon-Y_{M}+S_{k}
$$

and

$$
\begin{aligned}
\frac{\partial}{\partial t}(\rho \varepsilon)+\frac{\partial}{\partial x_{i}}\left(\rho \varepsilon \overline{u_{i}}\right)= & \frac{\partial}{\partial x_{j}}\left[\alpha_{\varepsilon} \mu_{e f f} \frac{\partial \varepsilon}{\partial x_{j}}\right]+C_{1 \varepsilon} \frac{\varepsilon}{k}\left(G_{k}+C_{3 \varepsilon} G_{b}\right) \\
& -C_{2 \varepsilon} \rho \frac{\varepsilon^{2}}{k}-R_{\varepsilon}+S_{\varepsilon}
\end{aligned}
$$

In these equations, $G_{k}$ and $G_{b}$ indicates the production of the turbulence kinetic energy with the effect of the mean velocity gradients and the buoyancy, respectively. The fluctuating dilatation in compressible turbulence to the overall dissipation rate is shown with the term $Y_{M}$ and model constants are shown with the terms $C_{1 \varepsilon}, C_{2 \varepsilon}$ and $C_{3 \varepsilon}$. Inverse effective Prandtl numbers for $k$ and $\varepsilon$ are shown with $\alpha_{k}$ and $\alpha_{\varepsilon}$, respectively. User-defined source terms are indicated with $S_{k}$ and $S_{\varepsilon}$ terms. $R_{\varepsilon}$ is the term for improving the accuracy of rapidly strained flows. $\mu_{e f f}$ is the effective turbulent viscosity.

The swirl or the rotation in the mean flow directly affects the turbulence. An option for taking into account the effects of swirl and rotation is available in The Yakhot and Orszag's [19] RNG model which is implemented in FLUENT. This option modifies the turbulent viscosity. The modification is done as:

$$
\mu_{t}=\mu_{t 0} f\left(\alpha_{s}, \Omega, \frac{k}{\varepsilon}\right)
$$

where $\mu_{t 0}$ is the turbulent viscosity without swirl effects included and can be calculated from Equation (2.8). $\Omega$ is the characteristic swirl number which is calculated by FLUENT, and $\alpha_{s}$ is a swirl constant. 


\subsubsection{Realizable k- $\varepsilon$ Model}

ANSYS FLUENT uses the Shih et al.'s [20] realizable k- $\varepsilon$ model ant this model has two main differences with the standard k- $\varepsilon$ model . Firstly, the realizable k- $\varepsilon$ model has an alternative formula for the turbulent viscosity. Moreover, the dissipation rate, $\varepsilon$, has a modeified transport equation.

The term "realizable" comes from the model property which the model fulfills the mathematical requirements on the Reynolds stresses with overseeing the physics of turbulent flow.

The combination of the Boussinesq relationship (Equation (2.5)) and the eddy viscosity equation (Equation (2.8)) gives us the following expression:

$$
\overline{u^{2}}=\frac{2}{3} k-2 v_{t} \frac{\partial U}{\partial x}
$$

Using Equation (2.8) and knowing $v_{t} \equiv \mu_{t} / \rho$, one can find that the normal stress, $\overline{u^{2}}$, can become negative or in other words "non-realizable" when the strain is large enough as;

$$
\frac{k}{\varepsilon} \frac{\partial U}{\partial x}>\frac{1}{3 C_{\mu}} \approx 3.7
$$

The most common way to provide stability is making the $C_{\mu}$ variable and sensitive to the mean flow.

The transport equations for the realizable $\mathrm{k}-\varepsilon$ model can be written as:

$$
\frac{\partial}{\partial t}(\rho k)+\frac{\partial}{\partial x_{j}}\left(\rho k \overline{u_{j}}\right)=\frac{\partial}{\partial x_{j}}\left[\left(\mu+\frac{\mu_{t}}{\sigma_{k}}\right) \frac{\partial k}{\partial x_{j}}\right]+G_{k}+G_{b}-\rho \varepsilon-Y_{M}+S_{k}
$$

and 


$$
\begin{aligned}
\frac{\partial}{\partial t}(\rho \varepsilon)+\frac{\partial}{\partial x_{i}}\left(\rho \varepsilon \overline{u_{j}}\right) & =\frac{\partial}{\partial x_{j}}\left[\left(\mu+\frac{\mu_{t}}{\sigma_{\varepsilon}}\right) \frac{\partial \varepsilon}{\partial x_{j}}\right]+\rho C_{1} S \varepsilon-\rho C_{2} \frac{\varepsilon^{2}}{k+\sqrt{v \varepsilon}} \\
& C_{1 \varepsilon} \frac{\varepsilon}{k} C_{3 \varepsilon} G_{b}+S_{\varepsilon}
\end{aligned}
$$

where

$$
C_{1}=\max \left[0.43, \frac{\eta}{\eta+5}\right], \eta=S \frac{k}{\varepsilon}, S=\sqrt{2 S_{i j} S_{i j}}
$$

In these equations, $G_{k}$ and $G_{b}$ indicates the production of the turbulence kinetic energy with the effect of the mean velocity gradients and the buoyancy, respectively. The fluctuating dilatation in compressible turbulence to the overall dissipation rate is shown with the term $Y_{M}$ and model constants are shown with the terms $C_{1 \varepsilon}$ and $C_{2}$. Turbulent Prandtl numbers for $k$ and $\varepsilon$ are shown with $\sigma_{k}$ and $\sigma_{\varepsilon}$, respectively. Userdefined source terms are indicated with $S_{k}$ and $S_{\varepsilon}$ terms.

Similar with other k- $\varepsilon$ turbulence models, the realizable k- $\varepsilon$ model uses the Equation (2.8) for calculating eddy viscosity. However, the difference between the realizable k- $\varepsilon$ and the other k- $\varepsilon$ models is; $C_{\mu}$ is not constant in the realizable k- $\varepsilon$ model and can be computed:

$$
C_{\mu}=\frac{1}{A_{0}+A_{s} \frac{k U^{*}}{\varepsilon}}
$$

where

$$
U^{*} \equiv \sqrt{S_{i j} S_{i j}+\Omega_{i j} \Omega_{i j}}
$$

and

$\Omega_{i j}=\Omega_{i j}-2 \varepsilon_{i j k} \omega_{k}$ 
$\Omega_{i j}=\overline{\Omega_{i j}}-\varepsilon_{i j k} \omega_{k}$

where the rate of rotation is shown with $\overline{\Omega_{i j}}$ and calculated based on a reference frame which has the angular velocity $\omega_{k} . A_{0}$ and $A_{s}$ are the model constants.

The production of turbulence kinetic energy, the term $G_{k}$, is modeled as the same for the standard k- $\varepsilon$ model, RNG k- $\varepsilon$ model and realizable k- $\varepsilon$ model. For the k- $\varepsilon$ models the production of the turbulence kinetic energy can be defined as:

$$
G_{k}=-\rho \overline{u_{i}^{\prime} u_{j}^{\prime}} \frac{\partial \overline{u_{j}}}{\partial x_{i}}
$$

The term $G_{k}$ can also be evaluated by taking the Boussinessq hypothesis into account;

$$
G_{k}=\mu_{t} S^{2}
$$

where $S$ is the modulus of the mean rate-of-strain tensor, defined as

$$
S \equiv \sqrt{2 S_{i j} S_{i j}}
$$

\subsubsection{Shear-Stress Transport (SST) k- $\omega$ Model}

ANSYS FLUENT uses the shear-stress transport (SST) $k-\omega$ model which is developed by Menter [21].

The SST k- $\omega$ model is analogous to the standard k- $\omega$ model but it has some further refinements. Firstly, it blends standard k- $\omega$ model with the k- $\varepsilon$ model. It solves the k$\omega$ model near-wall region and away from the surface it solves the k- $\varepsilon$ model. Moreover, the SST k- $\omega$ model uses a modified turbulent viscosity calculation for involving the turbulent shear stress effects. 
These additional features make the SST k- $\omega$ model more accurate and usable for the wider range of flows such as adverse pressure gradient flows and airfoil flows.

The transport equations for the SST k- $\omega$ model can be written as:

$$
\frac{\partial}{\partial t}(\rho k)+\frac{\partial}{\partial x_{i}}\left(\rho k \overline{u_{i}}\right)=\frac{\partial}{\partial x_{j}}\left(\Gamma_{k} \frac{\partial k}{\partial x_{j}}\right)+G_{k}-Y_{k}+S_{k}
$$

and

$$
\frac{\partial}{\partial t}(\rho \omega)+\frac{\partial}{\partial x_{j}}\left(\rho \omega \overline{u_{j}}\right)=\frac{\partial}{\partial x_{j}}\left(\Gamma_{\omega} \frac{\partial \omega}{\partial x_{j}}\right)+G_{\omega}-Y_{\omega}+D_{\omega}+S_{\omega}
$$

In these equations, $G_{k}$ and $G_{\omega}$ indicates the production of the turbulence kinetic energy and the turbulence dissipation rate with the effect of the mean velocity gradients, respectively. The effective diffusivity of the $k$ and $\omega$ are shown with the terms $\Gamma_{k}$ and $\Gamma_{\omega}$. Also dissipation of the $k$ and $\omega$ are shown with $Y_{k}$ and $Y_{\omega} . D_{\omega}$ indicates the cross-diffusion term. User-defined source terms are indicated with $S_{k}$ and $S_{\omega}$ terms.

Modeling of the turbulence production and dissipation of the $k$ and $\omega$ is explained in detail below.

For the Menter's [21] SST k- $\omega$ model production of turbulence kinetic energy are shown with the term $G_{k}$, and can be defined as:

$$
G_{k}=\min \left(G_{k}, 10 \rho \beta^{*} k \omega\right)
$$

where $\beta^{*}$ is a model constant and $G_{k}$ is defined in Equation (2.18) and (2.19).

The production of the $\omega$ is shown with the term $G_{\omega}$ and can be written as:

$$
G_{\omega}=\frac{\alpha}{v_{t}} G_{k}
$$


where $v_{t} \equiv \mu_{t} / \rho$ and

$$
\alpha=\frac{\alpha_{\infty}}{\alpha^{*}}\left(\frac{\alpha_{0}+R e_{t} / R_{\omega}}{1+R e_{t} / R_{\omega}}\right)
$$

where

$$
\alpha^{*}=\alpha_{\infty}^{*}\left(\frac{\alpha_{0}^{*}+R e_{t} / R_{k}}{1+R e_{t} / R_{k}}\right)
$$

where $\alpha_{\infty}, \alpha_{0}, \alpha_{\infty}{ }^{*}, \alpha_{0}{ }^{*}, R_{\omega}$ and $R_{k}$ are model constants and

$$
R e_{t}=\frac{\rho k}{\mu \omega}
$$

Dissipation of turbulence kinetic energy, $k$, are shown with the term $Y_{k}$ and for the SST k- $\omega$ model can be expressed as:

$$
Y_{k}=\rho \beta^{*} k \omega
$$

where

$$
\begin{gathered}
\beta^{*}=\beta_{i}^{*}\left[1+\zeta^{*} F\left(M_{t}\right)\right] \\
\beta_{i}^{*}=\beta_{\infty}^{*}\left(\frac{4 / 15+\left(R e_{t} / R_{\beta}\right)^{4}}{1+\left(R e_{t} / R_{\beta}\right)^{4}}\right)
\end{gathered}
$$

where $R e_{t}$ is given by Equation (2.27) and $\zeta^{*}, R_{\beta}, \beta_{\infty}^{*}$ model constants and $F\left(M_{t}\right)$ is the compressibility function and is given by;

$$
F\left(M_{t}\right)=\left\{\begin{array}{cc}
0 & M_{t} \leq M_{t 0} \\
M_{t}^{2}-M_{t 0}{ }^{2} & M_{t}>M_{t 0}
\end{array}\right.
$$


where $M_{t}^{2} \equiv 2 k / a^{2}$ and $a=\sqrt{\gamma R T} \cdot \gamma$ is the ratio of specific heats, $R$ is the Gaslaw constant, $T$ is the temperature and $\mu_{t 0}$ is a model constant.

The dissipation of $\omega$ is shown with the term $Y_{\omega}$ and is defined as:

$$
Y_{\omega}=\rho \beta \omega^{2}
$$

where

$$
\beta=\beta_{i}\left[1-\frac{\beta_{i}^{*}}{\beta_{i}} \zeta^{*} F\left(M_{t}\right)\right]
$$

where $F\left(M_{t}\right)$ is given in Equation (2.31), $\beta_{i}^{*}$ is given in Equation (2.30), $\zeta^{*}$ is model constant and $\beta_{i}$ is calculated as;

$$
\beta_{i}=F_{1} \beta_{i, 1}+\left(1-F_{1}\right) \beta_{i, 2}
$$

where $\beta_{i, 1}, \beta_{i, 2}$ are model constants and $F_{1}$ is blending function given by;

$$
\begin{gathered}
F_{1}=\tanh \left(\Phi_{1}^{4}\right) \\
\Phi_{1}=\min \left[\max \left(\frac{\sqrt{k}}{0.09 \omega y}, \frac{500 \mu}{\rho y^{2} \omega}\right), \frac{4 \rho k}{\sigma_{\omega, 2} D_{\omega}^{+} y^{2}}\right] \\
D_{\omega}^{+}=\max \left[2 \rho \frac{1}{\sigma_{\omega, 2}} \frac{1}{\omega} \frac{\partial k}{\partial x_{j}} \frac{\partial \omega}{\partial x_{j}}, 10^{-10}\right]
\end{gathered}
$$

where distance to the subsequent surface is shown with $y$ and the positive part of the cross-diffusion term is shown with $D_{\omega}^{+}, \sigma_{\omega, 1}$ and $\sigma_{\omega, 2}$ are model constants. 


\subsubsection{Reynolds Stress Model (RSM)}

ANSYS FLUENT uses the Launder et al.'s [22] Reynolds stress model (RSM) which is the most detailed turbulence model. The RSM solves transport equations for Reynolds stresses and an additional equation for the dissipation rate to close the Reynolds-averaged Navier-Stokes equations.

RSM is more precise than the one-equation and two-equation models since it considers swirl effects, rotation and rapid changes in the strain rate. However, the assumptions made to model the terms in the transport equations of the RSM model limits the correctness of the model.

Although, RSM has superior features compared to one or two-equation models, it does not guarantee clearly better results in all classes of flow. Moreover, it definitely needs more computational time than simpler models.

The transport equations for the Reynolds stresses term $\rho \overline{u_{i}^{\prime} u_{j}^{\prime}}$ are detailed in this section. The following equation shows the exact transport equation for the Reynolds Stress Model: 


$$
\begin{aligned}
& \underbrace{\frac{\partial}{\partial t}\left(\rho \overline{u_{i}^{\prime} u_{j}^{\prime}}\right)}_{\text {Local Time Derivative }}+\underbrace{\frac{\partial}{\partial x_{k}}\left(\rho \overline{u_{k}} \overline{u_{i}^{\prime} u_{j}^{\prime}}\right)}_{C_{i j} \equiv \text { Convection }}=\underbrace{-\frac{\partial}{\partial x_{k}}\left[\rho \overline{u_{i}^{\prime} u_{j}^{\prime} u_{k}^{\prime}}+\overline{p^{\prime}\left(\delta_{k j} u_{i}^{\prime}+\delta_{i k} u_{j}^{\prime}\right)}\right]}_{D_{T, i j} \equiv \text { Turbulent Diffusion }} \\
& +\underbrace{\frac{\partial}{\partial x_{k}}\left[\mu \frac{\partial}{\partial x_{k}}\left(\overline{u_{i}^{\prime} u_{j}^{\prime}}\right)\right]}_{D_{L, i j}=\text { Moleculer Diffusion }} \\
& \underbrace{-\rho\left(\overline{u_{i}^{\prime} u_{k}^{\prime}} \frac{\partial \overline{u_{j}}}{\partial x_{k}}+\overline{u_{j}^{\prime} u_{k}^{\prime}} \frac{\partial \overline{u_{i}}}{\partial x_{k}}\right)}_{P_{i j} \equiv \text { Stress Production }} \\
& \underbrace{-\rho \beta\left(g_{i} \overline{u_{j}^{\prime} \theta}+g_{j} \overline{u_{i}^{\prime} \theta}\right)}_{G_{i j} \equiv \text { Buoyancy Production }} \\
& +\underbrace{p^{\prime}\left(\frac{\partial u_{i}^{\prime}}{\partial x_{j}}+\frac{\partial u_{j}^{\prime}}{\partial x_{i}}\right)}_{\phi_{i j} \equiv \text { Pressure Strain }} \\
& \underbrace{-2 \mu \overline{\frac{\partial u_{i}^{\prime}}{\partial x_{k}} \frac{\partial u_{j}^{\prime}}{\partial x_{k}}}}_{\varepsilon_{i j} \equiv \text { Dissipation }} \\
& \underbrace{-2 \rho \Omega_{k}\left(\overline{u_{j}^{\prime} u_{m}^{\prime}} \varepsilon_{i k m}+\overline{u_{i}^{\prime} u_{m}^{\prime}} \varepsilon_{j k m}\right)}_{F_{i j} \equiv \text { Production by System Rotation }} \\
& +\underbrace{S_{\text {user }}}_{\text {User-Defined Source Term }}
\end{aligned}
$$

The terms in this equation can be separated into two parts according to modeling requirements; the $C_{i j}, D_{L, i j}, P_{i j}$ and $F_{i j}$ terms do not need any modeling while for closing the equations the $D_{T, i j}, G_{i j}, \phi_{i j}$ and $\varepsilon_{i j}$ terms need to be modeled.

Modeling of the turbulent diffusion, pressure strain, turbulence kinetic energy, dissipation rate and the turbulent viscosity are explained in detail below.

ANSYS FLUENT uses the Lien and Leschziner's [23] model to compute the turbulent diffusivity term, $D_{T, i j}$, as follows: 


$$
D_{T, i j}=\frac{\partial}{\partial x_{k}}\left(\frac{\mu_{t}}{\sigma_{k}} \frac{\overline{\partial u_{i}^{\prime} u_{j}^{\prime}}}{\partial x_{k}}\right)
$$

where $\sigma_{k}$ is a constant and derived by Lien and Lischziner as 0.82 , and $\mu_{t}$ can be computed using Equation (2.8).

FLUENT offers three different methods for the pressure-strain term, $\phi_{i j}$, such as Launder's [24] linear pressure-strain model, Speziale et al.'s [25] quadratic pressurestrain model and Wilcox's [26] stress-omega model. The Launder's [24] linear pressure-strain model is used in this study and explained below.

The pressure-strain term, $\phi_{i j}$, can be modeled by using the following decomposition:

$$
\phi_{i j}=\phi_{i j, 1}+\phi_{i j, 2}+\phi_{i j, w}
$$

where $\phi_{i j, 1}$ and $\phi_{i j, 2}$ shows the slow and rapid pressure-strain, respectively. $\phi_{i j, w}$ is the wall-reflection term and these can be modeled as:

$$
\phi_{i j, 1} \equiv-C_{1} \rho \frac{\varepsilon}{k}\left[\overline{u_{i}^{\prime} u_{j}^{\prime}}-\frac{2}{3} \delta_{i j} k\right]
$$

where $C_{1}$ is constant,

$$
\phi_{i j, 2} \equiv-C_{2}\left[\left(P_{i j}+F_{i j}+\frac{5}{6} G_{i j}-C_{i j}\right)-\frac{2}{3} \delta_{i j}\left(P+\frac{5}{6} G-C\right)\right]
$$

where $C_{2}$ is constant and Equation (2.38) defines the $P_{i j}, F_{i j}, G_{i j}$ and $C_{i j}$ terms,

$$
\begin{aligned}
\phi_{i j, w} \equiv & C_{1}^{\prime} \frac{\varepsilon}{k}\left(\overline{u_{k}^{\prime} u_{m}^{\prime}} n_{k} n_{m} \delta_{i j}-\frac{3}{2} \overline{u_{i}^{\prime} u_{k}^{\prime}} n_{j} n_{k}-\frac{3}{2} \overline{u_{j}^{\prime} u_{k}^{\prime}} n_{i} n_{k}\right) \frac{C_{\ell} k^{3 / 2}}{\varepsilon d} \\
& +C_{2}^{\prime}\left(\phi_{k m, 2} n_{k} n_{m} \delta_{i j}-\frac{3}{2} \phi_{i k, 2} n_{j} n_{k}-\frac{3}{2} \phi_{j k, 2} n_{i} n_{k}\right) \frac{C_{\ell} k^{3 / 2}}{\varepsilon d}
\end{aligned}
$$


where $C_{1}, C_{2}^{\prime}$ are model constants, $x_{k}$ component of the unit normal is shown with the $n_{k}$ term and the normal distance to wall is indicated with $d . C_{\ell}=C_{\mu}^{3 / 4} / \kappa$ where $C_{\mu}$ is the model constant and $\kappa$ is the von Karman constant.

RSM uses the following equation to model turbulence kinetic energy:

$$
k=\frac{1}{2} \overline{u_{i}^{\prime} u_{i}^{\prime}}
$$

Reynolds stresses' boundary conditions are obtained with the following model by solving the turbulence kinetic energy transport equation which is an option provided by ANSYS FLUENT:

$$
\begin{aligned}
\frac{\partial}{\partial t}(\rho k)+\frac{\partial}{\partial x_{i}}\left(\rho k \overline{u_{i}}\right) & =\frac{\partial}{\partial x_{j}}\left[\left(\mu+\frac{\mu_{t}}{\sigma_{k}}\right) \frac{\partial k}{\partial x_{j}}\right]+\frac{1}{2}\left(P_{i i}+G_{i i}\right) \\
& -\rho \varepsilon\left(1+2 M_{t}^{2}\right)+S_{k}
\end{aligned}
$$

where $\sigma_{k}$ is the model constant and the source term is shown with $S_{k}$. The Equation (2.45) is similar to Equation (2.6) used in the standard k- $\varepsilon$ model. The turbulence kinetic energy, $k$, values obtained from Equation (2.45) are only used for boundary conditions.

The dissipation tensor, which is given as $\varepsilon_{i j}$ in Equation (2.38), can be modeled as;

$$
\varepsilon_{i j}=\frac{2}{3} \delta_{j}\left(\rho \varepsilon+Y_{M}\right)
$$

where additional dissipation term is shown with the term $Y_{M}=2 \rho \varepsilon M_{t}^{2}$ and the turbulent Mach number for this term can be defined as $M_{t}=\sqrt{2 k / a^{2}}$ and $a$ is the speed of sound $(\equiv \sqrt{\gamma R T})$. A similar transport equation, which is used in the standard k- $\varepsilon$ model, is solved to compute the scalar dissipation rate, $\varepsilon$ : 


$$
\begin{aligned}
\frac{\partial}{\partial t}(\rho \varepsilon)+\frac{\partial}{\partial x_{i}}\left(\rho \varepsilon \overline{u_{i}}\right) & =\frac{\partial}{\partial x_{j}}\left[\left(\mu+\frac{\mu_{t}}{\sigma_{\varepsilon}}\right) \frac{\partial \varepsilon}{\partial x_{j}}\right]+C_{1 \varepsilon} \frac{1}{2}\left[P_{i i}+C_{\varepsilon 3} G_{i i}\right] \frac{\varepsilon}{k} \\
& -C_{2 \varepsilon} \rho \frac{\varepsilon^{2}}{k}+S_{\varepsilon}
\end{aligned}
$$

where $\sigma_{\varepsilon}, C_{\varepsilon 1}$ and $C_{\varepsilon 2}$ are model constants and $C_{\varepsilon 3}$ is calculated based on the local flow direction, which is comparative to the gravitational vector, and User-defined source term is indicated with $S_{\varepsilon}$.

The turbulent viscosity, $\mu_{t}$, is computed similar to the $\mathrm{k}-\varepsilon$ models as given in Equation (2.8) where $C_{\mu}$ is a constant.

\subsubsection{Scale-Adaptive Simulation (SAS) Model}

The Scale-Adaptive (SAS) turbulence model resolves the turbulent characteristics of the unstable flow with an improved URANS formulation. The URANS simulation produces only the large scale eddies whereas the SAS model resolves eddies in an active way. This way helps to resolve the turbulent flow in the detached regions.

SAS models adjust to the resolved structures in URANS simulation with the information provided by the von Karman length-scale dynamically. This adjustment results in a LES-like behavior in unsteady regions of the flow field and in the steady regions model shows standard RANS capabilities.

All two-equation models suffer from lack of an underlying exact transport equation. That is because the exact equation for the $\varepsilon$ does not consider the large scales, but the dissipative scales. The purpose of these models is to model the influences of the large scale motions on the mean flow.

SAS model is not using purely heuristic and dimensional arguments for formulating a scale-equation rather it uses a more consistent approach. SAS model solves an exact transport equation for turbulent kinetic energy times length scale, $k L$. ANSYS 
FLUENT uses the transport equations given by Egorov and Menter [27] for the SASSST model. These equations can be written as:

$$
\begin{aligned}
& \frac{\partial}{\partial t}(\rho k)+\frac{\partial}{\partial x_{i}}\left(\rho k \overline{u_{i}}\right)=G_{k}-\rho c_{\mu} k \omega+\frac{\partial}{\partial x_{j}}\left[\left(\mu+\frac{\mu_{t}}{\sigma_{k}}\right) \frac{\partial k}{\partial x_{j}}\right] \\
& \frac{\partial}{\partial t}(\rho \omega)+\frac{\partial}{\partial x_{i}}\left(\rho \omega \overline{u_{i}}\right)=\alpha \frac{\omega}{k} G_{k}-\rho \beta \omega^{2}+Q_{S A S}+\frac{\partial}{\partial x_{i}}\left[\left(\mu+\frac{\mu_{t}}{\sigma_{\omega}}\right) \frac{\partial \omega}{\partial x_{j}}\right] \\
& +\left(1-F_{1}\right) \frac{2 \rho}{\sigma_{\omega, 2}} \frac{1}{\omega} \frac{\partial k}{\partial x_{j}} \frac{\partial \omega}{\partial x_{j}}
\end{aligned}
$$

In these equations, $Q_{S A S}$ is the additional SAS source term for the turbulence eddy frequency $\omega$ and $\sigma_{\omega, 2}$ is the $\sigma_{\omega}$ value for the $k$ - $\varepsilon$ regime of the SST model.

The additional source term $Q_{S A S}$ is expressed as [27]:

$$
Q_{S A S}=\max \left[\rho \eta_{2} \kappa S^{2}\left(\frac{L}{L_{v \kappa}}\right)^{2}-C \frac{2 \rho k}{\sigma_{\Phi}} \max \left(\frac{1}{\omega^{2}} \frac{\partial \omega}{\partial x_{j}} \frac{\partial \omega}{\partial x_{j}}, \frac{1}{k^{2}} \frac{\partial k}{\partial x_{j}} \frac{\partial k}{\partial x_{j}}\right), 0\right]
$$

where model constants are shown with $\eta_{2}, \sigma_{\Phi}$ and C. $L$ is the length scale of the modeled turbulence;

$$
L=\frac{\sqrt{k}}{c_{\mu}^{1 / 4} \omega}
$$

Moreover, the term $L_{v \kappa}$ in Equation (2.50) represents the von Karman length scale and is a three-dimensional version of the classic boundary layer definition:

$$
L_{B L}{ }^{v \kappa}=\kappa \frac{\partial u}{\partial y} / \frac{\partial^{2} u}{\partial y^{2}}
$$

and 


$$
L_{v \kappa}=\frac{\kappa S}{\left|U^{\prime \prime}\right|}
$$

where $\kappa$ is the von Karman constant and $S$ is the first velocity derivative, which is a scalar invariant of the strain rate tensor $S_{i j}$ :

$$
\begin{gathered}
S=\sqrt{2 S_{i j} S_{i j}} \\
S_{i j}=\frac{1}{2}\left[\frac{\partial u_{i}}{\partial x_{j}} \frac{\partial u_{j}}{\partial x_{i}}\right]
\end{gathered}
$$

and the second velocity derivative $U^{\prime \prime}$ can be obtained using the magnitude of the velocity Laplacian:

$$
\left|U^{\prime \prime}\right|=\sqrt{\sum_{i}\left(\frac{\partial^{2} u_{i}}{\partial x_{j} \partial x_{j}}\right)^{2}}
$$




\section{CHAPTER 3}

\section{MODEL DEVELOPMENT AND MESH INDEPENDENCY}

In this chapter, test case used in this thesis is described and development of the CFD model is explained in detail. Mesh independency study is elaborated and parameters used in the mesh independency are tabulated. Finally, mean streamwise velocity profiles of five different meshes used for the mesh independency are compared and appropriate mesh is selected for the further analyses.

\subsection{Description of the Test Case}

A bend with strong curvature $\left(R_{c} / D=0.65\right)$ is used to study the complex flow patterns in square sectioned U-bends. The geometry, which consists of a square duct with 50 $\mathrm{mm}$ hydraulic diameter, with inner and outer radii $7.5 \mathrm{~mm}$ and $57.5 \mathrm{~mm}$, respectively, is shown in Figure 3.1. The outer and inner bends of duct are shown on the figure with the "O" and "I" labels, respectively.

The geometric configuration of the bend is constructed based on the experimental setup used in Cheah et al.'s [11] study. This configuration is selected because of two main reasons. Firstly, Cheah et al. [11] provides a detailed experimental data for this type of geometric configuration which is important for validation of numerical models. Moreover, strong curvature bends cause the most challenging complex flow patterns in different type of bend curvatures.

The Reynolds number calculated using hydraulic diameter is $\mathrm{Re}=100,000$. For a duct flow Reynolds number can be defined as; 


$$
\operatorname{Re}=\frac{U D_{H}}{v}
$$

where $U$ is the mean flow velocity, $v$ is the kinematic viscosity and $D_{H}$ is the hydraulic diameter of the duct and for square sectioned ducts is equal to $D$, which is the one side of the duct.

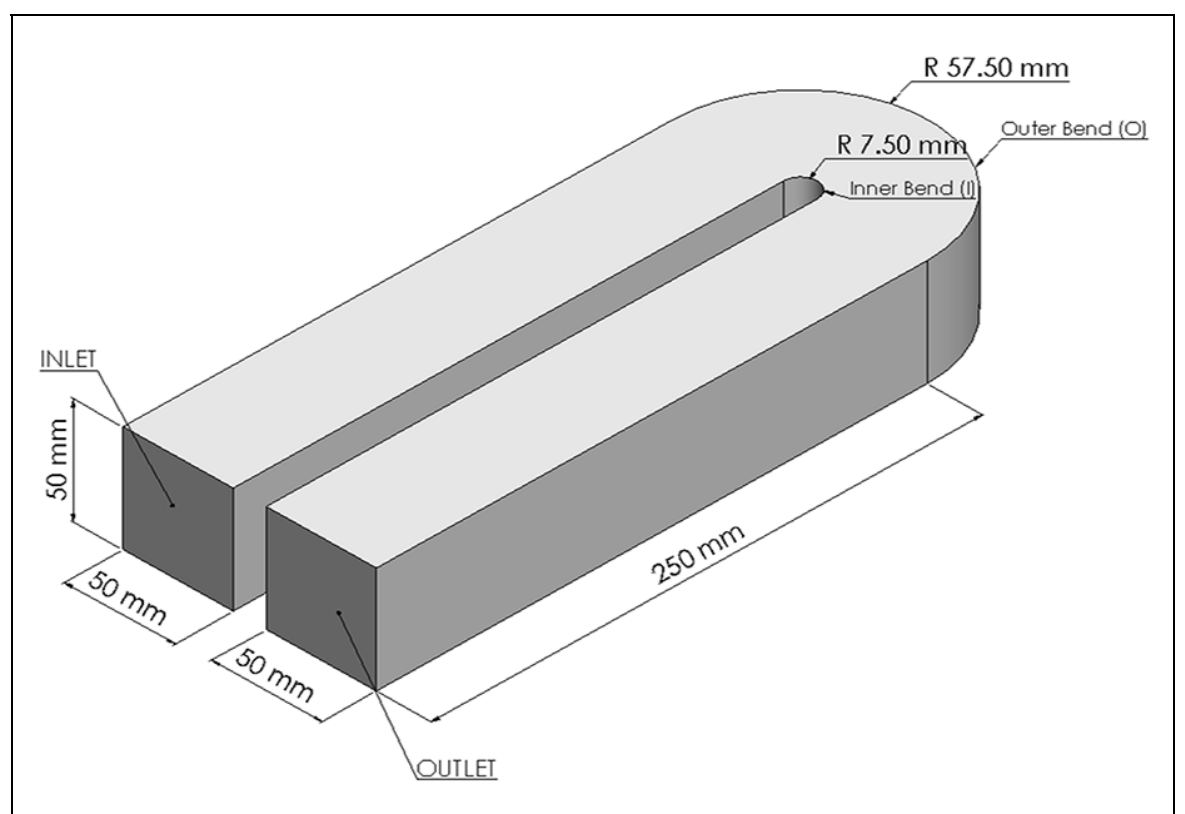

Figure 3.1 The schematic display of the fluid domain for the test case

Moreover, the detailed dimensions of the U-bend used in this study are shown in the Figure 3.2 where $r^{\prime}$ is the transverse distance measured from inner bend to outer bend and the top or bottom wall corresponds to $2 y / D=0$ plane.

In the simulations, the working fluid is water which is the fluid used in the Cheah et al.'s [11] experiments. 


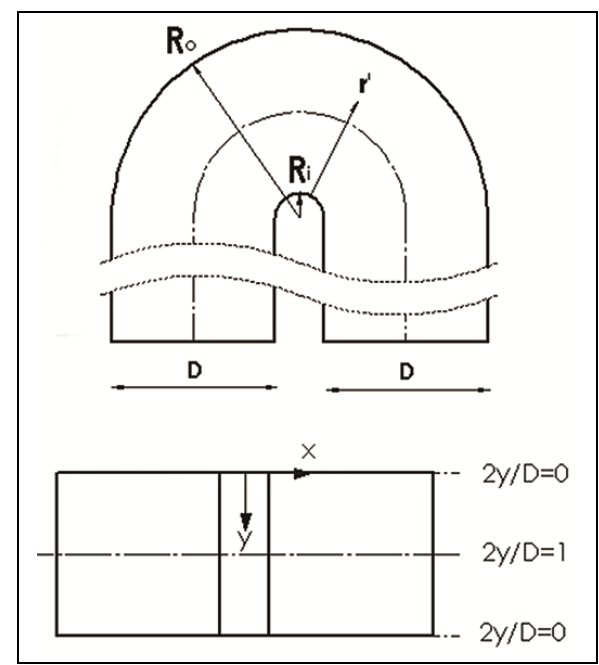

Figure 3.2 The detailed dimensions of the U-bend

\subsection{Development of the CFD Model}

Computational fluid dynamic (CFD) models are developed using ANSYS FLUENT to simulate the flow in square sectioned $U$-bend with a sharp curvature $R_{c} / D=0.65$.

Djebedjian et al. [16] also focused on the same geometric configuration and used ANSYS FLUENT on their numerical simulations. They compared the performances of five different turbulence models that are; Standard k- $\varepsilon$ model, Renormalizationgroup (RNG) k- $\varepsilon$ model, Realizable k- $\varepsilon$ model, k- $\omega$ model and Reynolds stress model (RSM). They performed a mesh independency study using GAMBIT with three different meshes and selected the mesh that has 140,625 nodes for their simulations. Moreover, they used first order upwind differencing scheme for the discretization.

Main flow parameters used in the construction of the models are explained in this section. The wall boundaries are modeled as no slip boundary condition. At the inlet, the velocity is specified and the turbulent intensity is calculated using the equation provided in Orrego, D., et al.'s study [28]:

$$
I=0.16(R e)^{-1 / 8} 100(\%)
$$


where $R e$ is the Reynolds number of the flow.

For the inlet boundary condition, velocity, which is calculated from the flow $R e$ and the hydraulic diameter $D$, is given as uniform and normal to the inlet cross section. Pressure outlet with zero gage static pressure is applied as the outlet boundary condition. The entrance length before the flow enters the bend is set as five times of the hydraulic diameter, 5D, which can be seen in Figure 3.1. The applied boundary conditions are also shown in Table 3.1 .

Table 3.1 Details of the boundary conditions

\begin{tabular}{|c|c|c|}
\hline \multirow{4}{*}{ Inlet } & Velocity (m/s) & 1.74 \\
\cline { 2 - 3 } & $\begin{array}{c}\text { Turbulent Intensity } \\
(\%)\end{array}$ & 3.8 \\
\cline { 2 - 3 } & $\begin{array}{c}\text { Hydraulic diameter } \\
(\mathrm{m})\end{array}$ & 0.05 \\
\hline Outlet & Pressure outlet $(\mathrm{Pa})$ & $\mathrm{P}_{\text {static_gage }}=0$ \\
\hline Wall & $\begin{array}{c}\text { No-slip boundary } \\
(\mathrm{m} / \mathrm{s})\end{array}$ & $\mathrm{u}_{\text {wall }}=0$ \\
\hline
\end{tabular}

The following turbulence models are used in the present study: standard k- $\varepsilon$ model, RNG k- $\varepsilon$ model, Realizable k- $\varepsilon$ model, k- $\omega$ SST model, Reynolds Stress Model (RSM) and Scale-Adaptive Simulation Model (SAS). Other than RSM and SAS turbulence models, models are run as steady.

Convergence of the results is checked in order to ensure the flow have been solved completely. For this purpose, $10^{-6}$ value is determined for iterative convergence of the various transport equations' residuals. The simulations in the present steady are run until all the residuals fall below this particular value. A residual plot for one of the simulations is shown in Figure 3.3. 


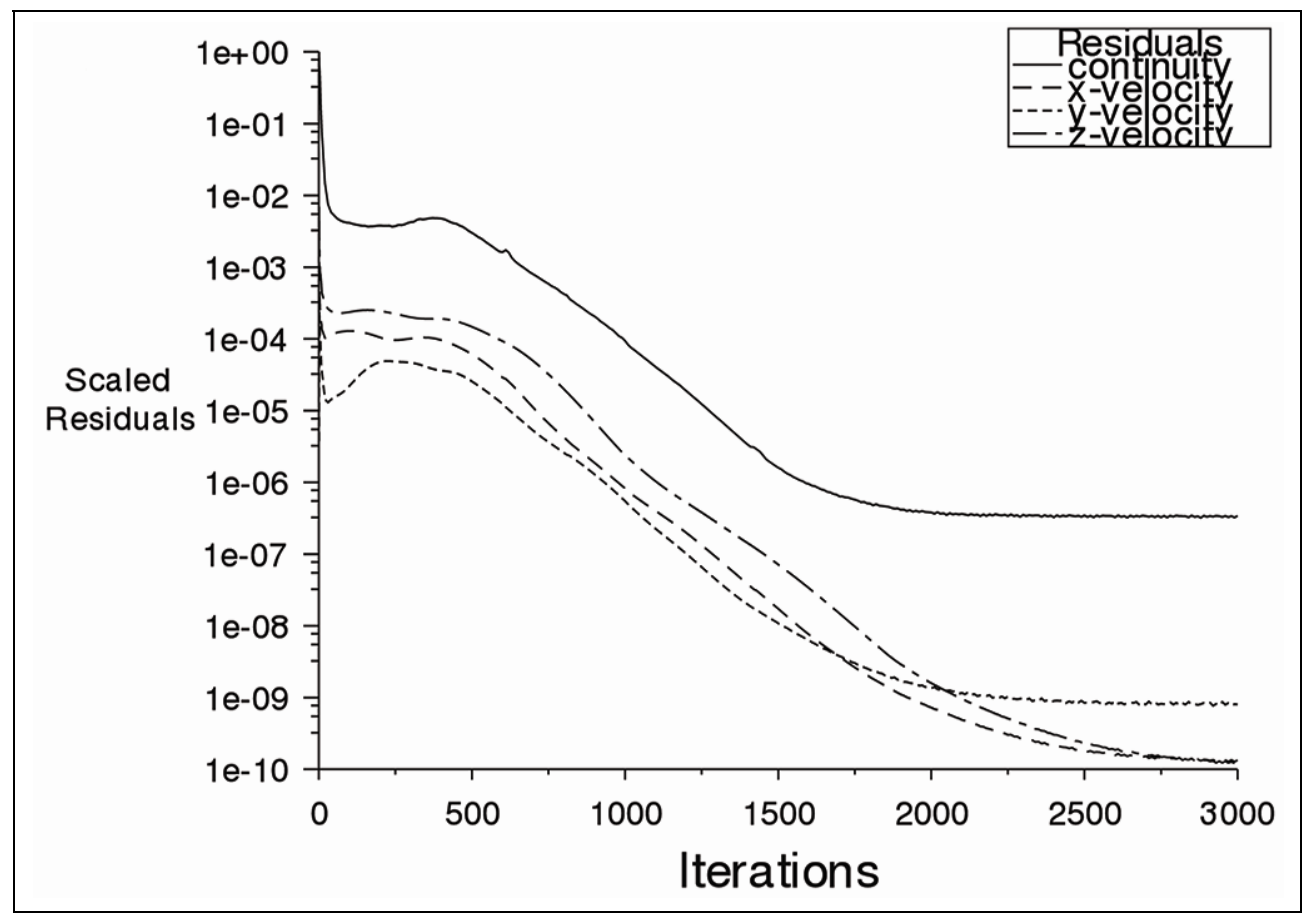

Figure 3.3 Solver residuals used for determining the convergence level of the simulation

The secondary convergence criterion is determined as the solution does not change any more with further number of iterations. For this purpose, convergence of the results is traced by using six different monitor points. Two monitor points are located in the inlet section, two are in the bend section and the others are in the exit section, which are indicated in Figure 3.4. 


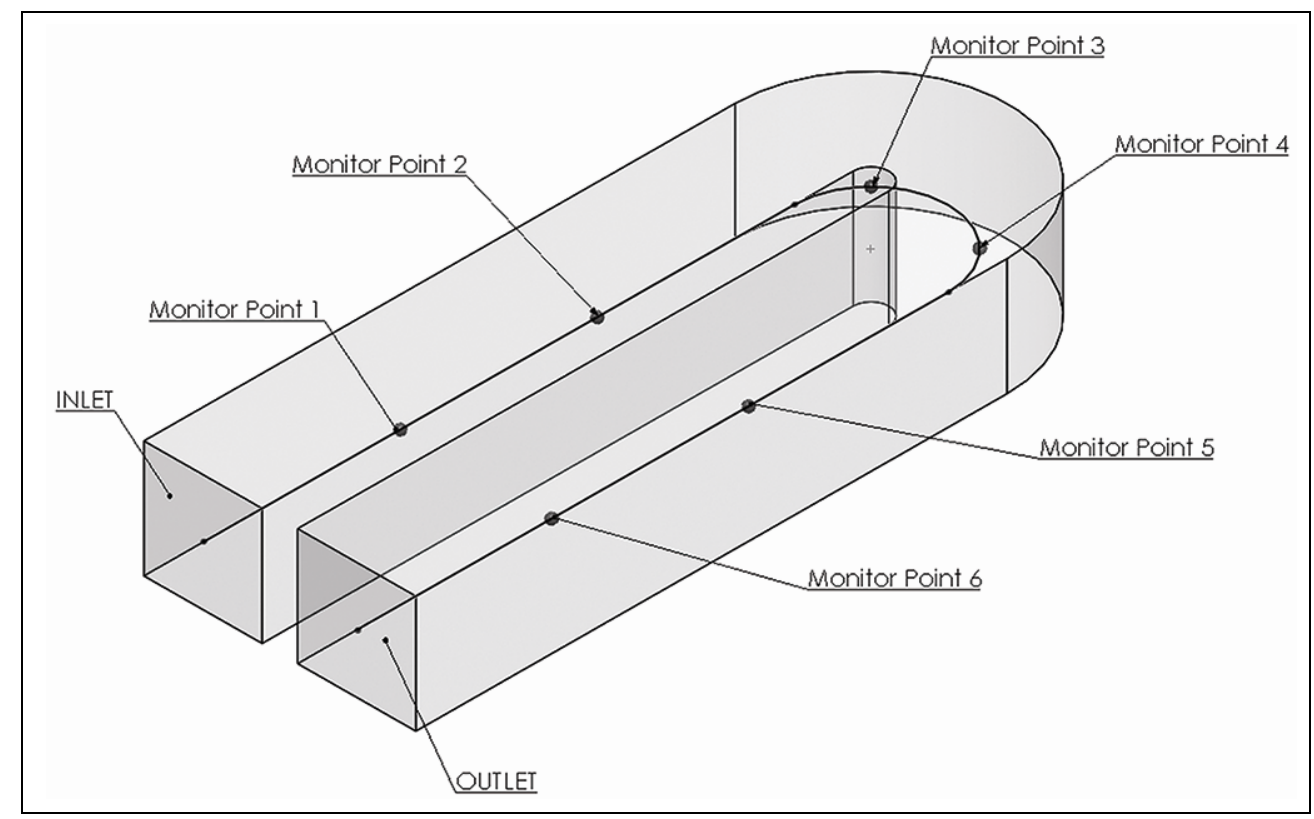

Figure 3.4 The location of the monitor points used for determining the convergence level of the simulations

In the transient simulations of RSM and SAS models, the stabilized solutions, which are not changing with time step, are considered as converged results with tracing the monitor points. The results are taken as final solution when the monitor point values do not change more than $1 \%$ in the following time step.

Figure 3.5 and Figure 3.6 show area weighted average velocity convergence history for a sample simulation. Figure 3.5 shows the convergence results for the monitor points located in the inlet and exit sections of the bend and Figure 3.6 shows the convergence results for the monitor points located in the bend section. 


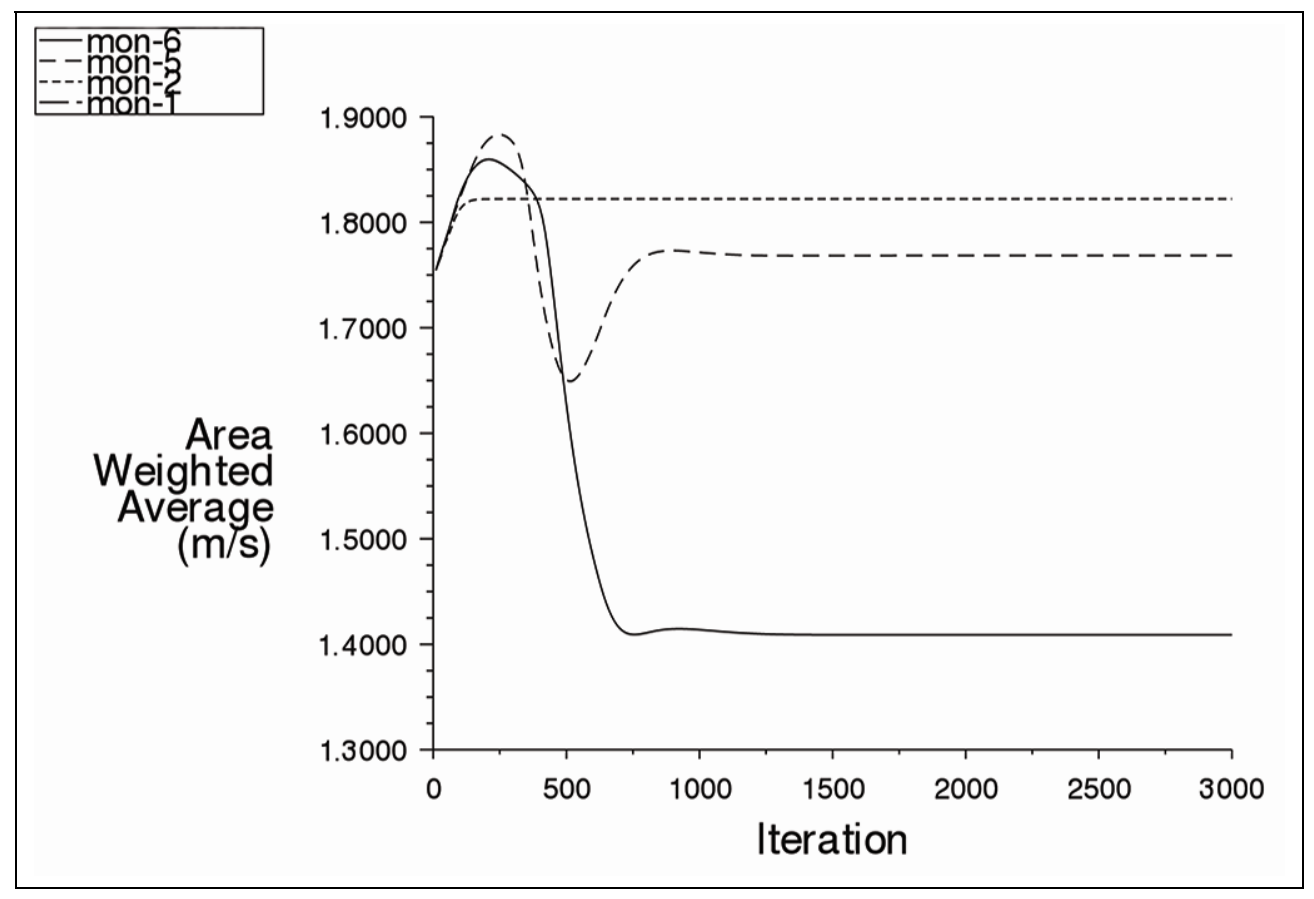

Figure 3.5 Convergence results for the monitor points located in the inlet and exit sections

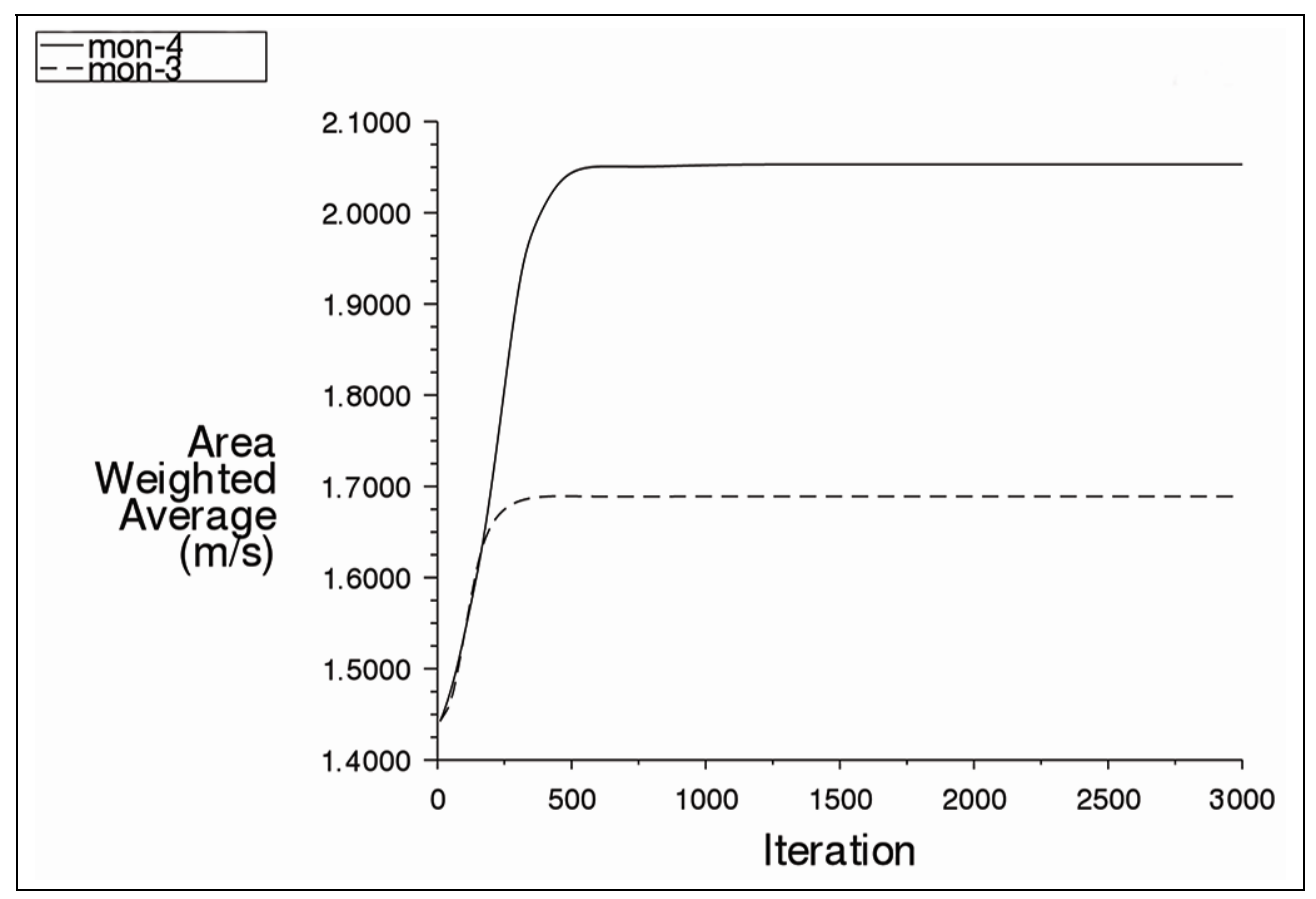

Figure 3.6 Convergence results for the monitor points located in the bend section 


\subsection{Mesh Independency Study}

The mesh independency study is performed for the analyses of $180^{\circ}$ bend with $\mathrm{R}_{\mathrm{c}} / \mathrm{D}=0.65$. The standard $\mathrm{k}-\varepsilon$ model is used with Enhanced wall treatment (EWT) as the near wall treatment.

Five different meshes are generated to study the mesh independency. The near-wall treatment used in the simulations directly affects the concentration of the mesh. The dimensionless distance $\mathrm{y}^{+}$can be described as;

$$
y^{+}=\frac{\Delta y_{1} u_{\tau}}{v}
$$

where $\Delta y_{1}$ is the first cell height from the wall; $u_{\tau}$ indicates the friction velocity and $v$ is the kinematic viscosity of water.

To find first cell height, calculation of the frictional velocity is necessary;

$$
u_{\tau}=\sqrt{\frac{\tau_{w}}{\rho}}
$$

where $\rho$ is the fluid density and in numerical calculations water is used as working fluid, which is also stated as working fluid in Cheah et al. [11] experiments.

The wall shear stress, $\tau_{w}$ can be calculated from skin friction coefficient, $C_{f}$, such that;

$$
\tau_{w}=\frac{1}{2} C_{f} \rho U^{2}
$$

where $U$ is the freestream velocity and shown in Table 3.1 and $C_{f}$ for internal flows can be estimated by using the following empirical formula;

$$
C_{f}=0.079(R e)^{-0.25}
$$


Since the forces on the wall are key to simulations inside the bend and prediction of the flow separation inside the bend is a part of the study, resolving the viscous sublayer is critical for numerical simulations. For this purpose, the standard k- $\varepsilon$ model is used with Enhanced wall treatment (EWT) as the near wall treatment.

For EWT simulations, $y^{+}$value is kept below 1, at least 3 nodes are put inside the viscous sublayer $\left(\mathrm{y}^{+}<5\right)$, and approximately at least 10 nodes are located inside the boundary layer to provide the necessary resolution for the boundary layer. The mesh is kept dense at the bend section but relatively coarse at the inlet and outlet sections of the pipe to reduce computational effort.

In this study, the k- $\varepsilon$ turbulence models and Reynolds Stress Model (RSM) are used with Enhanced wall treatment (EWT). Moreover, the k- $\omega$ turbulence model is used with SST (Shear Stress Transport) model and the Scale-Adaptive Simulation model is implemented in ANSYS with SST in nature. Similar to EWT, for the SST turbulence models, $y^{+}$value should be kept close to 1 to take the full advantage of model. According to these requirements, $y^{+}$value is kept below 1 in all meshes generated in mesh independence study to use the selected mesh with any turbulence model used in the present study.

Meshes, generated for mesh independency study, have three main control parameters; sweep bias and number of division, inflation on the walls inside the square duct and sizing of duct edges. Although the inlet and outlet sections are kept coarse, to achieve smooth transition to bend section, where the mesh is dense, "Sweep Bias" method is used with a Bias Factor of 3 on these sections. To keep $y^{+}$ close to $1, \Delta y_{1}$, the first layer thickness is calculated using Equations (3.3), (3.4), (3.5) and (3.6).

The resulting $y^{+}$value is checked after the numerical simulations. Figure 3.7 shows the $y^{+}$values versus mesh count for a sample simulation and it is important to note that the maximum $y^{+}$value does not exceed 1 . 


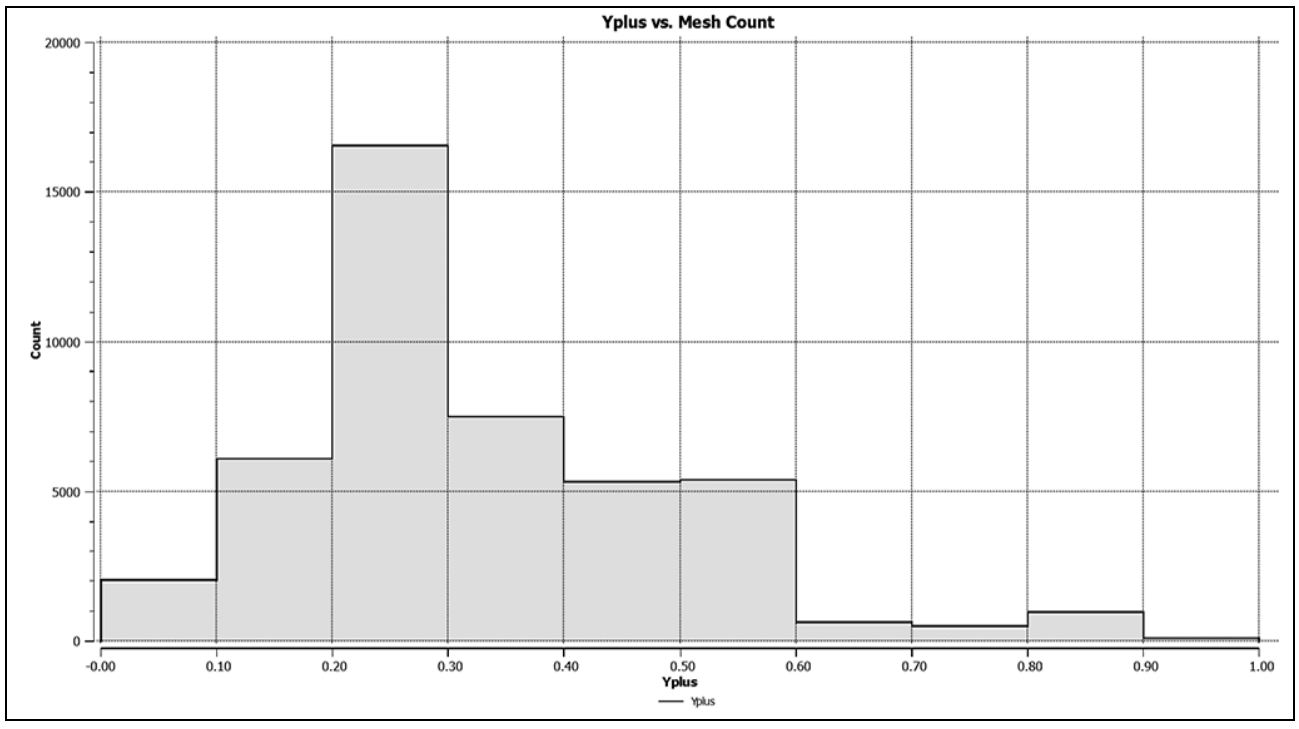

Figure 3.7 The histogram of $\mathrm{y}^{+}$values

Moreover, the contours of constant $y^{+}$values at the bend walls are shown in the Figure 3.8. It is easy to see that the $y^{+}$value reaches its maximum in the bend and this value is close to 1 .

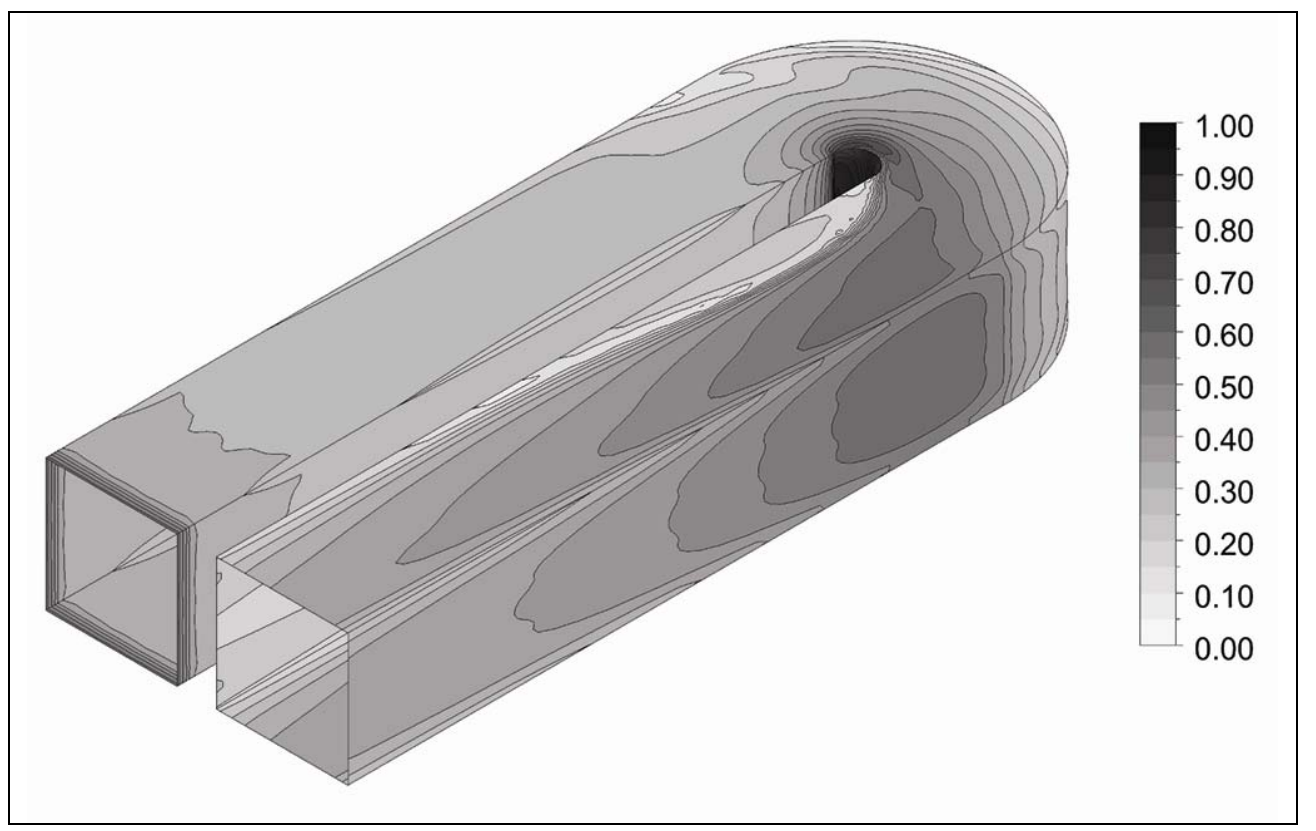

Figure 3.8 Contours of constant $\mathrm{y}^{+}$values in the bend 
Detailed information about mesh generation parameters used in the mesh independency study is given in Table 3.2. It is important to note that the first layer thickness, $\Delta y_{1}$, is kept same for all meshes to achieve $y^{+}$requirement and resolve viscous sublayer.

Quality of the mesh can be evaluated with the maximum and average skewness and the minimum and average orthogonal quality. When the angles in the mesh volume are equal skewness becomes zero, whereas coplanar nodes in the mesh increases the skewness value and for the skewness equals to one, all nodes within the volumes are nearly coplanar [29].

Table 3.2 The summary of the parameters used in mesh independency study

\begin{tabular}{|c|c|c|c|c|c|c|c|}
\hline & & & Mesh 1 & Mesh 2 & Mesh 3 & Mesh 4 & Mesh 5 \\
\hline \multirow{6}{*}{ Sweep } & \multirow{2}{*}{ Inlet } & \# of Division & 60 & 100 & 120 & 180 & 210 \\
\hline & & Bias & 3 & 3 & 3 & 3 & 3 \\
\hline & \multirow{2}{*}{ Bend } & \# of Division & 80 & 120 & 130 & 180 & 240 \\
\hline & & Bias & - & - & - & - & - \\
\hline & \multirow{2}{*}{ Outlet } & \# of Division & 60 & 100 & 120 & 180 & 210 \\
\hline & & Bias & 3 & 3 & 3 & 3 & 3 \\
\hline \multirow{3}{*}{ Inflation } & \multicolumn{2}{|c|}{ First Layer Thickness } & $\begin{array}{l}0.02 \\
\mathrm{~mm}\end{array}$ & $\begin{array}{l}0.02 \\
\mathrm{~mm}\end{array}$ & $\begin{array}{l}0.02 \\
\mathrm{~mm}\end{array}$ & $\begin{array}{c}0.02 \\
\mathrm{~mm}\end{array}$ & $\begin{array}{l}0.02 \\
\mathrm{~mm}\end{array}$ \\
\hline & \multicolumn{2}{|c|}{ Maximum \# of Layers } & 18 & 18 & 18 & 18 & 18 \\
\hline & \multicolumn{2}{|c|}{ Growth Rate } & 1.2 & 1.2 & 1.2 & 1.2 & 1.2 \\
\hline Sizing & \multicolumn{2}{|c|}{ Edge Sizing } & $6 \mathrm{~mm}$ & $4.5 \mathrm{~mm}$ & $3 \mathrm{~mm}$ & $2.3 \mathrm{~mm}$ & $1.5 \mathrm{~mm}$ \\
\hline
\end{tabular}


Zero skewness show the finite volumes which are most desired. Accuracy and stability of the calculations drop drastically with the effects of the degenerated volumes. Therefore, the skewness coefficient is not higher than 0.95 is desired for the simulations to obtain stable and accurate solutions.

The orthogonal quality is another parameter to decide on the quality of the mesh generated for computations. The value of 0 shows worst orthogonal quality and a value of 1 shows the best. It is recommended to keep minimum orthogonal quality higher than 0.1 .

In the case of the mesh alternatives used in the mesh independency study, the maximum skewness is less than or equal to 0.5 and minimum orthogonal quality is higher than 0.59. For this reason, the meshes used for mesh independency study are of a high quality. Mesh size is increased in the order of 2 times at each step. Thus, the coarsest mesh used in the mesh independency study (Mesh 1), has 169,041 total number of nodes and the preview is shown in Figure 3.9. The finest mesh used in the mesh independency study (Mesh 5), has 2,344,567 total number of nodes and the preview is shown in Figure 3.10.

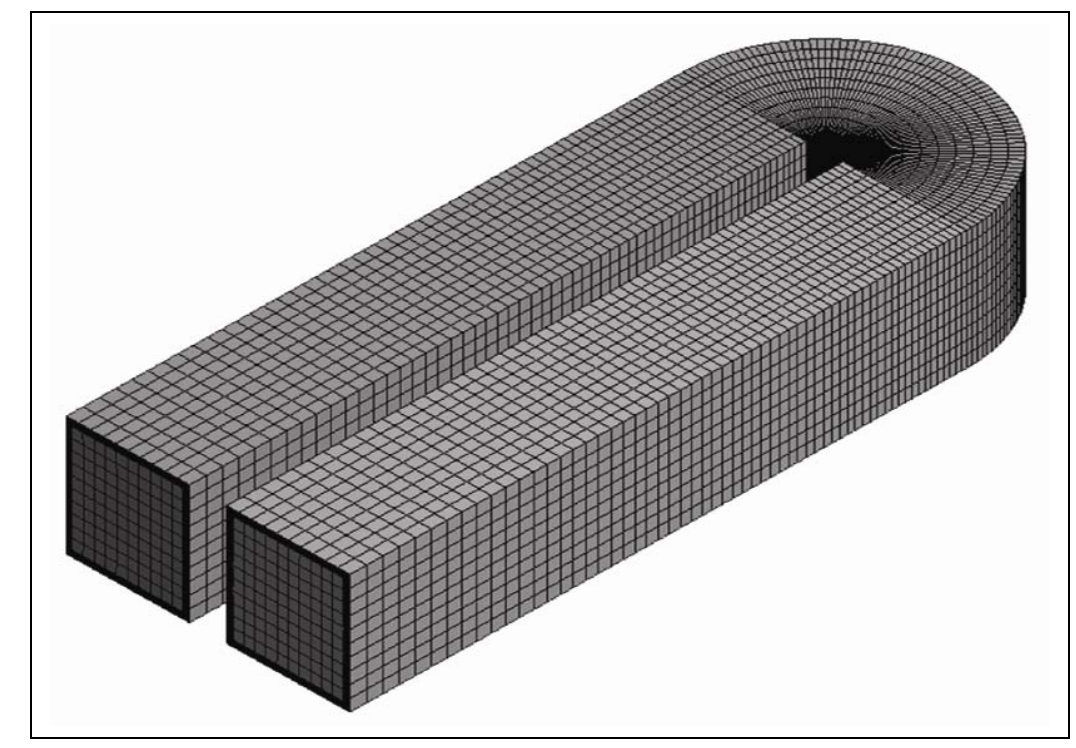

Figure 3.9 The coarsest mesh used in the mesh independency study 


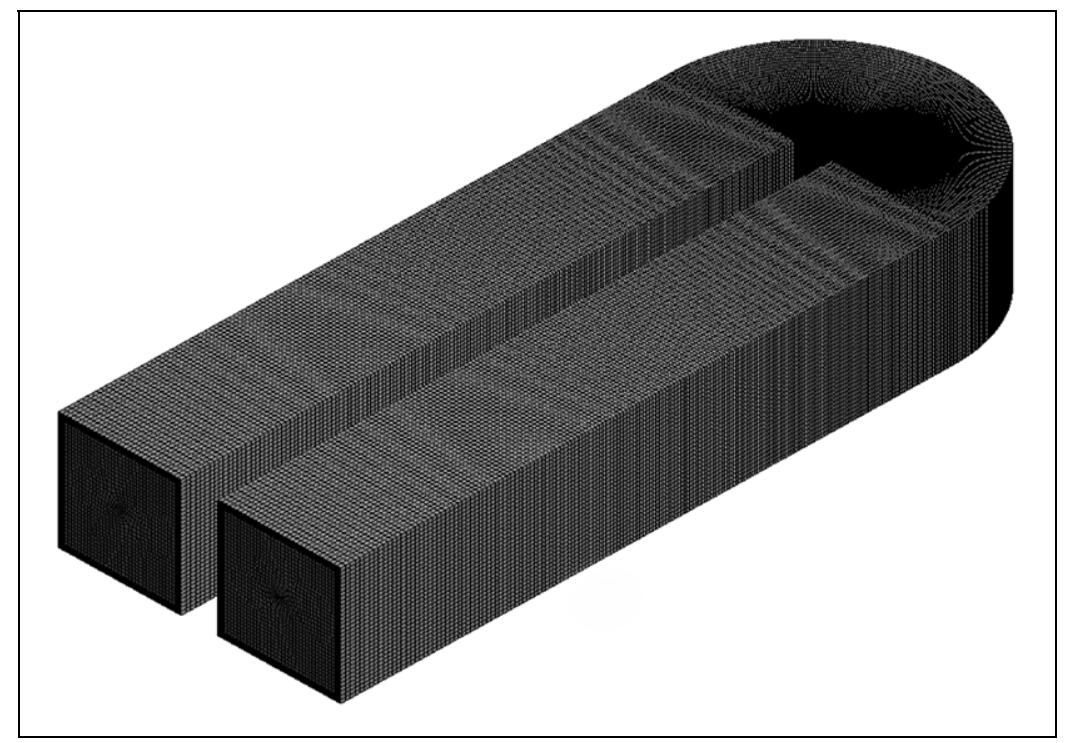

Figure 3.10 The finest mesh used in the mesh independency study

Details of the statistics of the meshes used in the mesh independency study are tabulated in Table 3.3.

Table 3.3 Statistics of meshes used in the mesh independency study

\begin{tabular}{|c|c|c|c|c|c|}
\hline & Mesh 1 & Mesh 2 & Mesh 3 & Mesh 4 & Mesh 5 \\
\hline Number of Nodes & 169041 & 300456 & 574308 & 1143133 & 2344567 \\
\hline Number of Elements & 164000 & 292160 & 559810 & 1116720 & 2296800 \\
\hline Maximum Skewness & 0.500 & 0.500 & 0.500 & 0.500 & 0.500 \\
\hline Average Skewness & 0.262 & 0.252 & 0.218 & 0.198 & 0.176 \\
\hline $\begin{array}{c}\text { Minimum Orthogonal } \\
\text { Quality }\end{array}$ & 0.701 & 0.599 & 0.707 & 0.707 & 0.707 \\
\hline $\begin{array}{c}\text { Average Orthogonal } \\
\text { Quality }\end{array}$ & 0.878 & 0.877 & 0.907 & 0.919 & 0.933 \\
\hline
\end{tabular}


The resulting $\mathrm{U} / \mathrm{U}_{0}$ values at different angular positions are compared for five different meshes in Figure 3.11. In this figure, the x-axis shows the angle inside the bend where inlet of the bend represents 0-degree and the outlet 180-degree. Moreover, the $\mathrm{y}$-axis shows the $\mathrm{U} / \mathrm{U}_{0}$ values where $\mathrm{U}_{0}$ is constant and taken as mean inlet velocity to the bend.

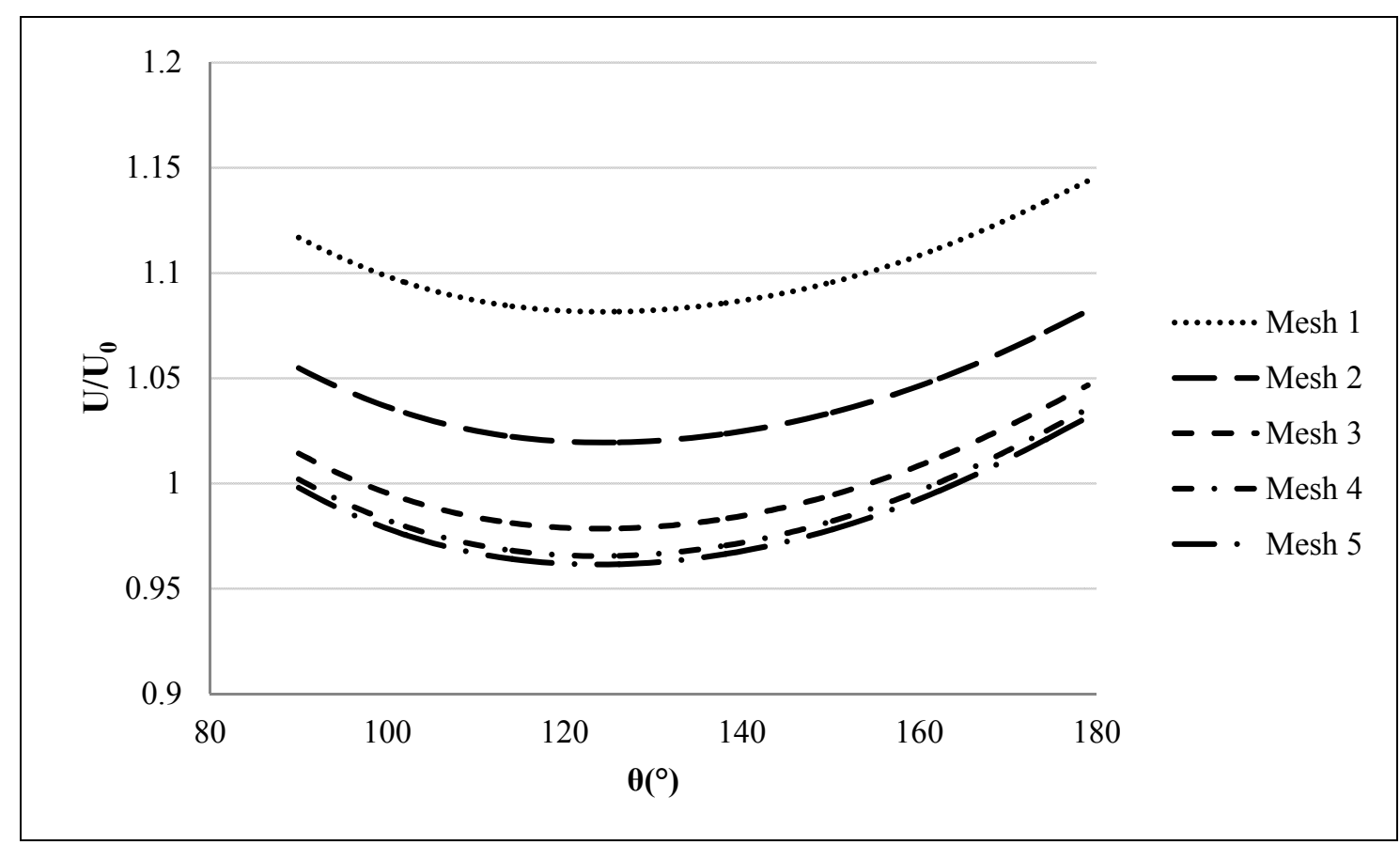

Figure 3.11 Mesh independency results on mean streamwise velocity

It is worth to mention that, the experimental value $\mathrm{U} / \mathrm{U}_{0}$ measured at $r^{\prime} / D=0.5$ and $2 y / D=1$ is used for the mesh independency study where $r^{\prime}$ is the transverse distance measured from inner to outer wall which is also indicated in Figure 3.2. This transverse distance is normalized by the width of the duct, $\mathrm{r}^{\prime} / \mathrm{D}$.

In Figure 3.12 and Figure 3.13, $\mathrm{r}^{\prime} / \mathrm{D}$ vs. $\mathrm{U} / \mathrm{U}_{0}$ values are plotted at $2 y / D=0.25$ and $2 y / D=1$ planes where the latter is representing symmetry plane (the top or bottom wall corresponds to $2 y / D=0$ which are indicated in Figure 3.2). Interpreting the results of Figure 3.11, Mesh 5 and Mesh 4 shows less than 1\% discrepancy. 


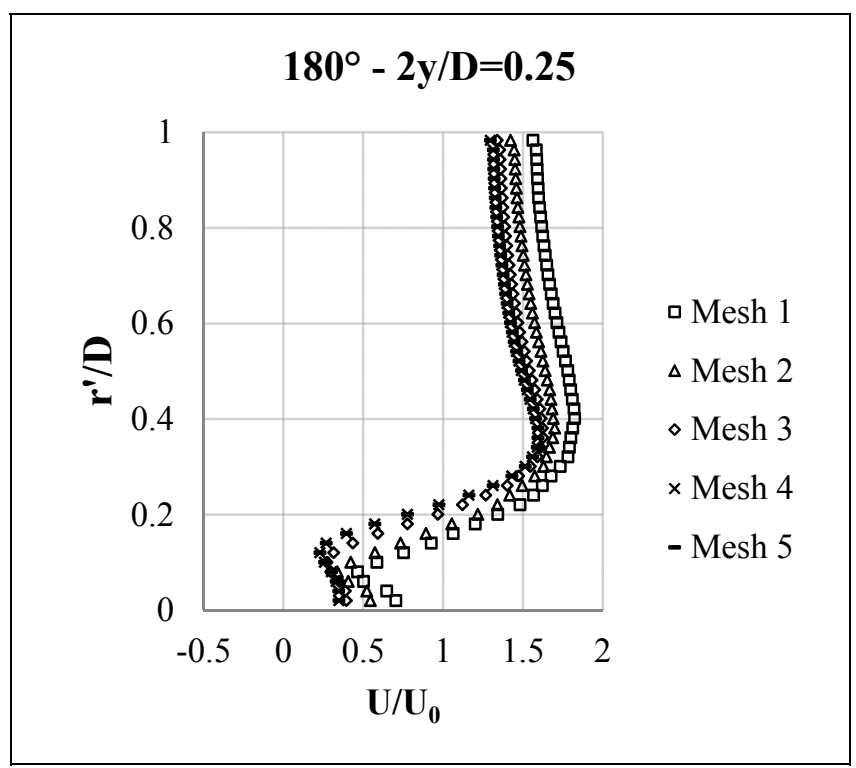

Figure 3.12 Mean streamwise velocity profiles at $180^{\circ}$ bend angle $2 \mathrm{y} / \mathrm{D}=0.25$ plane

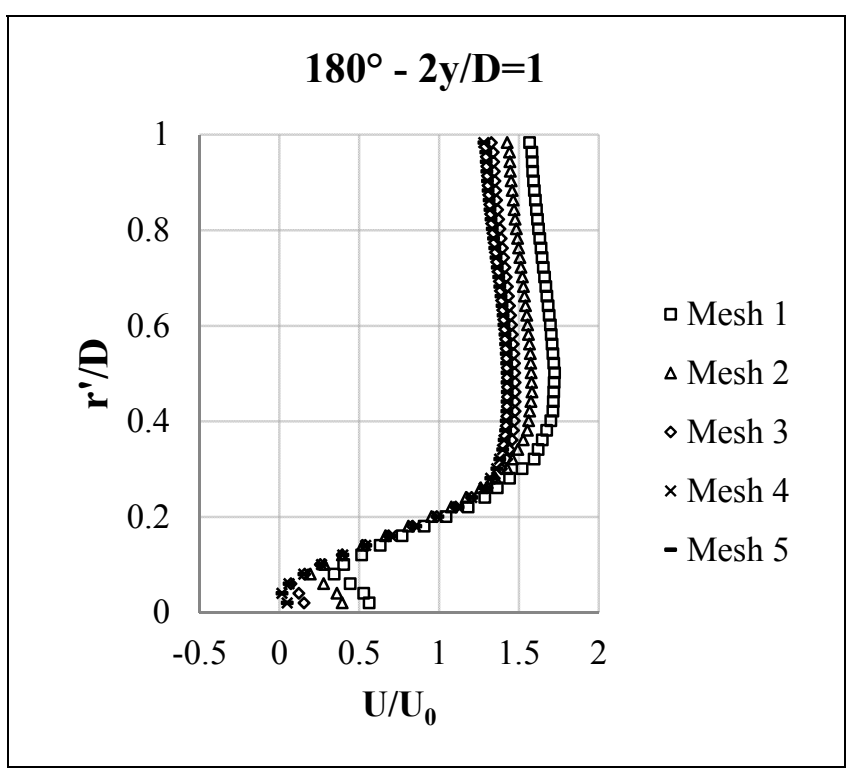

Figure 3.13 Mean streamwise velocity profiles at $180^{\circ}$ bend angle $2 \mathrm{y} / \mathrm{D}=1$ plane 
The comparison of velocity profiles also demonstrates that the solution is not changing more than $1 \%$ with further refinement in the mesh. Therefore, the mesh independency is considered to be achieved and the Mesh 4, which is shown in Figure 3.14 , is used in the following computations.

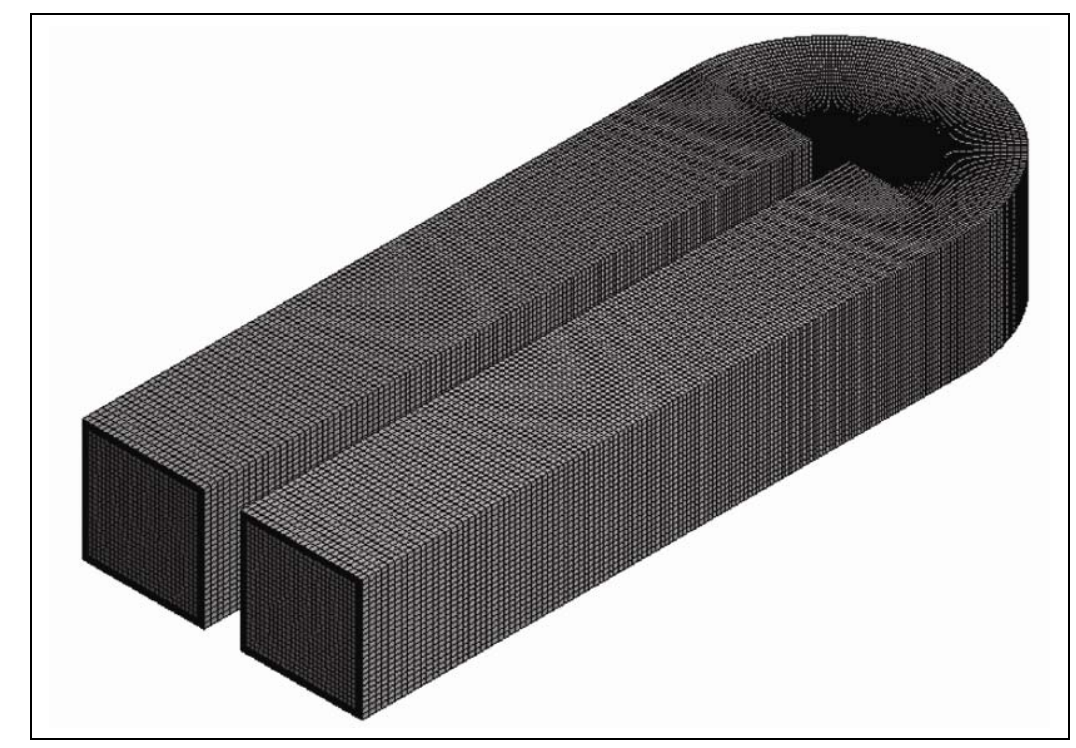

Figure 3.14 The preview of the selected mesh (Mesh 4) for numerical simulations

Detailed previews of the selected mesh at the bend section and at the 90-degree section of the bend are shown in Figure 3.15 and Figure 3.16, respectively.

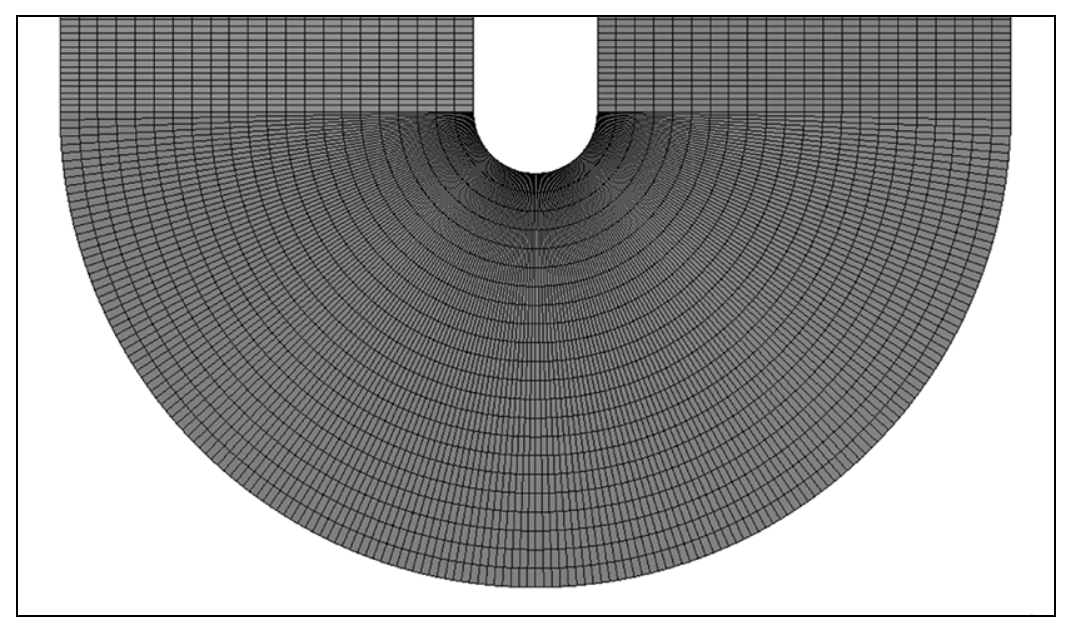

Figure 3.15 The preview of the selected mesh at the bend section 


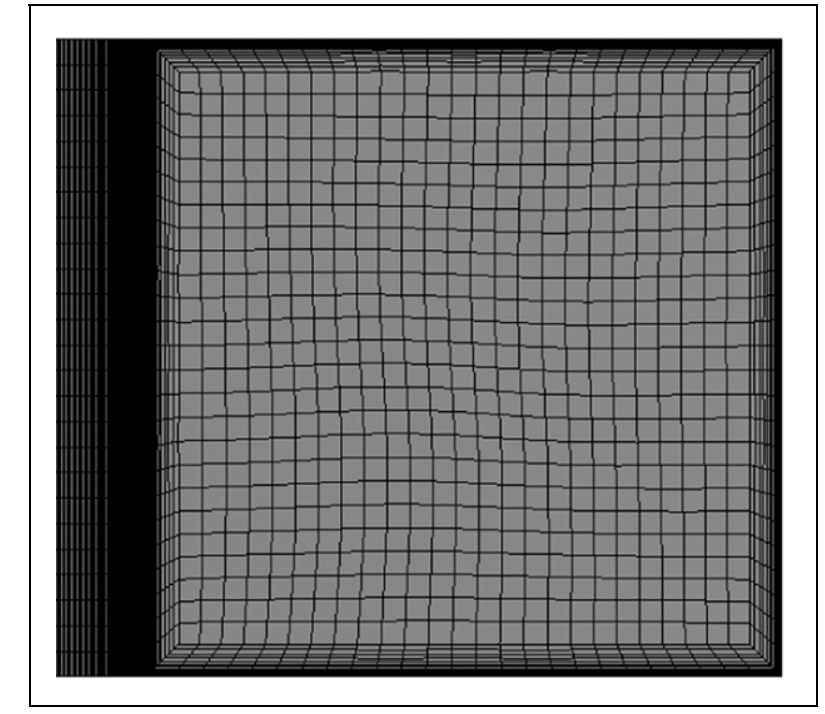

Figure 3.16 The preview of the selected mesh at the 90-degree bend section 


\section{CHAPTER 4}

\section{VERIFICATION AND COMPARISON OF DIFFERENT TURBULENCE MODELS}

In this chapter, the numerical results, obtained from the simulations in ANSYS FLUENT software for different turbulence models, are subjected to detailed verification by comparing them with available experimental and numerical results on literature.

\subsection{Velocity Profiles at Bend Sections}

Cheah et al.'s [11] experimental results of the dimensionless U values are compared with the present computed results for six different turbulence models in this section. The turbulence models used in the present study are: standard k- $\varepsilon$ model, RNG k- $\varepsilon$ model, Realizable k- $\varepsilon$ model, k- $\omega$ SST model, Reynolds Stress Model (RSM) and Scale-Adaptive Simulation Model (SAS).

Standard k- $\varepsilon$, Realizable k- $-\varepsilon$, RNG k- $\varepsilon$ and k- $\omega$ SST are used with steady analyses. Since Scale-Adaptive Simulation Model (SAS) is specified only in transient calculations, it is used in transient analyses. The transient analysis for Reynolds Stress Model (RSM) is used due to convergence problems encountered during steady simulations.

The mean streamwise velocity profiles of different turbulence models are compared with the experimental data [11] at three bend sections of $\theta=90^{\circ}, 135^{\circ}$ and $180^{\circ}$ in Figure 4.1, Figure 4.2, Figure 4.3, respectively. Each figure consists of two rows; top rows show the results for $2 y / D=0.25$ and bottom rows show the results for the $2 y / D$ $=1$. 


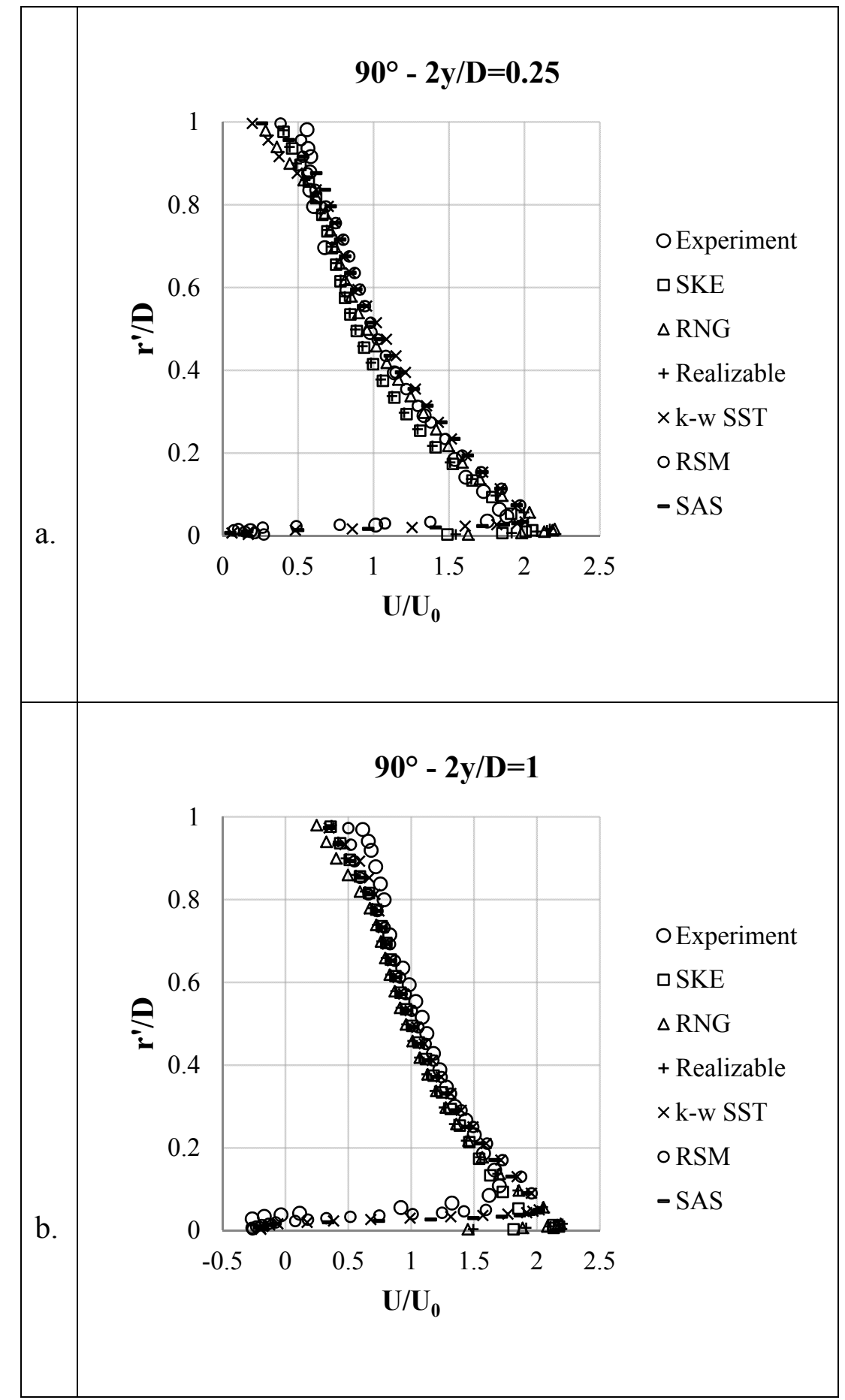

Figure 4.1 The mean streamwise velocity profiles at $90^{\circ}$ in the bend; (a) $2 \mathrm{y} / \mathrm{D}=0.25$;

(b) $2 \mathrm{y} / \mathrm{D}=1$ 


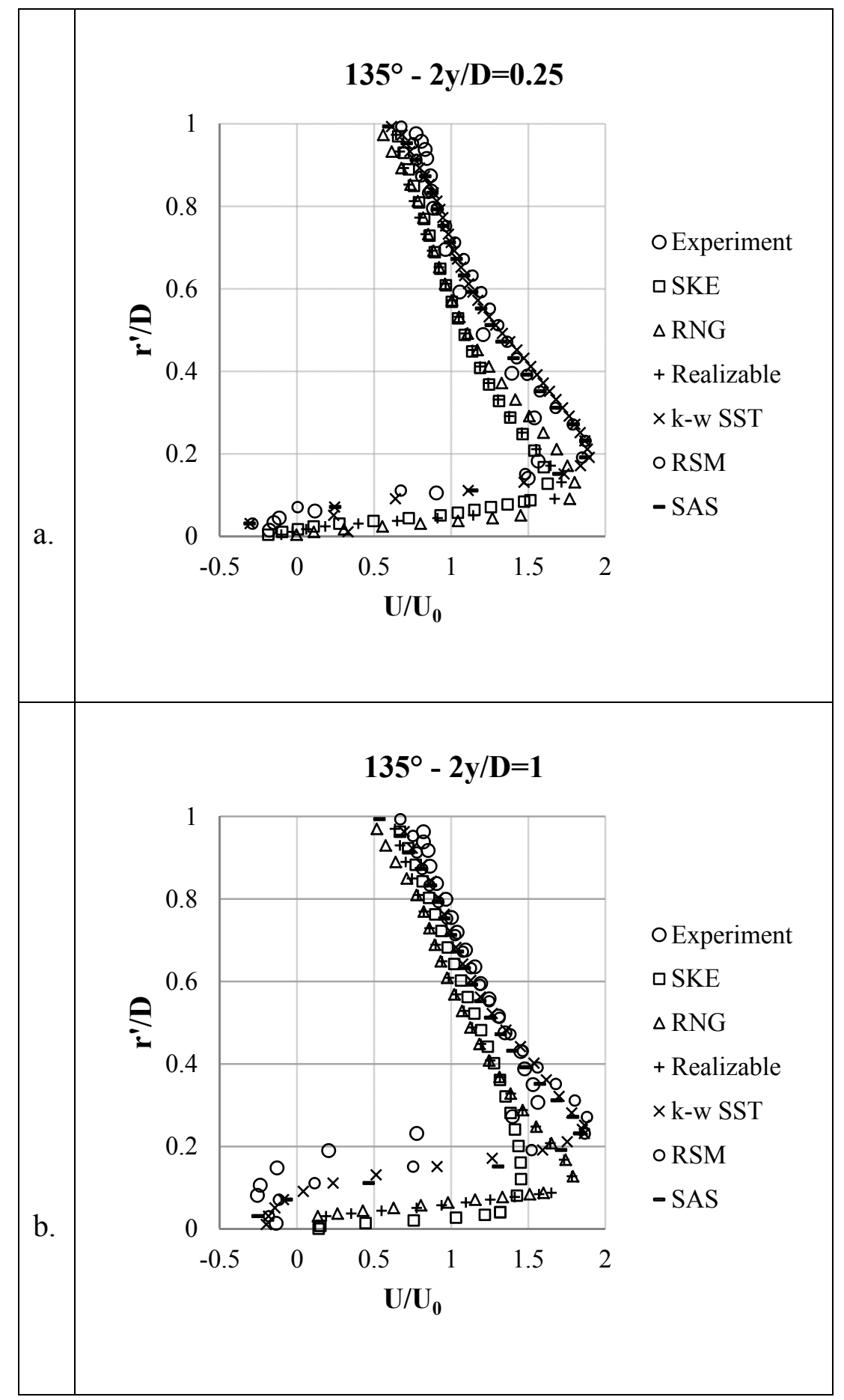

Figure 4.2 The mean streamwise velocity profiles at $135^{\circ}$ in the bend; (a) $2 y / D=0.25$; (b) $2 y / D=1$ 


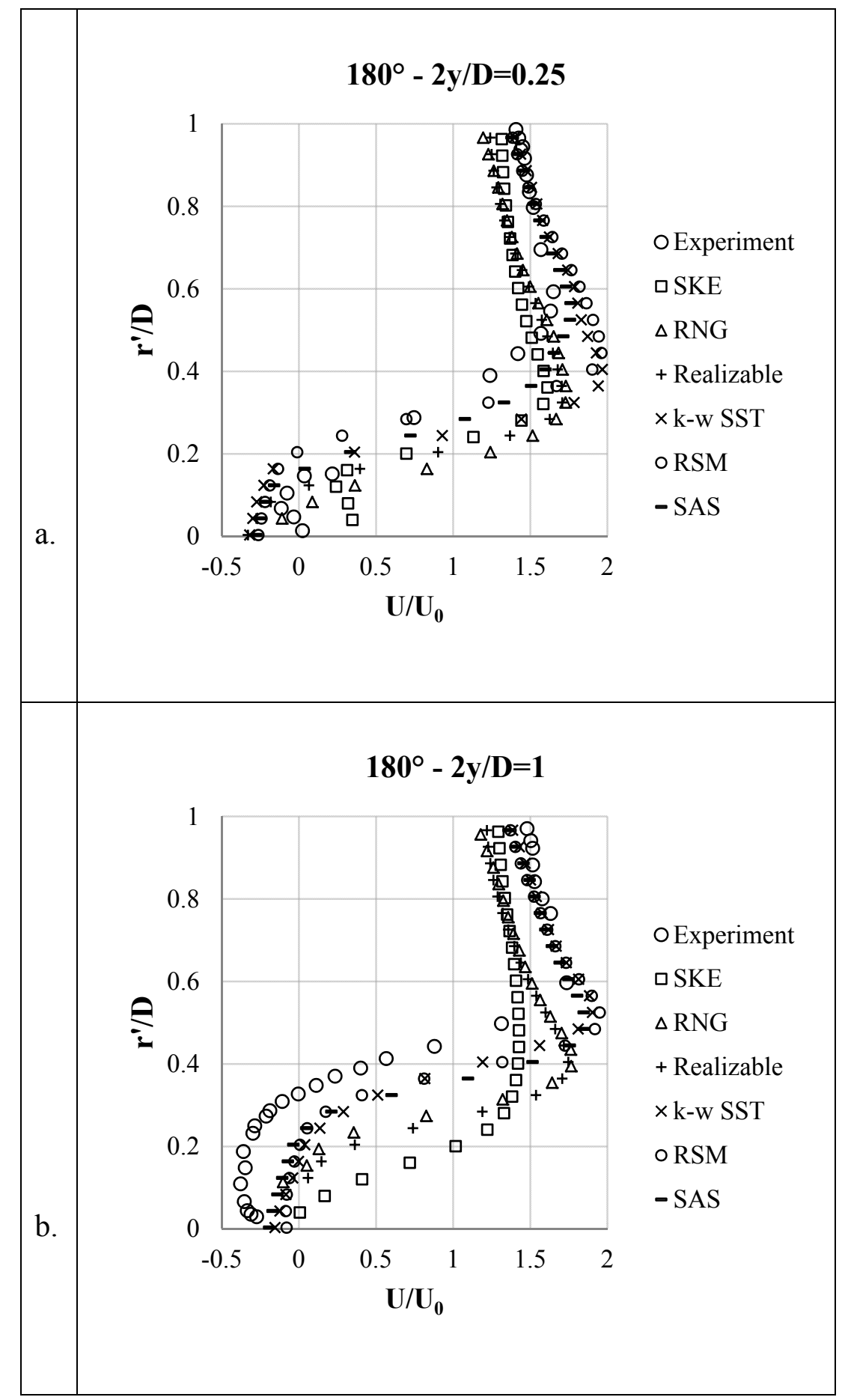

Figure 4.3 The mean streamwise velocity profiles at $180^{\circ}$ in the bend; (a) $2 \mathrm{y} / \mathrm{D}=0.25$;

(b) $2 \mathrm{y} / \mathrm{D}=1$ 
At $\theta=90^{\circ}$, Figure 4.1 , the simulation results and the experimental results near the bottom (or top) wall $2 y / D=0.25$ and at the centerline $2 y / D=1$ are quite coherent. There is no significant deviation between the different turbulence model results and the experimental results except for the slight variation at the regions very close to the wall where $\mathrm{r}^{\prime} / \mathrm{D}$ values are less than 0.5 . However, this coherence starts to deteriorate at higher angular positions.

Starting from the $\theta=135^{\circ}$, at symmetry plane $2 y / D=1$, Figure $4.2(\mathrm{~b})$, the variation between the results of turbulence models are apparent; the k- $\omega$ SST, RSM and SAS model results demonstrate a better trend considering the experimental results.

For $\theta=180^{\circ}$, near the bottom (or top) wall $2 y / D=0.25$, Figure $4.3(\mathrm{a}$ ), the results of different turbulence models are populated around the experimental results, and nearly all turbulence model except the standard k- $\varepsilon$ model, are considered as quite successful for capturing the flow structure considering the experimental results. However, at symmetry plane $2 y / D=1$, Figure $4.3(\mathrm{~b})$, the discrepancy between the turbulence model results and the experimental results is evident. The k- $\omega$ SST, RSM and SAS model results demonstrate better coherence with the experimental results. The standard k- $\varepsilon$ model results' degrades drastically at the symmetry plane for $\theta=180^{\circ}$.

Considering the velocity profiles of the present study, shown in the Figure 4.1 to Figure 4.3, the RSM model predictions are considered as the best in accordance with the experimental values obtained by Cheah et al. [11]. However, it is evident that the variation between the results of k- $\omega$ SST and RSM models is quite minimal. When the computation effort and time (shown in the later sections) are taken into account, the k- $\omega$ SST model is selected for further modeling and is proposed as the best numerical approach for this type of application. It is important to mention that the separation point results, discussed in the later sections, also support this selection. The k- $\omega$ SST model shows superior prediction as 85 -degree, which is very close to the experimental data of 90-degree, compared to the results of the other turbulence models. 
Figure 4.4 to Figure 4.6 shows the comparison between the experimental results of Cheah et al. [11] and present analyses' standard k- $\varepsilon$ and k- $\omega$ SST model results and the Djebedjian et al.'s [16] best numerical model predictions (the RSM model).

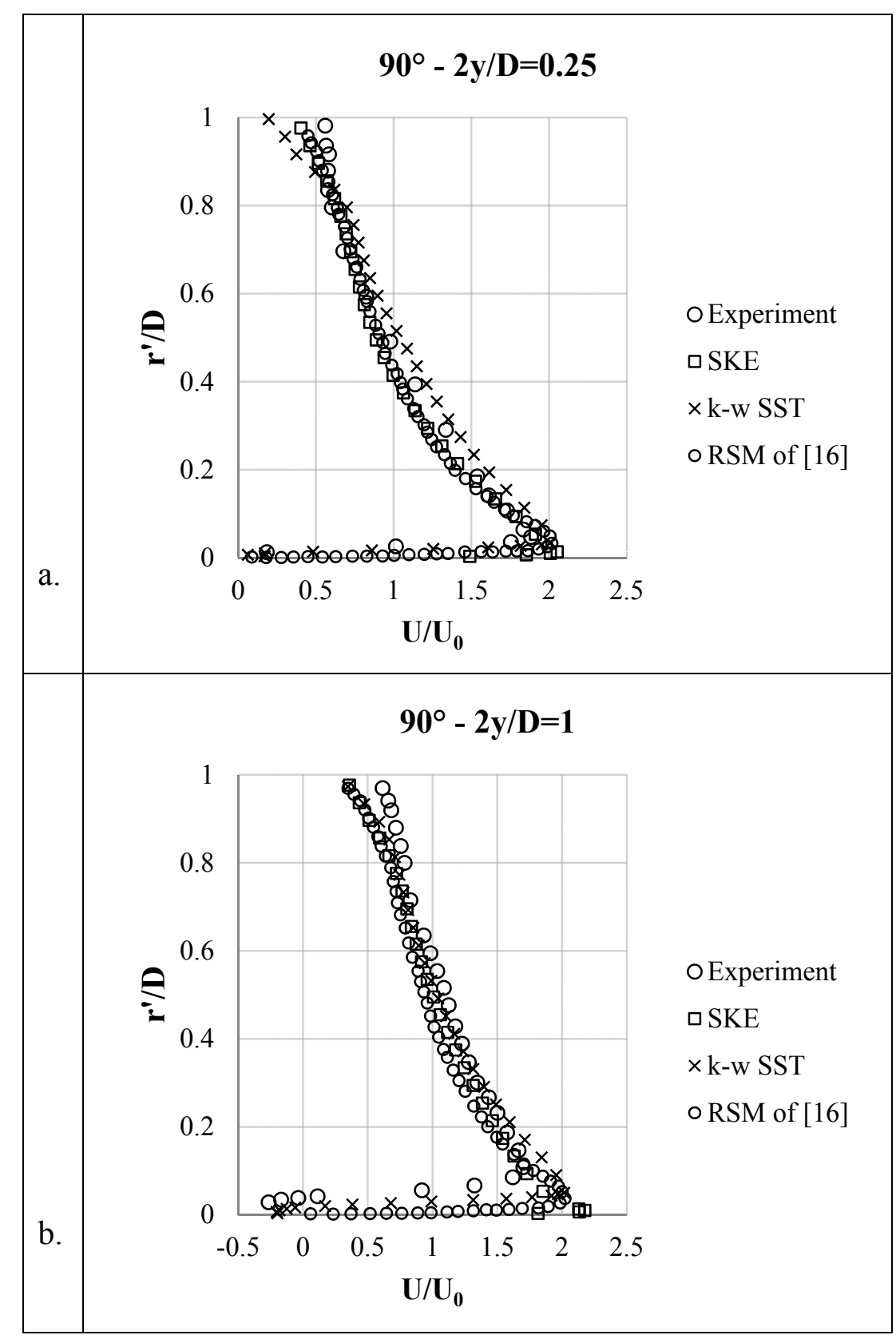

Figure 4.4 The comparison of the experimental results, present analyses' standard k- $\varepsilon$ and k- $\omega$ SST model results, and the previous studies Djebedjian et al.'s best predictions (RSM model) at $90^{\circ}$ bend angle; (a) $2 \mathrm{y} / \mathrm{D}=0.25$; (b) $2 \mathrm{y} / \mathrm{D}=1$ 


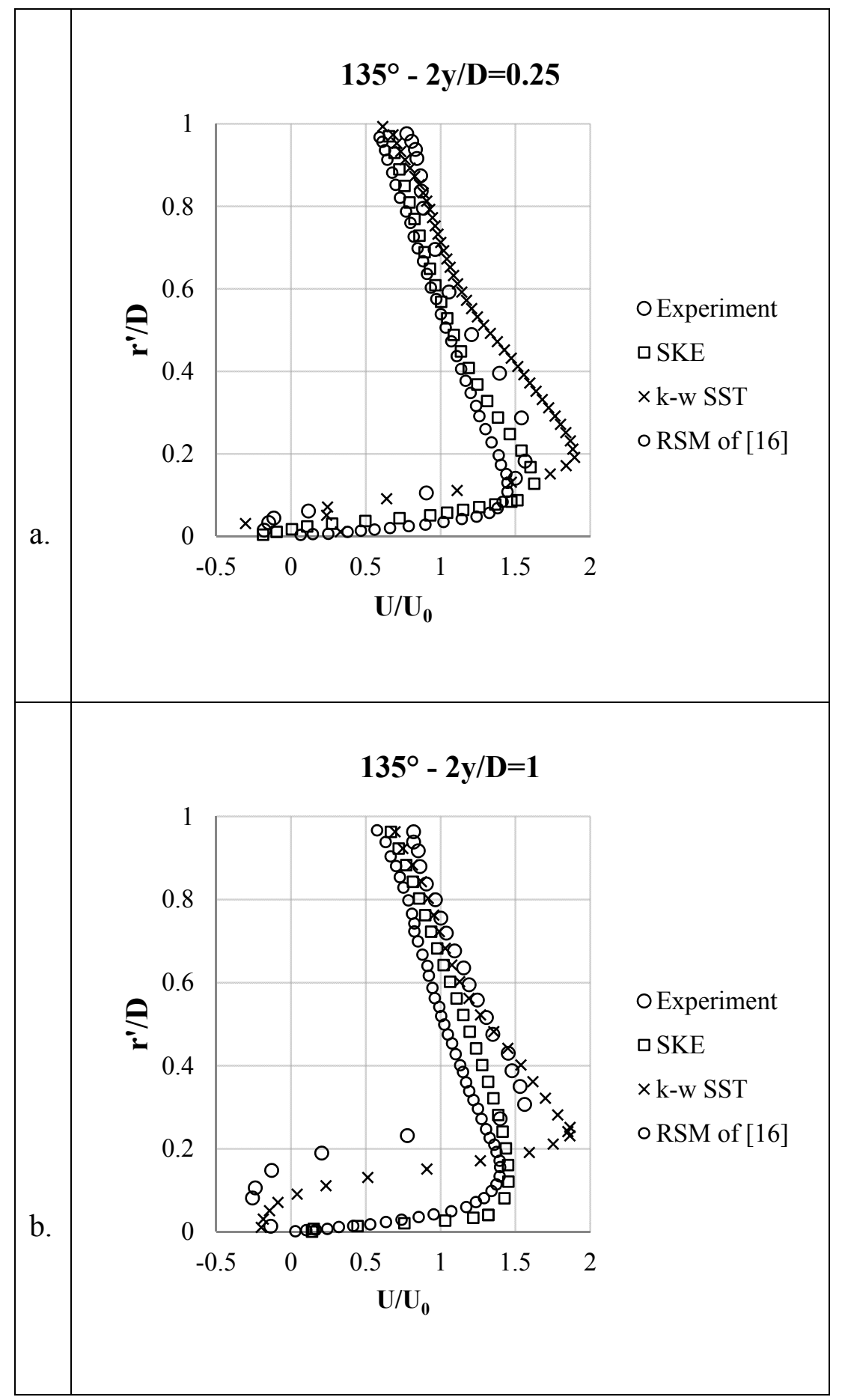

Figure 4.5 The comparison of the experimental results, present analyses' standard k- $\varepsilon$ and k- $\omega$ SST model results, and the previous studies Djebedjian et al.'s best predictions (RSM model) at $135^{\circ}$ bend angle; (a) $2 \mathrm{y} / \mathrm{D}=0.25$; (b) $2 \mathrm{y} / \mathrm{D}=1$ 


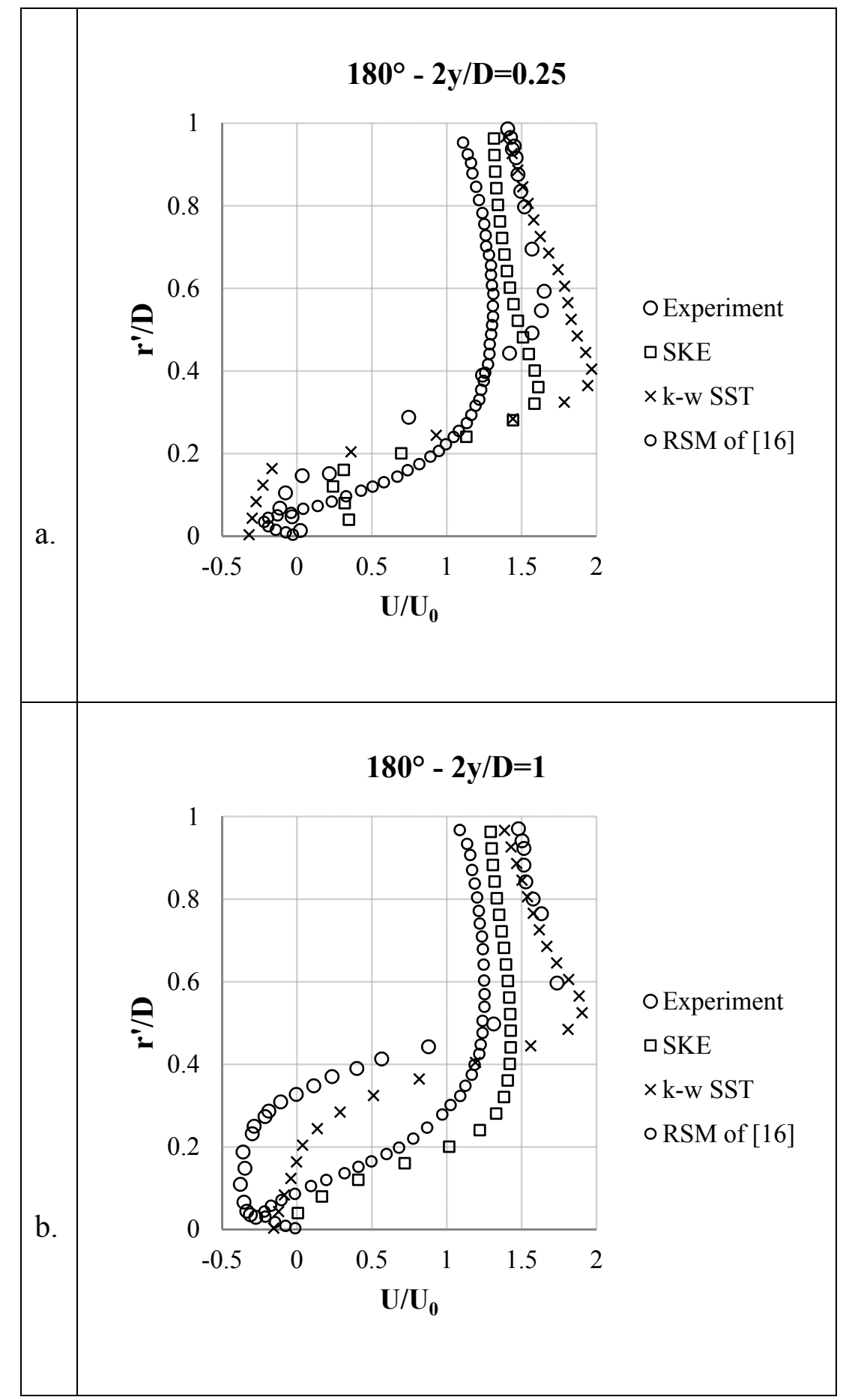

Figure 4.6 The comparison of the experimental results, present analyses' standard k- $\varepsilon$ and k- $\omega$ SST model results, and the previous studies Djebedjian et al.'s best predictions (RSM model) at $180^{\circ}$ bend angle; (a) $2 \mathrm{y} / \mathrm{D}=0.25$; (b) $2 \mathrm{y} / \mathrm{D}=1$ 
Figure 4.4 to Figure 4.6 is constructed in the same way as Figure 4.1 to Figure 4.3 and indicates the improvement obtained in the current study compared to the previous numerical approaches. The current study's k- $\omega$ SST model results show significant improvement in almost all planes at all angular positions when compared with the previous investigation.

\subsection{Flow Patterns}

Streamlines and contours of constant turbulent intensity levels for standard k- $\varepsilon$ and k$\omega$ SST models for three different angular positions are shown in Figure 4.7 to Figure 4.10. Figure 4.7 and Figure 4.8 show streamlines for standard k- $\varepsilon$ model and k- $\omega$ SST model, respectively. Figure 4.9 and Figure 4.10 show turbulence intensities for standard k- $\varepsilon$ model and k- $\omega$ SST model, respectively. Each row in the figures represents angular positions, $90^{\circ}, 135^{\circ}$ and $180^{\circ}$, flow top to bottom, respectively. The inner and outer sides of the bend are indicated as "I" and "O".

For the Figure 4.7 and Figure 4.8, the circulation zones represent the Dean vortices and the inverse gray scale, located right side of the figures, indicates the velocity on the streamlines. The darker sections that occur in the circulation zones display velocity increase close to the cores of the Dean vortices.

Secondary flows due to faster flowing central part of the flow can be seen on the streamlines at all cross sections. The results are consistent with the previous observations of Enayet et al., [30]; Azzola et al., [7]; Sudo et al., [31], [32]. According to these studies, in a curved pipe, flow has a higher velocity at the center of the bend and relatively low velocity close to the wall sides. When proceeds along the bend high and slow velocity fluid zones follow each other and create C-shaped streamwise velocity contours which can be observed in Figure 4.7 and Figure 4.8 [5]. 


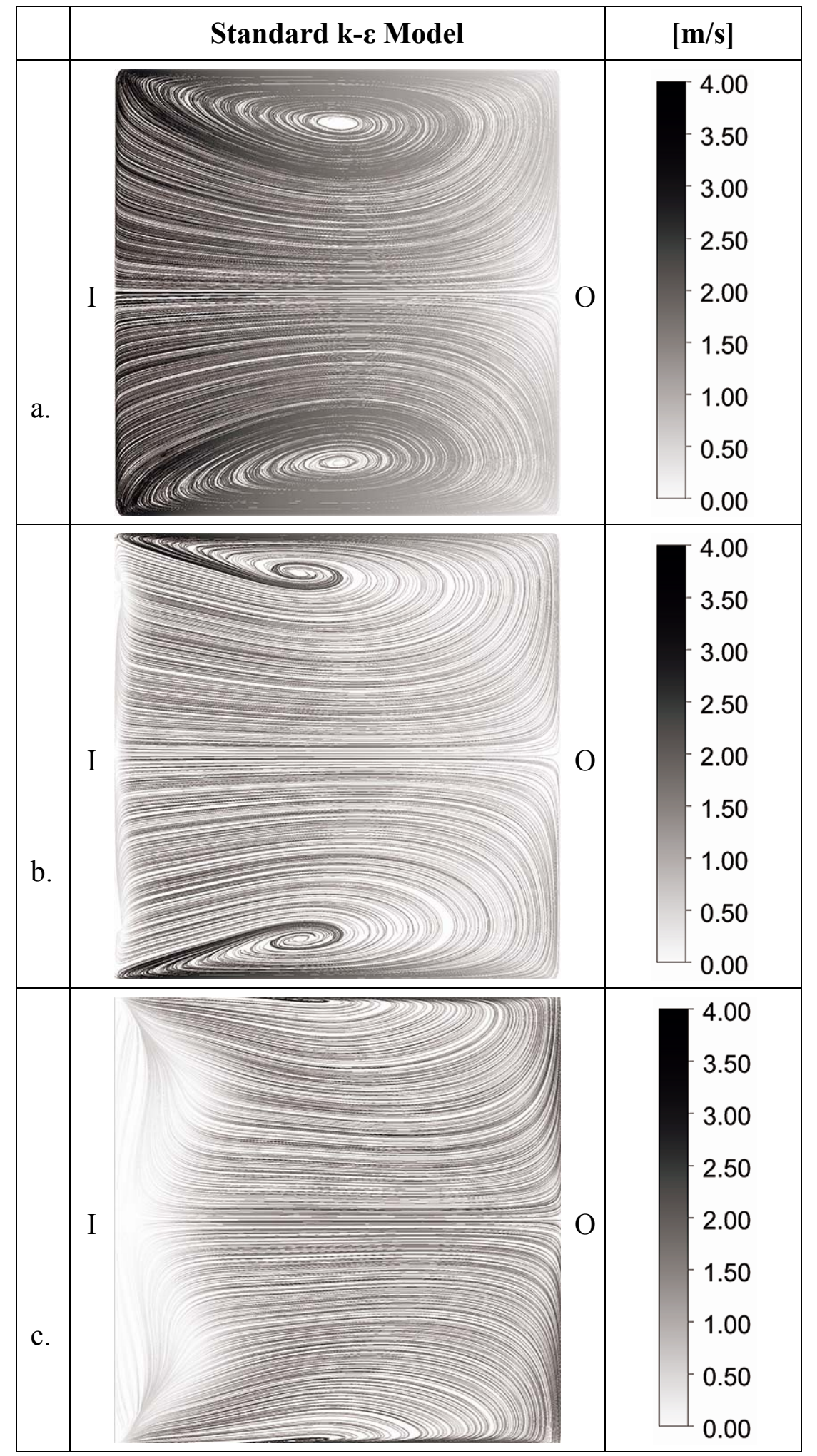

Figure 4.7 The streamlines associated with secondary flow patterns predicted by the standard k- $\varepsilon$ model at; (a) $\theta=90^{\circ}$; (b) $\theta=135^{\circ}$; (c) $\theta=180^{\circ}$ 


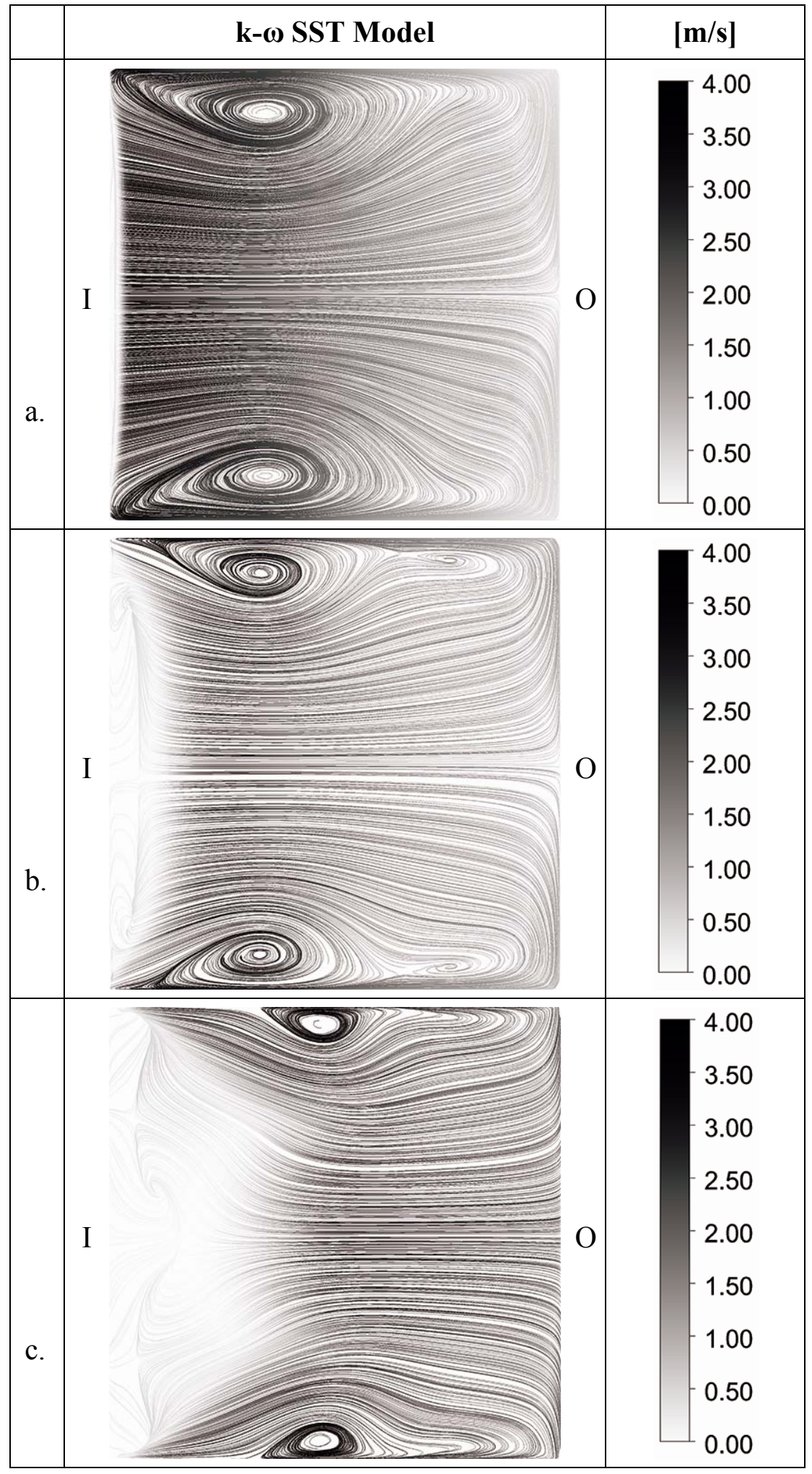

Figure 4.8 The streamlines associated with secondary flow patterns predicted by the k- $\omega$ SST model at; (a) $\theta=90^{\circ}$; (b) $\theta=135^{\circ}$; (c) $\theta=180^{\circ}$ 


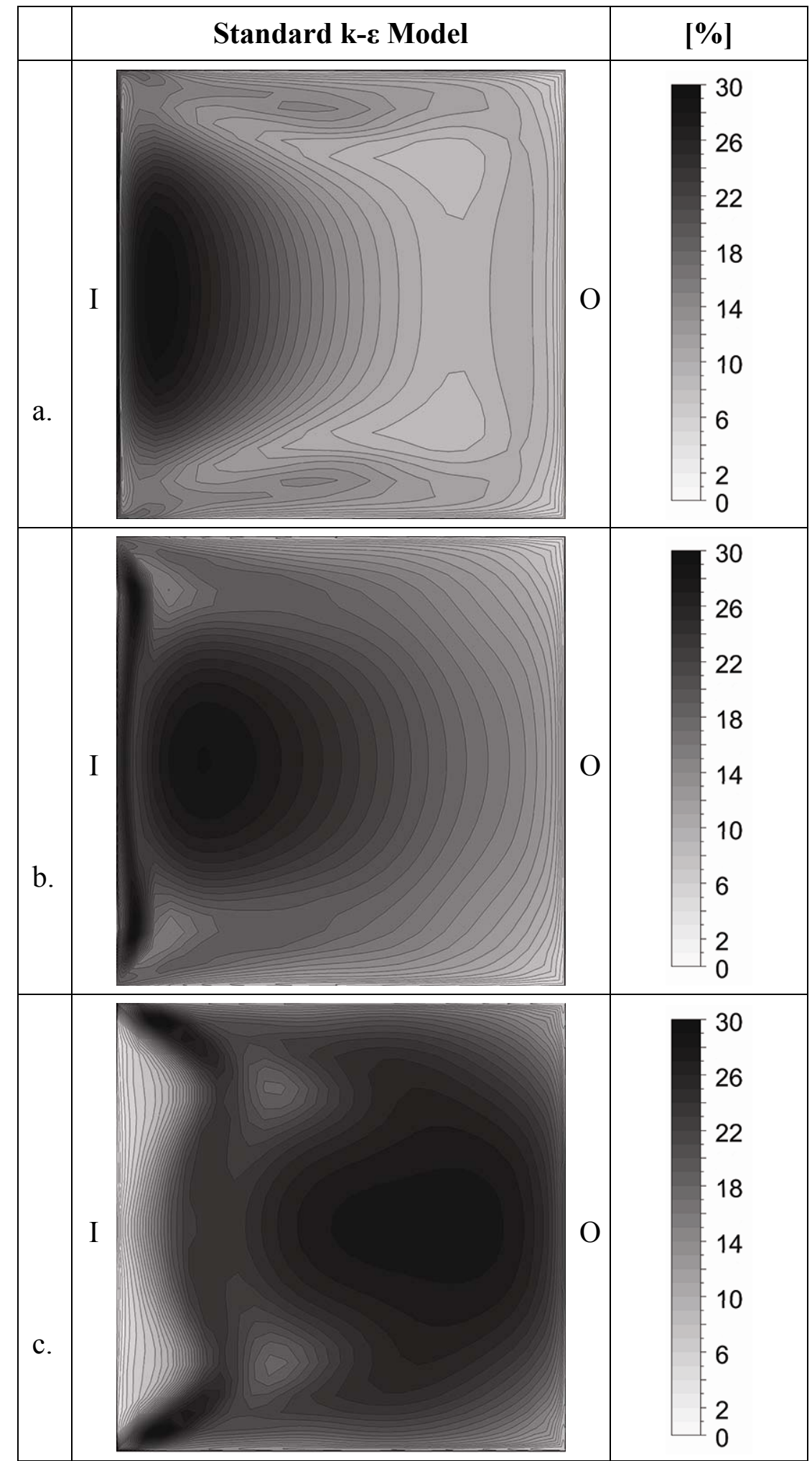

Figure 4.9 The contours of constant turbulence intensity levels predicted by the standard k- $\varepsilon$ model at; (a) $\theta=90^{\circ}$; (b) $\theta=135^{\circ}$; (c) $\theta=180^{\circ}$ 


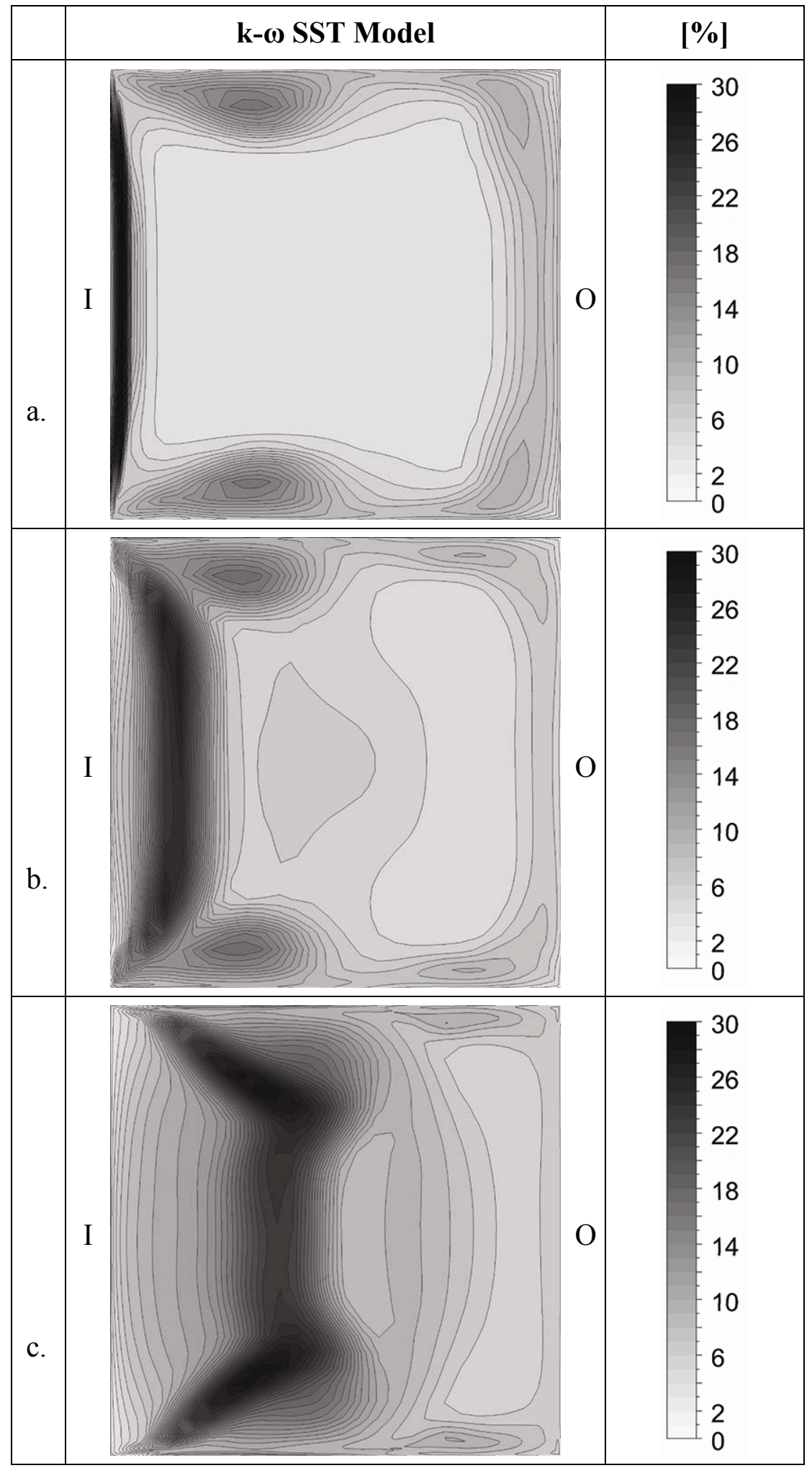

Figure 4.10 The contours of constant turbulence intensity levels predicted by the k- $\omega$ SST model at; (a) $\theta=90^{\circ}$; (b) $\theta=135^{\circ}$; (c) $\theta=180^{\circ}$ 
The streamlines, at $90^{\circ}$ bend section show similar flow patterns for the standard k- $\varepsilon$ and k- $\omega$ SST models. Both models predict a pair of counter rotating circulations (vorticity concentrations), whereas the spatial distribution is located slightly closer to the inner bend and relatively smaller for the SST model compared to the standard k- $\varepsilon$ model.

At $135^{\circ}$ bend section, the k- $\omega$ SST model estimates two pairs of counter-rotating circulation regions induced by the centrifugal forces and the standard k- $\varepsilon$ model estimates only one pair.

An extra pair of very weak circulation zone prediction, which is close to the outer side of the bend, by the k- $\omega$ SST model can also be seen at $180^{\circ}$ angular position shown in Figure 4.8. In addition, for the same angular position of $180^{\circ}$, the circulations predicted by k- $\omega$ SST model are very close to the wall at high strength, where for the standard $\mathrm{k}-\varepsilon$ model predictions it is not the case.

Considering the turbulence intensities at angular positions of $90^{\circ}, 135^{\circ}$ and $180^{\circ}$ by the standard k- $\varepsilon$ model and k- $\omega$ SST model shown in the Figure 4.9 and Figure 4.10, the standard k- $\varepsilon$ model turbulence intensity results do not indicate any coherence compared to flow circulation regions seen in streamline topologies. The maximum turbulent intensity regions are formed at the mid-plane close to the inner side of the bend, which do not match with the regions of circulation zones.

However, k- $\omega$ SST model turbulence intensity predictions, demonstrate coherence with the circulation zones in the field such that high turbulent intensity regions correspond to the circulation regions, consequently representing high vorticity concentrations. The maximum turbulence intensity can reach up to $30 \%$, which is seen at the plane of $\theta=90^{\circ}$ near vortex core close to the inner bend. In addition, the turbulence intensity at the center location decreases when the flow moves along the bend. The maximum turbulence intensity location moves to the central parts of the bend angular positions $\theta=135^{\circ}$ and $180^{\circ}$. 


\subsection{Computation Time}

The computation requirements of different turbulence models used in this study are summarized in Table 4.1. The solution method used in each turbulence model is shown in the first column. Standard k- $\varepsilon$, Realizable k- $\varepsilon$, RNG k- $\varepsilon$ and k- $\omega$ SST are used with steady analyses. Since Scale-Adaptive Simulation Model (SAS) is specified only in transient calculations, it is used in transient analyses. The transient analysis for Reynolds Stress Model (RSM) is used due to convergence problems encountered during steady simulations.

Table 4.1 The computation requirements of different turbulence models

\begin{tabular}{cccc}
$\begin{array}{c}\text { Solution } \\
\text { Method }\end{array}$ & $\begin{array}{c}\text { Turbulence } \\
\text { Model }\end{array}$ & $\begin{array}{c}\text { Iterations to } \\
\text { Converge }\end{array}$ & $\begin{array}{c}\text { Computation Time } \\
\text { (hh:mm) }\end{array}$ \\
\hline Steady & Standard k- $\varepsilon$ & 1750 & $2: 05$ \\
& Realizable k- $\varepsilon$ & 2250 & $2: 41$ \\
& RNG k- $\varepsilon$ & 5000 & $6: 17$ \\
k- $\omega$ SST & 4750 & $6: 54$ \\
Melution & Turbulence & Time Steps to & Computation Time \\
(hod:mm) & Converge & $39: 40$ \\
\hline \multirow{2}{*}{ Transient } & RSM & 959 & $41: 44$
\end{tabular}

Five cores of an Intel Core i7 2.4 GHz CPU workstation are used for performing the numerical computations, simultaneously. In transient runs for RSM and SAS, time step size is calculated using the Courant Number, which uses, average linear velocity and minimum grid cell dimension. According to calculations, time step size is taken as $1.5 \times 10^{-5}$ seconds and Courant Number is kept under 1 to improve the stability of the solver and the accuracy of the results. 


\subsection{Separation Points}

LDA (laser-Doppler anemometry) measurement technique is used by Cheah et al. [11] to obtain velocity profiles and thus for detecting separation points in their experiments. The resolution in radial direction inside the bend is given as $0.6 \mathrm{~mm}$ [11] is also used in the present study to detect the separation points in the bend. According to the resolution of Cheah et al.'s study [11], the separation points , are obtained on a semicircle which is drawn $0.6 \mathrm{~mm}$ away from the inner bend. Figure 4.11 indicates the resolution semicircle that is used for the results of the present study. The resolution in the study of Djebedjian et al. [16] is not specified.

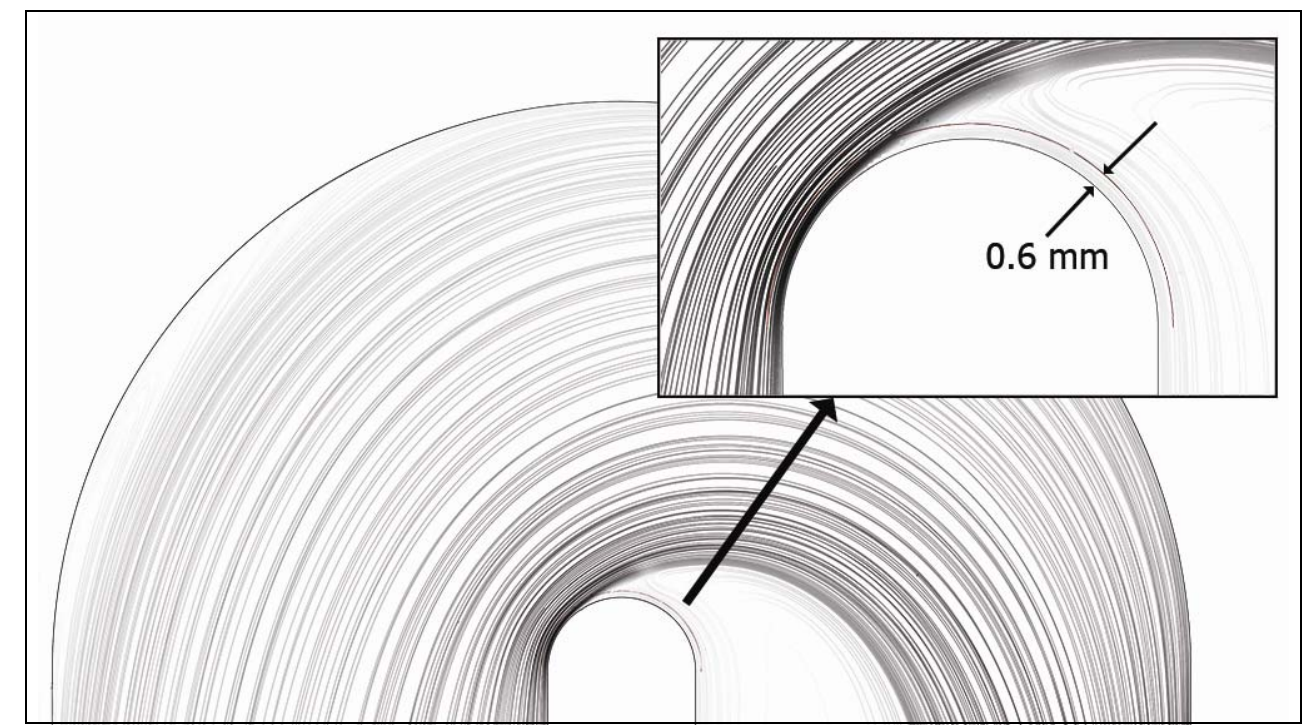

Figure 4.11 Demonstration of experimental resolution used in Cheah et al.'s study [11]

Table 4.2 shows the comparison of separation points predicted by different turbulence models in the current study with the previous study of Djebedjian et al. [16] and the experimental results of Cheah et al. [11]. In Cheah et al's study [11] the separation point inside the bend is predicted at around $\theta=90^{\circ}$ which is shown in the last row of the Table 4.2. First two columns of Table 4.2 represent the results of the present study at different resolution levels. The first column indicates the results at 
the resolution of computational model whereas in the second column the separation point calculations are performed at the experiment resolutions, which is specified for the LDA measurement of Cheah et al.’s [11] study.

Table 4.2 The location of separation points

\begin{tabular}{|c|c|c|c|c|}
\hline & $\begin{array}{c}\text { Separation } \\
\text { Points of } \\
\text { current study } \\
\left(\theta^{\circ}\right)\end{array}$ & $\begin{array}{c}\text { Separation } \\
\text { Points of } \\
\text { current study at } \\
\text { experiment } \\
\text { resolution }\left(\theta^{\circ}\right) \\
\end{array}$ & $\begin{array}{c}\text { Separation } \\
\text { Points of } \\
\text { previous study } \\
\left(\theta^{\circ}\right)[16]\end{array}$ \\
\hline \multirow{6}{*}{$\begin{array}{c}\text { Turbulence } \\
\text { Models }\end{array}$} & $\begin{array}{c}\text { Standard } \\
\text { k- } \varepsilon\end{array}$ & 113 & 127 & 149 \\
\hline & RNG k- $\varepsilon$ & 111 & 126 & 127 \\
\hline & $\begin{array}{c}\text { Realizable } \\
\text { k- } \varepsilon\end{array}$ & 108 & 124 & 128 \\
\hline & k- $\omega$ SST & 67 & 85 & 151 \\
\hline & RSM & 59 & 73 & 123 \\
\hline & SAS & 63 & 79 & - \\
\hline \multicolumn{2}{|c|}{ Experiments [11] } & 90 & 90 & 90 \\
\hline
\end{tabular}

Among all the models of the present study and Djebedjian et al. [16] study, k- $\omega$ SST model of the present study shows remarkable performance in predicting the separation point. The separation point inside the bend is predicted at 85 degree by the k- $\omega$ SST model, which is very close to the experimental results. The SAS and RSM model predictions at the experimental resolution can also be considered as acceptable.

Although Djebedjian et al. [16] and the present study used the same turbulence models, which are shown in Table 4.2, there are three possible reasons for the deviations in separation point locations. The first one is; Djebedjian et al. used a course mesh in their numerical simulations especially in the bend section. However, in the present study the mesh in the bend section is kept fine relative to the inlet and 
outlet sections. Djebedjian et al. [16] used a mesh with 140,625 total number of nodes whereas in the present study the selected mesh has 1,143,133 total number of nodes after the mesh independency study. Secondly, using different differencing schemes; Djebedjian et al. [16] used first order upwind differencing scheme in their analyses, in the present study second order upwind differencing scheme is used. Finally, experimental resolution of the Cheah et al.'s [11] study did not taken into account in the Djebedjian et al.'s [16] study for determining the separation points inside the bend. 


\section{CHAPTER 5}

\section{FLOW CONTROL STRATEGY}

In this chapter, details of the flow control applied in the bend to decrease turbulence levels and eliminate Dean vortices are explained. Development of the CFD model for the flow control analyses is discussed and details of the model are tabulated. Here, results of the flow control strategy as flow patterns, vorticities and turbulence intensities are compared with the base model.

\subsection{Details of Control Strategy}

It is evident that the curvature in U-bends causes complex flow structures including Dean vortices and high levels of turbulence that are not seen in straight duct flows. Different control strategies are studied to regulate the flow inside the bend and to reduce turbulence levels in U-bends.

The following three different flow control strategies have been investigated: minichannels in the bend section, baffles in the exit half of the bend, and airfoils inside the bend.

Firstly, the mini-channels are located inside the bend section, the elimination of Dean vortices and the reduction in turbulence intensity are obtained, particularly in the 90 and 135-degree planes. However, these channels caused large pressure drops inside the bend and increased the turbulence intensity in 180-degree plane.

Secondly, the baffles are put in the exit half of the bend, no significant effect was observed considering the Dean vortices and turbulence intensity values. 
When the streamlined shaped structures are put inside the bend to guide the flow and possibly to eliminate the effect of Dean vortices, quite successful results are obtained. Two airfoils are located on the 45-degree plane of the bend with equally spaced, which is shown in Figure 5.1.

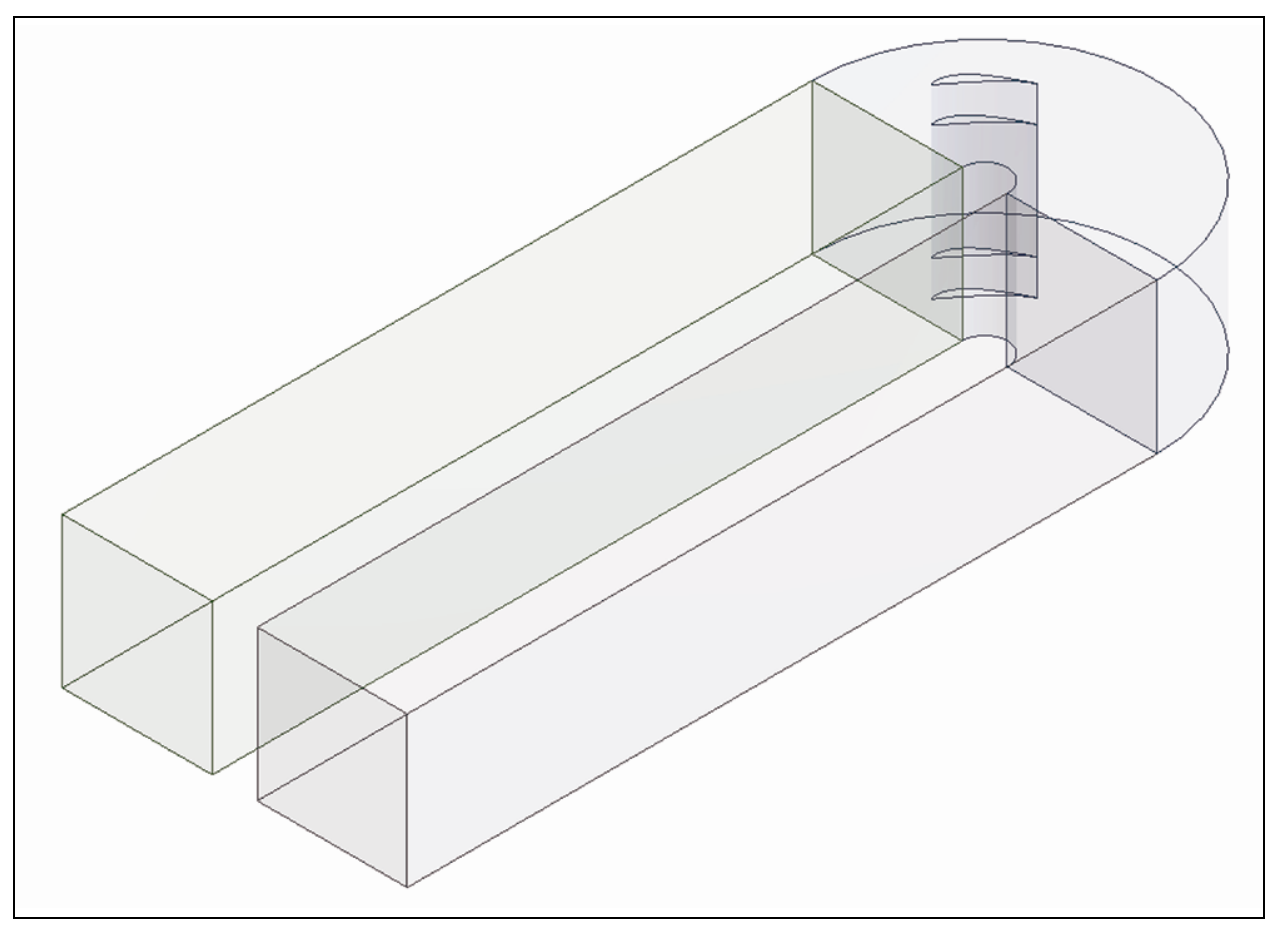

Figure 5.1 The schematic display of the fluid domain with airfoils at the 45-degree plane used as flow control technique

Airfoil is the cross-sectional shape obtained by cutting a wing in the perpendicular plane. The camber line is the line that has equal distance from the upper and lower surfaces and it starts at the leading edge of the airfoil and ends at the trailing edge. Mean camber line is the major design feature of an airfoil. The chord line can be obtained by connecting the leading and trailing edge of an airfoil with a straight line. Moreover, camber of an airfoil means the maximum distance between the camber line and chord line of an airfoil [33]. The parameters which are used to define and airfoil are also shown in Figure 5.2. Airfoils can be classified as in two groups; 
symmetric or uncambered and cambered airfoils. For symmetric airfoils, upper and lower surfaces of the airfoil have same distance to the mean camber line which results with coincident mean camber and chord lines. For cambered airfoils, mean camber line is above the chord line [34].

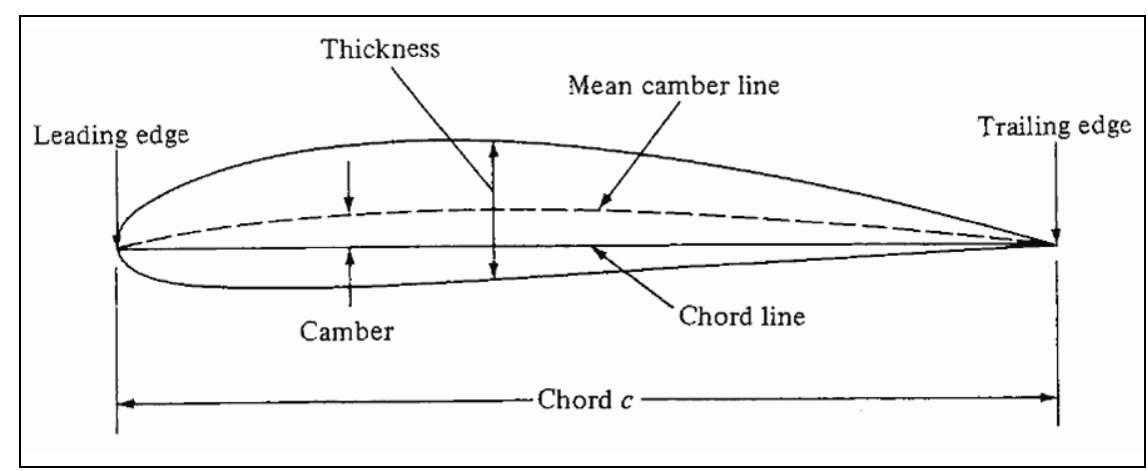

Figure 5.2 Airfoil nomenclature [33]

Airfoils are generally used to obtain additional lift and drag in fluid flows but in this study the main objective of airfoils is directing the flow inside the bend. For this reason FX 74-CL5-140 MOD type uncambered airfoils are used with equal spacing in the 45-degree plane, which are seen in Figure 5.1. The FX 74-CL5-140 type airfoil has one of the highest camber percentage in airfoils as $9.72 \%$ which is required to make the flow follow the curvature inside the bend, and makes FX 74-CL5-140 type airfoil suitable for flow control strategy of the present study [34].

FX 74-CL5-140 MOD type airfoil is a modified version of the FX-CL5-140. Builder of this airfoil, Chuck Hollinger, enlarged the FX-74-CL-140 airfoil in order to measure coordinates and build the FX74-CL5-140 MOD version. Although the FX 74-CL5-140 was originally designed for Reynolds' between 1000k and 3000k, the modified FX 74-CL5-140 does perform well at relatively low Reynolds numbers' including Reynolds number of 100,000 which is the Reynolds Number of the present study [34]. Operation Reynolds Numbers and given camber properties plays important role for the selection of this airfoil. 


\subsection{Flow Control Model Development}

For the flow control strategy, computational fluid dynamic (CFD) model is developed using ANSYS FLUENT to simulate airfoils effects' in the bend. The flow parameters are kept same with the base model and two FX 74-CL5-140 MOD type airfoils are located equally in the 45-degree plane, which can be seen in Figure 5.1.

The mesh of the numerical model, which is shown in Figure 5.3, is kept dense at the bend section but relatively coarse at the inlet and outlet sections of the duct to reduce the computational effort similar to the previous analyses. The walls of airfoils surfaces' are inflated to model boundary layers precisely.

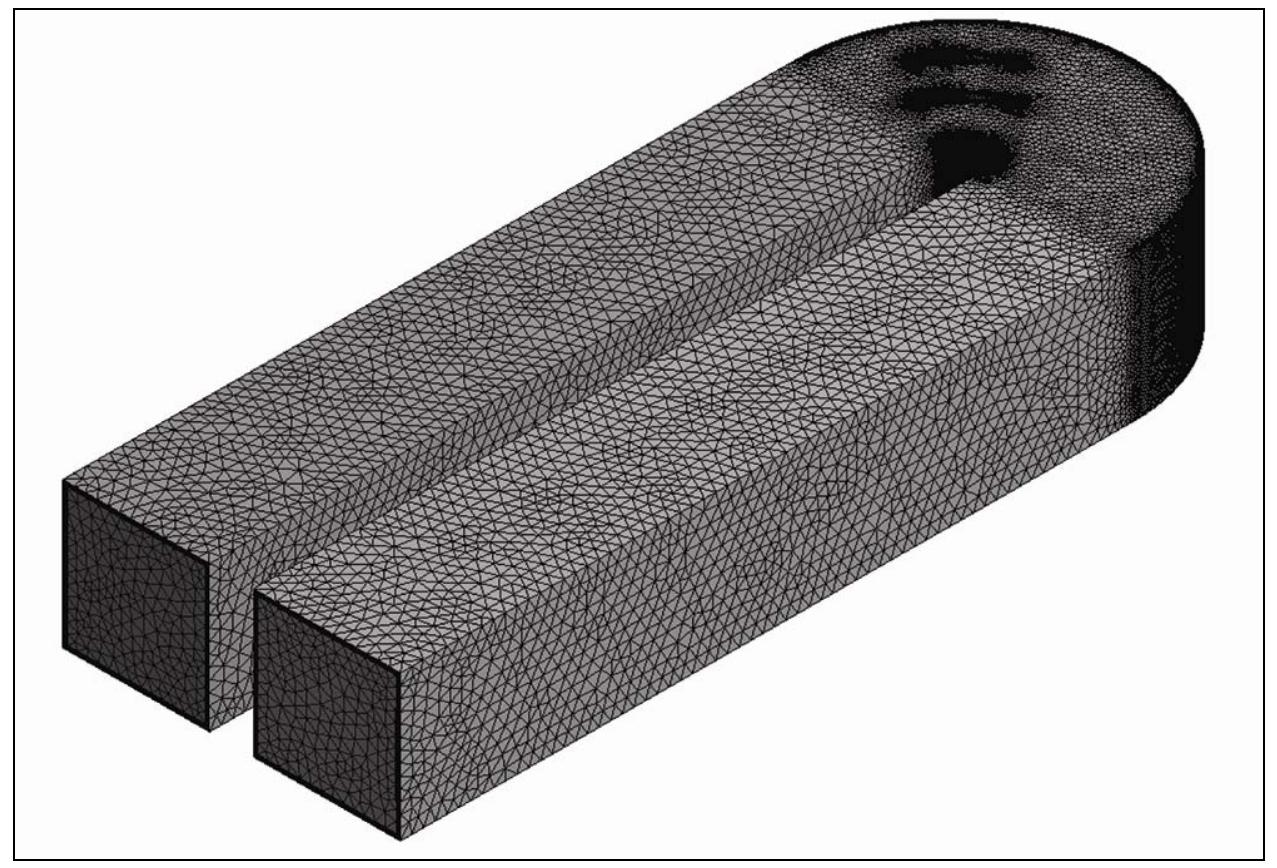

Figure 5.3 The preview of the mesh used for the simulations with airfoils

The preview of the mesh inside the bend and on the airfoils can be seen from Figure 5.4. These improvements also increased the mesh size which is in Figure 5.3. The total number of nodes in the simulation of flow control technique exceeded over 5.5 million. Table 5.1 summarizes the parameters and statistics of the mesh used in the flow control strategy. 


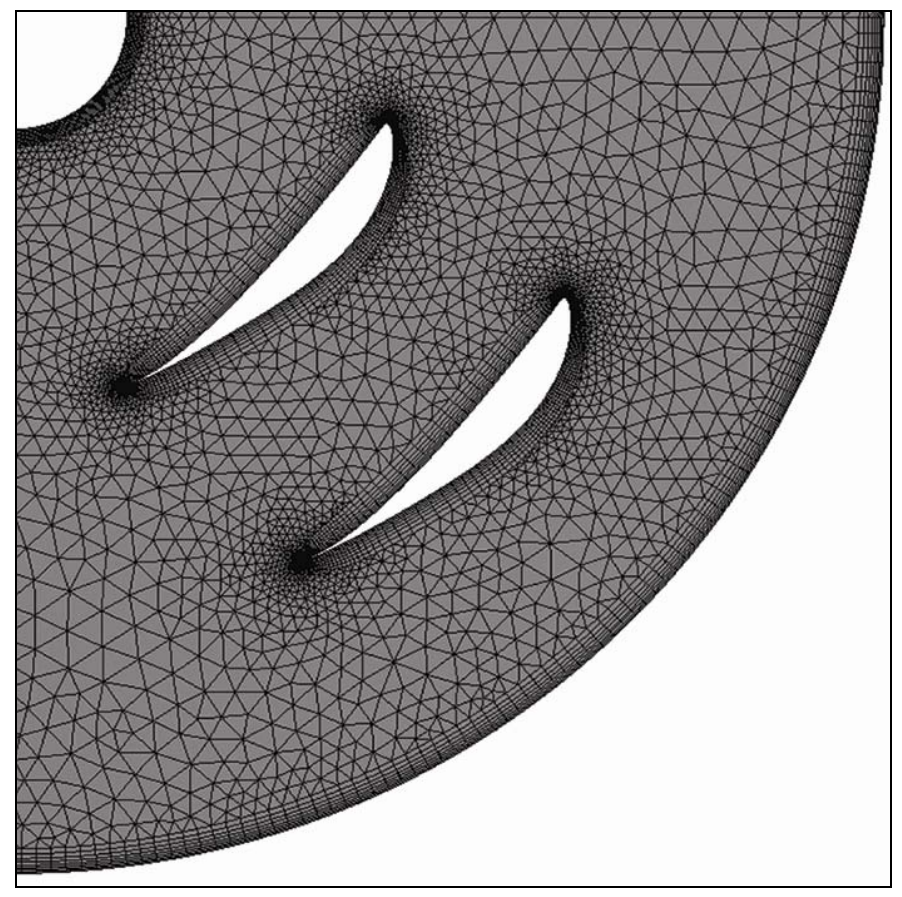

Figure 5.4 The preview of the mesh inside the bend and on the airfoils

Table 5.1 Parameters and statistics of mesh used in the flow control

\begin{tabular}{|c|c|c|c|}
\hline & \multicolumn{3}{|c|}{ Flow Control Mesh } \\
\hline \multirow{2}{*}{$\begin{array}{l}\text { Body } \\
\text { Sizing }\end{array}$} & \multirow{2}{*}{$\begin{array}{c}\text { Element } \\
\text { Size }\end{array}$} & Bend & $2 \mathrm{~mm}$ \\
\hline & & Inlet \& Outlet & $4 \mathrm{~mm}$ \\
\hline \multirow{3}{*}{ Inflation } & \multicolumn{2}{|c|}{ First Layer Thickness } & $0.02 \mathrm{~mm}$ \\
\hline & \multicolumn{2}{|c|}{ Max. Number of Layers } & 18 \\
\hline & \multicolumn{2}{|c|}{ Growth Rate } & 1.2 \\
\hline \multirow{6}{*}{$\begin{array}{c}\text { Mesh } \\
\text { Statistics }\end{array}$} & \multicolumn{2}{|c|}{ Nodes } & 5786504 \\
\hline & \multicolumn{2}{|c|}{ Elements } & 16359576 \\
\hline & \multicolumn{2}{|c|}{ Maximum Skewness } & 0.526 \\
\hline & \multicolumn{2}{|c|}{ Average Skewness } & 0.219 \\
\hline & \multicolumn{2}{|c|}{ Minimum Orthogonal Quality } & 0.327 \\
\hline & \multicolumn{2}{|c|}{ Average Orthogonal Quality } & 0.891 \\
\hline
\end{tabular}




\subsection{Results of Flow Control Strategy}

\subsubsection{Flow Patterns}

The flow patterns, obtained from numerical simulations after the flow control is applied to the bend section by locating airfoils, are compared with the base case, which is the k- $\omega$ SST model results, in this section. The contours of velocity and streamlines are used to represent the flow patterns inside the bend. Figure 5.5 shows the contours of velocity at the simulation domain for the base case and for the controlled case.

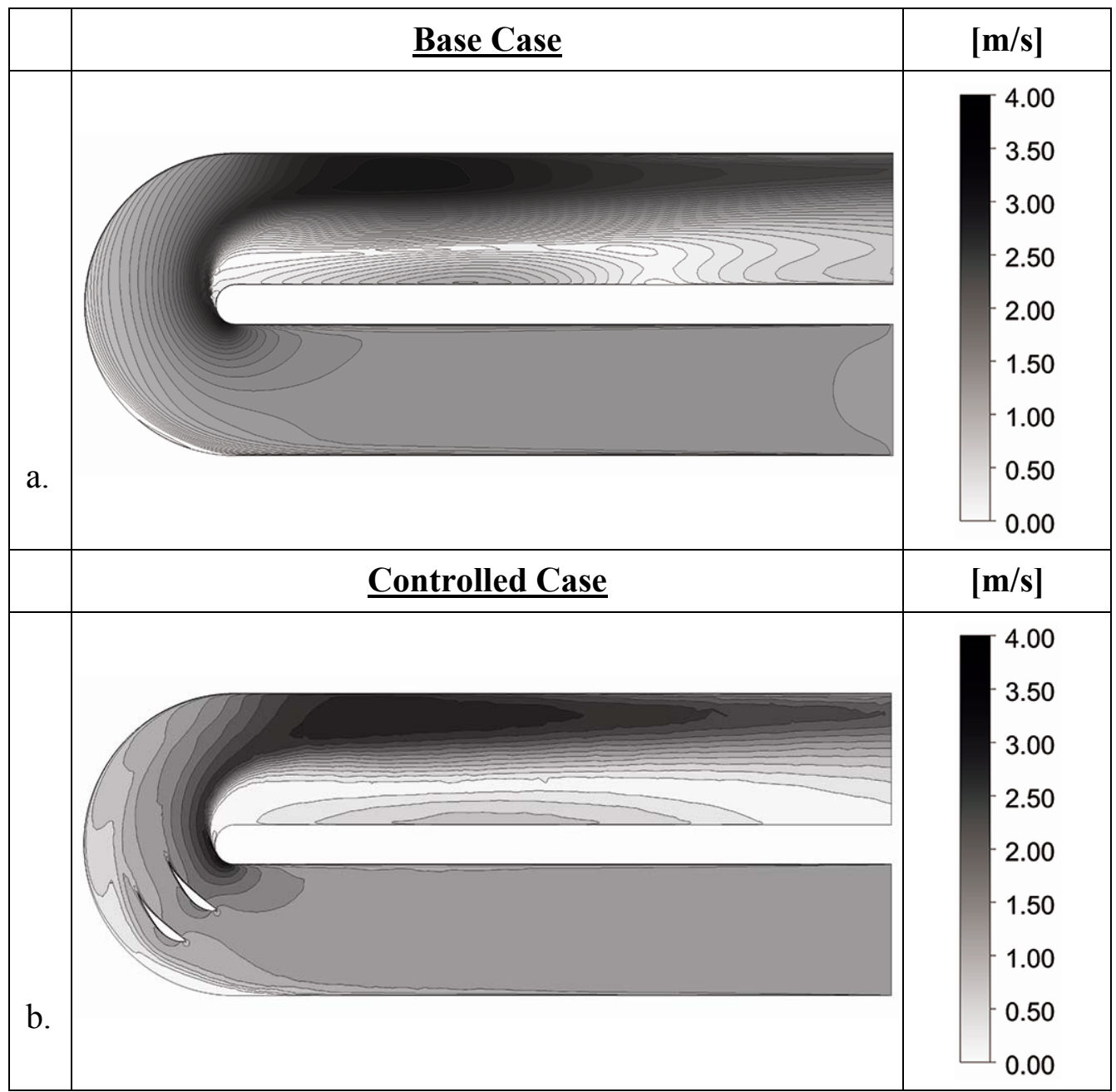

Figure 5.5 The contours of velocity at the simulation domain are shown in (a) for the base model and in (b) for the controlled case 
From Figure 5.6, it is important to notice that the maximum velocity after the bend decreases when the flow control strategy is applied. Moreover, a more homogenous flow pattern is obtained after the bend exit with the airfoils located inside the bend.

Streamlines for base model and model with control strategy at four different angular positions, 90, 120, 150 and 180-degree planes, are shown in Figure 5.6 to Figure 5.9. The top rows show the results for the base model and the bottom rows show the streamlines after the airfoils put inside the bend. The circulation zones in these figures are typical indications of Dean vortices and the inverse gray scale indicates the velocity on the streamlines. The darker sections that occur in the circulation zones display velocity increase close to the cores of the Dean vortices.

It is easy to see that at the 90-degree deflection two strong Dean vortices are located near the top and bottom parts of the inner bend from Figure 5.6(a). After the application of the flow control technique by locating airfoils inside the bend, two Dean vortices are split into six weak circulation zones which can be seen in Figure 5.6(b). These weak Dean vortices are located near the top and bottom of the bend section. Flow control not only splits the vortices in the 90-degree plane but also contributes to weaken the strength of the vortices. The comparison of the first and second rows of the Figure 5.6 easily shows that vortices in the base case are effective up to outer bend and middle plane of the bend whereas after the flow control this effect pines away. 


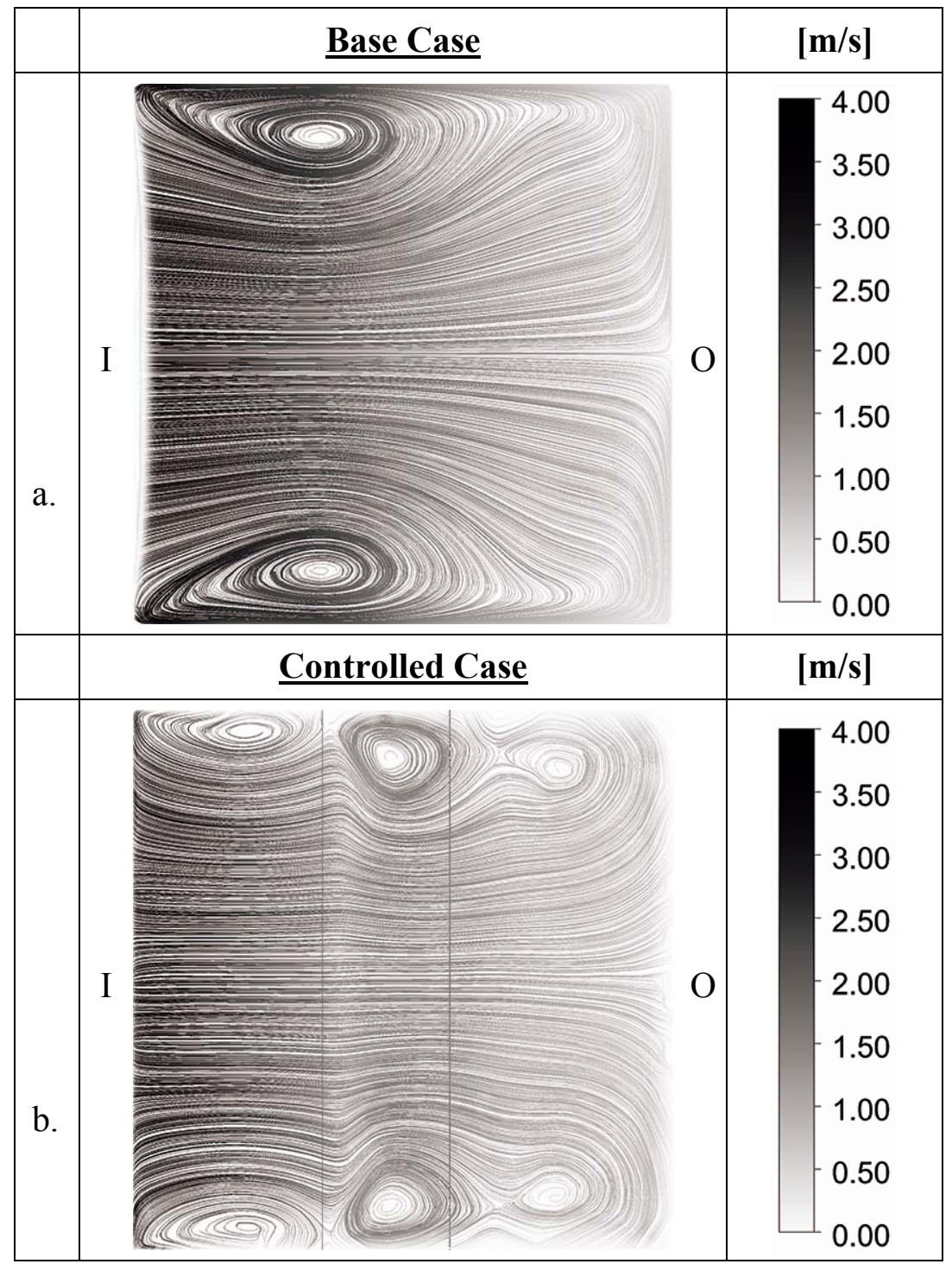

Figure 5.6 The streamlines associated with secondary flow patterns at $\theta=90^{\circ}$ are shown in (a) for the base model and in (b) for the controlled case

The streamlines at 120-degree plane are shown in Figure 5.7. Secondary flow patterns can be seen close to the top and bottom portions near the inside bend. In addition to two strong vortices, base case has two very weak vortices close to the outer bend. It is obvious that counter-rotating vortices vanish completely with the contribution of airfoils located in the bend which can be seen on Figure 5.7(b). 


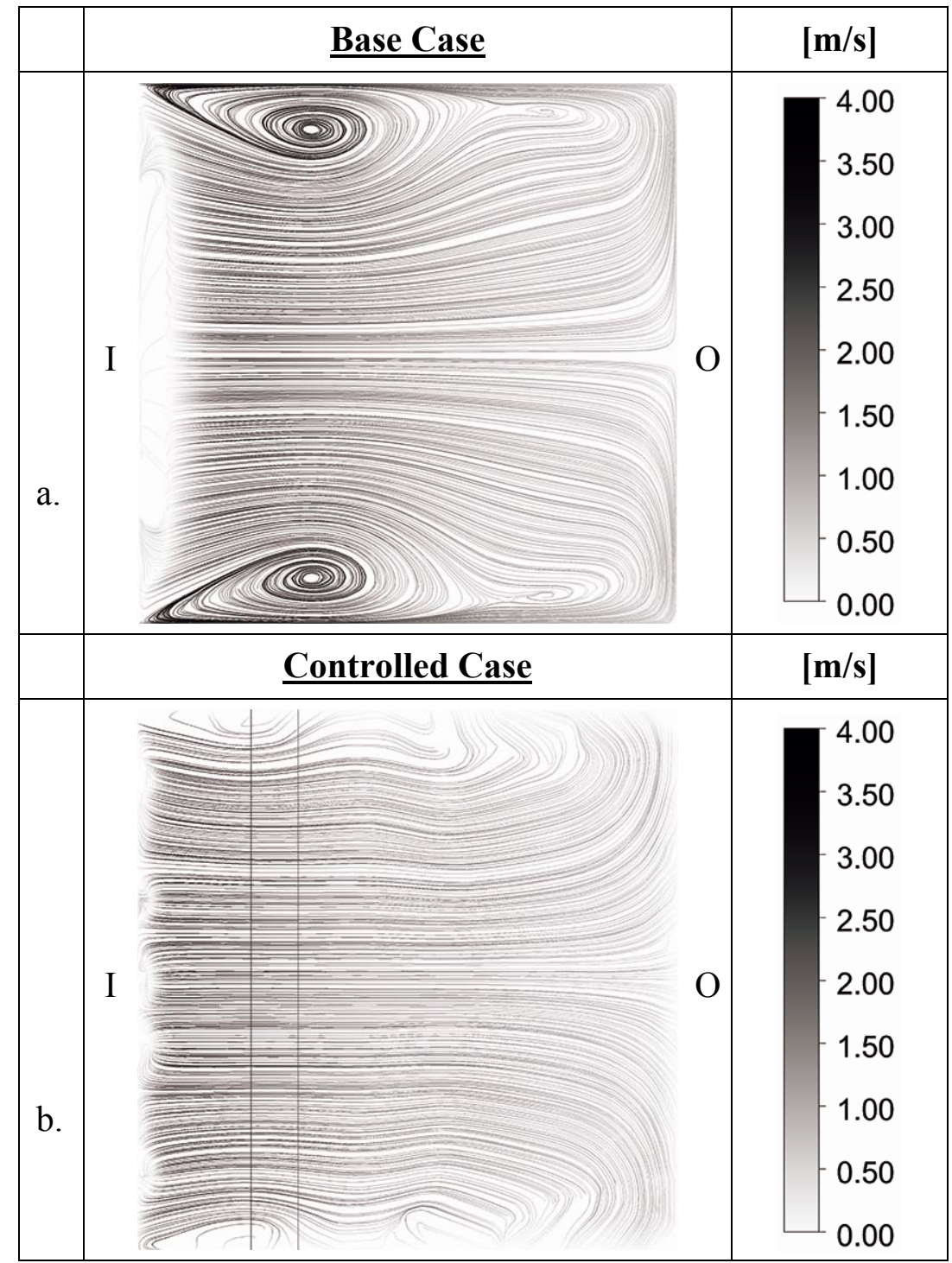

Figure 5.7 The streamlines associated with secondary flow patterns at $\theta=120^{\circ}$ are shown in (a) for the base model and in (b) for the controlled case

Figure 5.8 shows the streamlines at the 150 -degree plane. Base case, which is shown in Figure 5.8(a), has three counter rotating vortex zones on the each side of the mid plane; one is on the inner bend and is weak but has a mid-range impact zone, the other is close to the top or bottom side of the bend and a very weak one is located close to the outer bend as in 120-degree plane. The controlled case, which is shown in Figure 5.8(b), has no Dean vortex zones. 


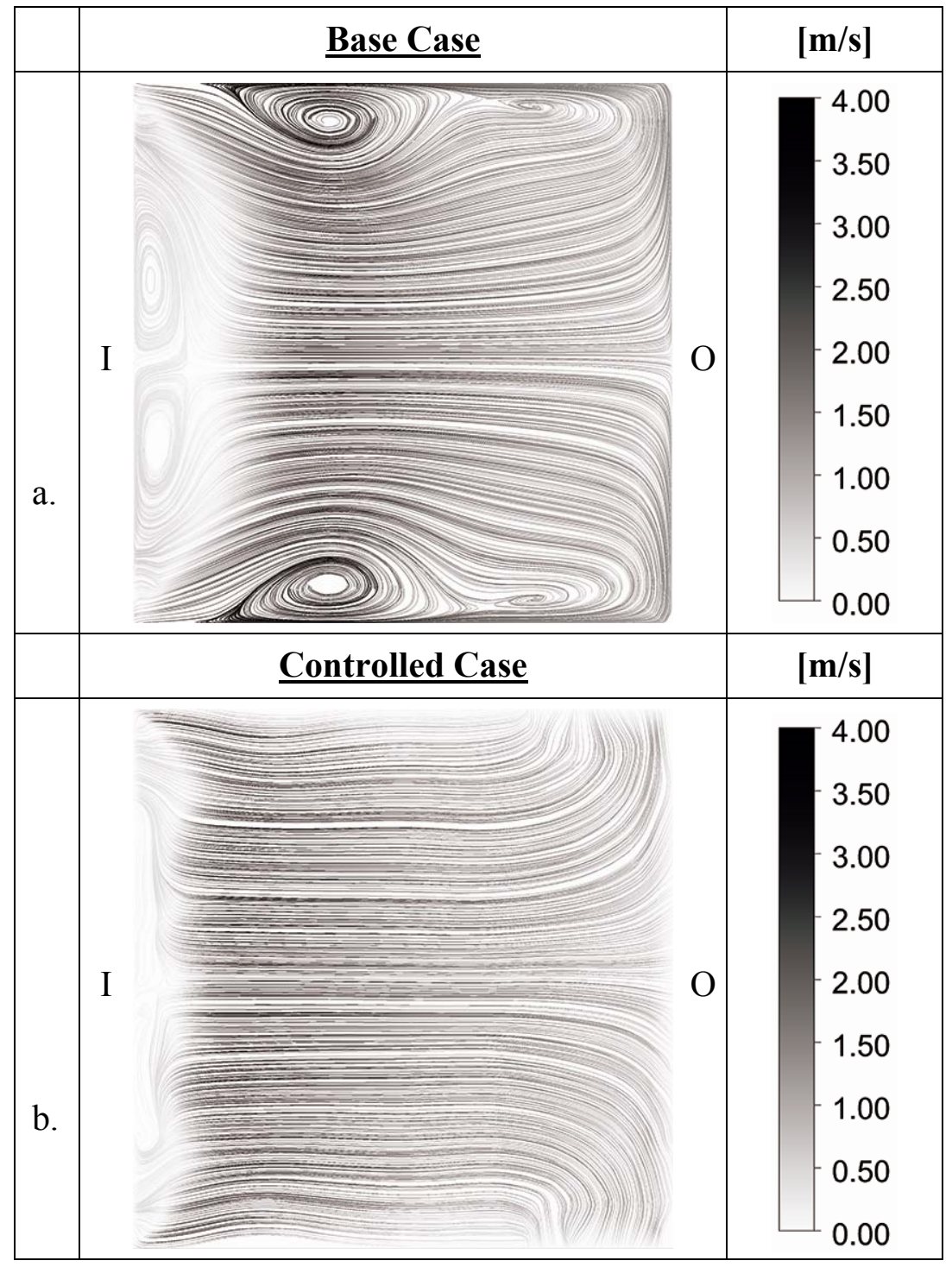

Figure 5.8 The streamlines associated with secondary flow patterns at $\theta=150^{\circ}$ are shown in (a) for the base model and in (b) for the controlled case

At the 180-degree deflection, the control strategy applied to the bend with airfoils shows its results clearly in Figure 5.9. The base case has two Dean vortices located on the top and bottom sides of the bend, symmetrically. The strength of the vortices is similar to vortices in other planes discussed in the bend but at 180-degree plane impact zone of the vortices is smaller. Controlled case has no recirculation zones which can be seen in Figure 5.9(b). 


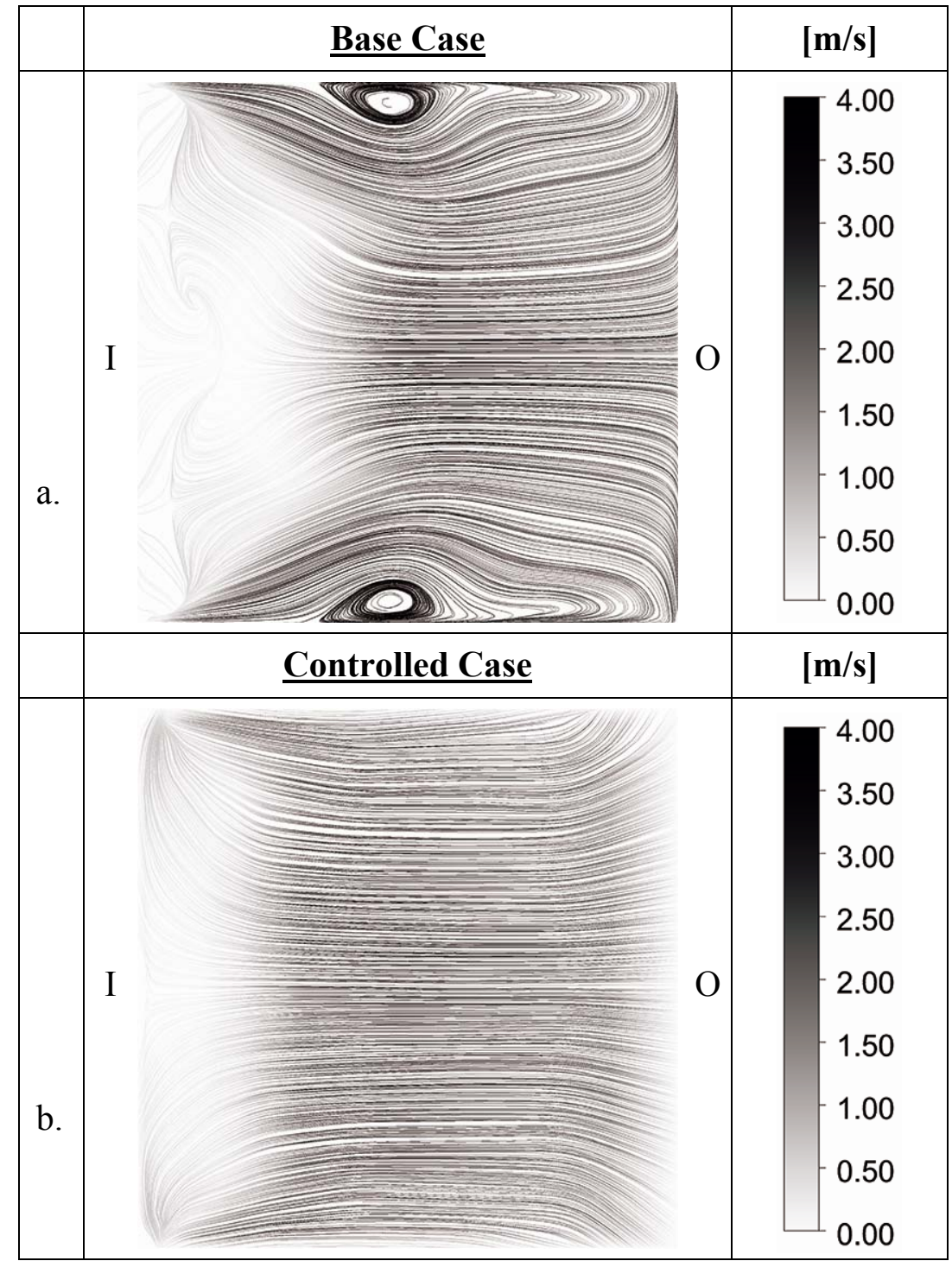

Figure 5.9 The streamlines associated with secondary flow patterns at $\theta=180^{\circ}$ are shown in (a) for the base model and in (b) for the controlled case 


\subsubsection{Vorticities}

This section compares the contours of constant vorticity levels obtained for the base model and the model with airfoils. Visualization and understanding of the vortices can be powerful with the help of the visualization of the vorticity field. Therefore, the complete vorticity field is visualized [35].

Vorticity magnitudes are provided as a gray scale on the right hand side of the each figure. It is important to note that the scale of the vorticity contours is given in logarithmic scale to obtain the coherent visual quality on the images and to cover wide range of vorticity magnitudes.

Significant variations are also detected in vorticity contours when comparing base model with the model with airfoils. The maximum vorticity magnitudes dramatically drop when airfoils are used. This is evident in all bend sections. In addition, considering the vorticity concentrations, much more homogenous concentrations are obtained in the model airfoils are used, which means that the variation between maximum and minimum values of vorticity reduces significantly.

Figure 5.10 shows the contours of vorticity at 90-degree plane for the base and controlled cases. Base case has high vorticity regions located at the lower and upper portions of the bend close to inner bend. These can be easily detectable in the vorticity contour plot. It should be noted that an additional region of high vorticity is associated with the low-velocity zone near the inner bend. With the application of the flow control, high vorticity regions disperse on the plane and lose their strength. Plane average vorticity value decreases from 257 to $240 \mathrm{1} / \mathrm{s}$ which is a $6.6 \%$ decrease with the contribution of the flow control strategy. 


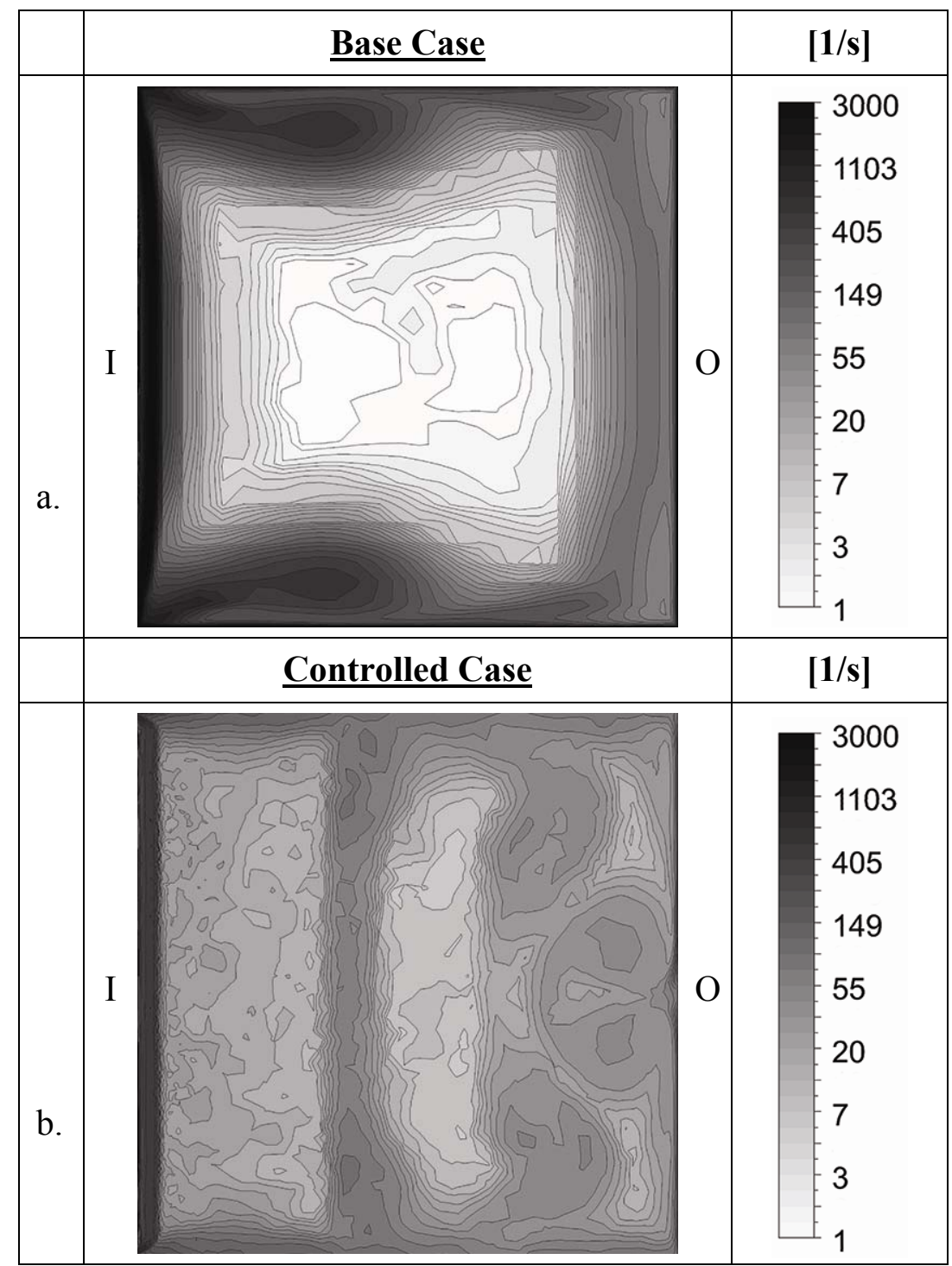

Figure 5.10 The contours of constant vorticity levels at $\theta=90^{\circ}$ are shown in (a) for the base model and in (b) for the controlled case.

Vorticity contours for the 120-degree plane are shown in Figure 5.11. Maximum vorticity occurs on the mid-plane close to the inner bend where the low velocity region is located according to streamline figures. Considering the vorticity concentrations, much more homogenous concentrations are obtained in the model airfoils are used. Plane average vorticity at the 120-degree plane for the base case is $2001 / \mathrm{s}$ and airfoils, which are put inside the bend, decrease this value to $1691 / \mathrm{s}$. This means a $15.5 \%$ decrease in average vorticity on the plane. 


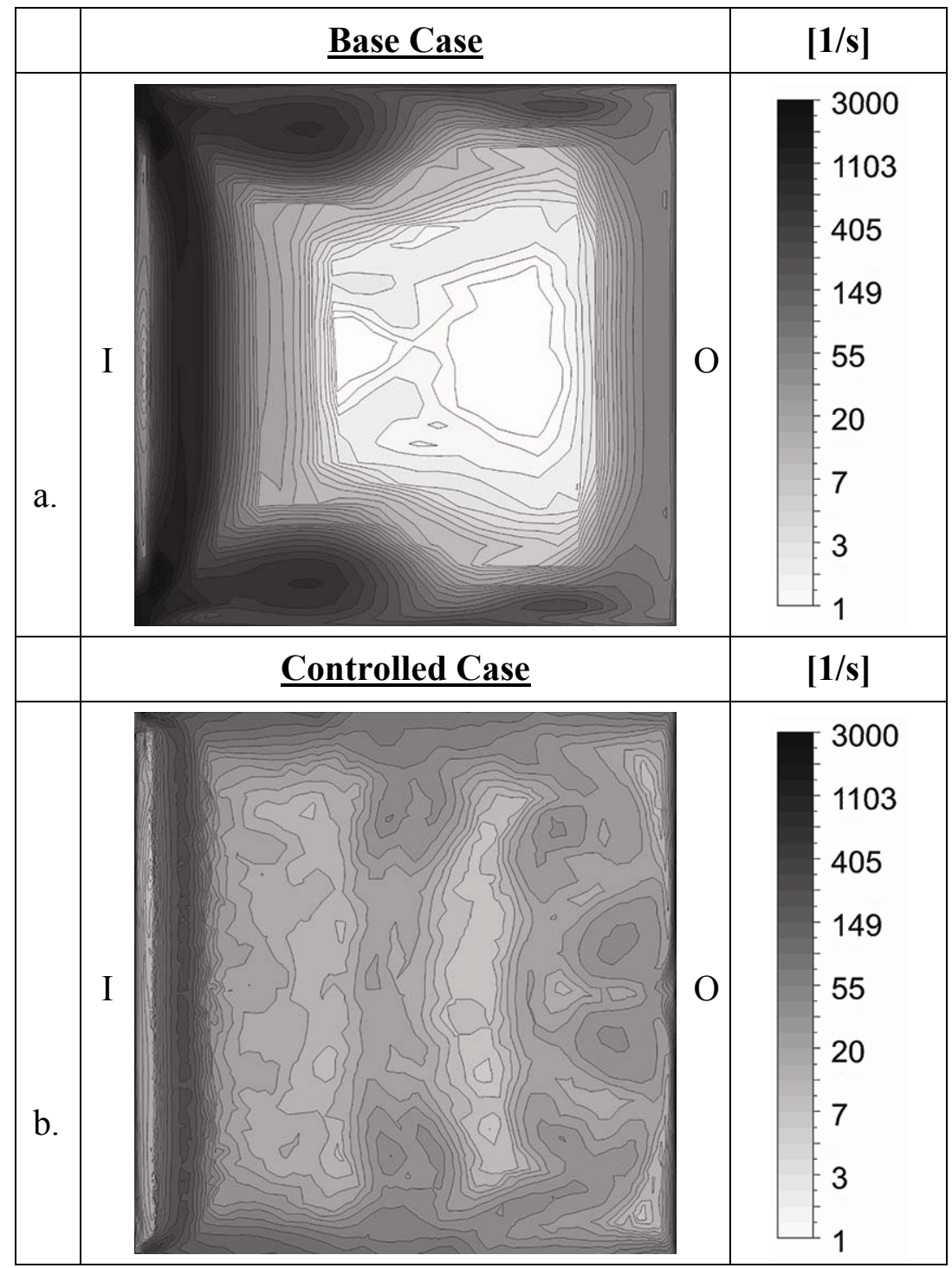

Figure 5.11 The contours of constant vorticity levels at $\theta=120^{\circ}$ are shown in (a) for the base model and in (b) for the controlled case.

Figure 5.12 shows the contours of vorticity for the 150-degree plane. Base case has three high vortex regions on the either side of the mid-plane. These regions also match with the regions shown in streamlines. Figure 5.11 shows that, after the application of flow control strategy, distribution of constant vorticity levels becomes more uniform. This uniformity also reflects on the plane average vorticity results. For the base case plane average vorticity is $2391 / \mathrm{s}$ and for the controlled case this 
value is $1861 / \mathrm{s}$. This stands for a $22.2 \%$ decrease for the average vorticity in this plane.

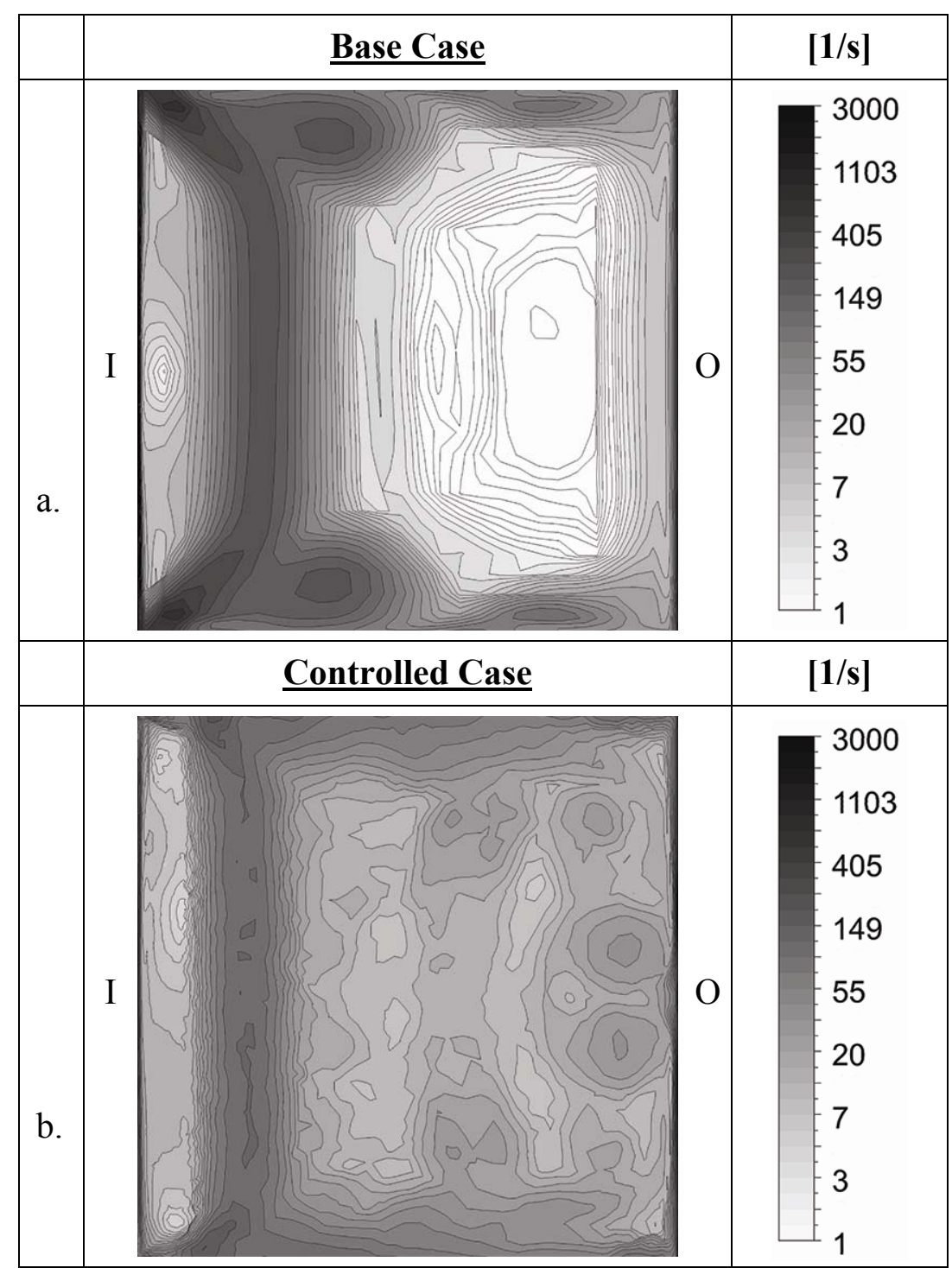

Figure 5.12 The contours of constant vorticity levels at $\theta=150^{\circ}$ are shown in (a) for the base model and in (b) for the controlled case.

The vorticity regions formed in the 180-degree plane have highest values in all the examined planes in this study. This can be comprehensible by comparing the darkness of the vorticity contours of all planes. Figure 5.13 shows the vorticity 
contours for the base and controlled cases of 180-degree plane. Base model has an average vorticity of $274 \mathrm{1} / \mathrm{s}$, which is the highest value in all planes, and flow control strategy assists this value to decrease 174 1/s. This means a $36.5 \%$ decline in average vorticity.

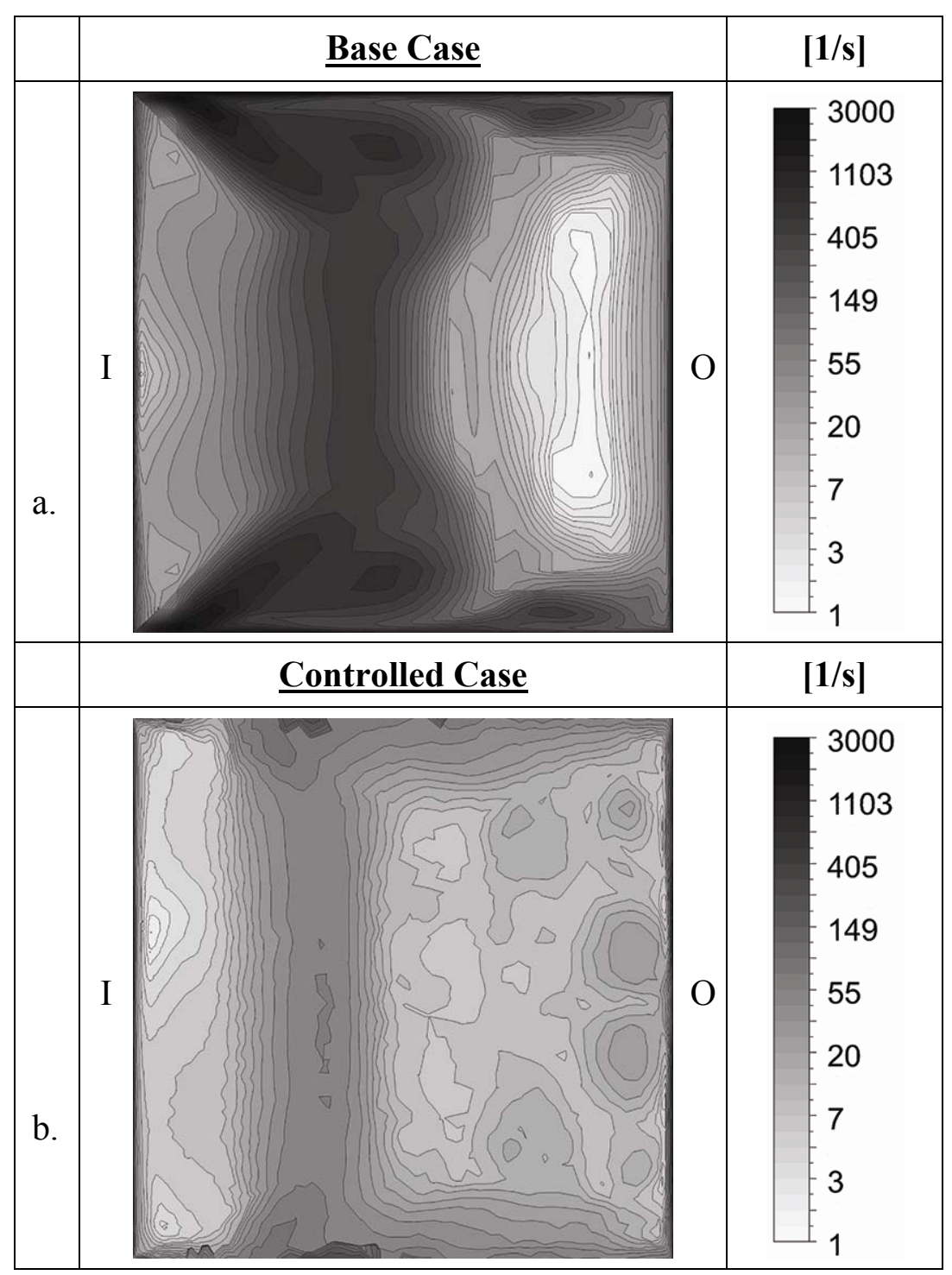

Figure 5.13 The contours of constant vorticity levels at $\theta=180^{\circ}$ are shown in (a) for the base model and in (b) for the controlled case. 
Plane average vorticity values for different bend angles, which are discussed in this section, are summarized in Table 5.2. In this table the first column shows the bend sections inside the bend, the second and third columns show the plane average vorticity values for the base and flow controlled models, respectively. The last column, which is shown in gray shading, shows the difference between the vorticity values of the base and controlled cases in percentage.

Table 5.2 The plane average vorticity levels of the base model and the controlled case

\begin{tabular}{|c|c|c|c|}
\hline \multicolumn{4}{|c|}{ Plane Average Vorticities } \\
\hline Plane & Base Model & Model with Airfoil & \% change \\
\hline 90 & 257 & 240 & $\mathbf{- 6 . 6}$ \\
\hline 120 & 200 & 169 & $\mathbf{- 1 5 . 5}$ \\
\hline 150 & 239 & 186 & $\mathbf{- 2 2 . 2}$ \\
\hline 180 & 274 & 174 & $\mathbf{- 3 6 . 5}$ \\
\hline
\end{tabular}

\subsubsection{Turbulence Intensities}

The contours of constant turbulent intensity levels obtained at angular positions of $90^{\circ}, 120^{\circ}, 150^{\circ}$ and $180^{\circ}$ for the base and controlled cases are shown in Figure 5.14 to Figure 5.17. The inverse gray scale, located right side of the boxes, indicates the strength of the turbulent intensity.

According to turbulence intensity predictions, the turbulent intensity contours show coherence with the circulation zones in the field such that high turbulent intensity regions correspond to high circulation zones, consequently representing high intensity of vortices. 
For 90-degree plane turbulence intensity increases at the regions close to inner side of the bottom and top of the bend. These results are also match with the vorticity contours that are shown in previous section. At 90-degree plane maximum and average turbulent intensities reach up to $30.2 \%$ and $6.5 \%$ for the base model, respectively. The applied flow control decreases maximum turbulent intensity to $17.5 \%$ and average turbulent intensity to $5.9 \%$ for this plane.

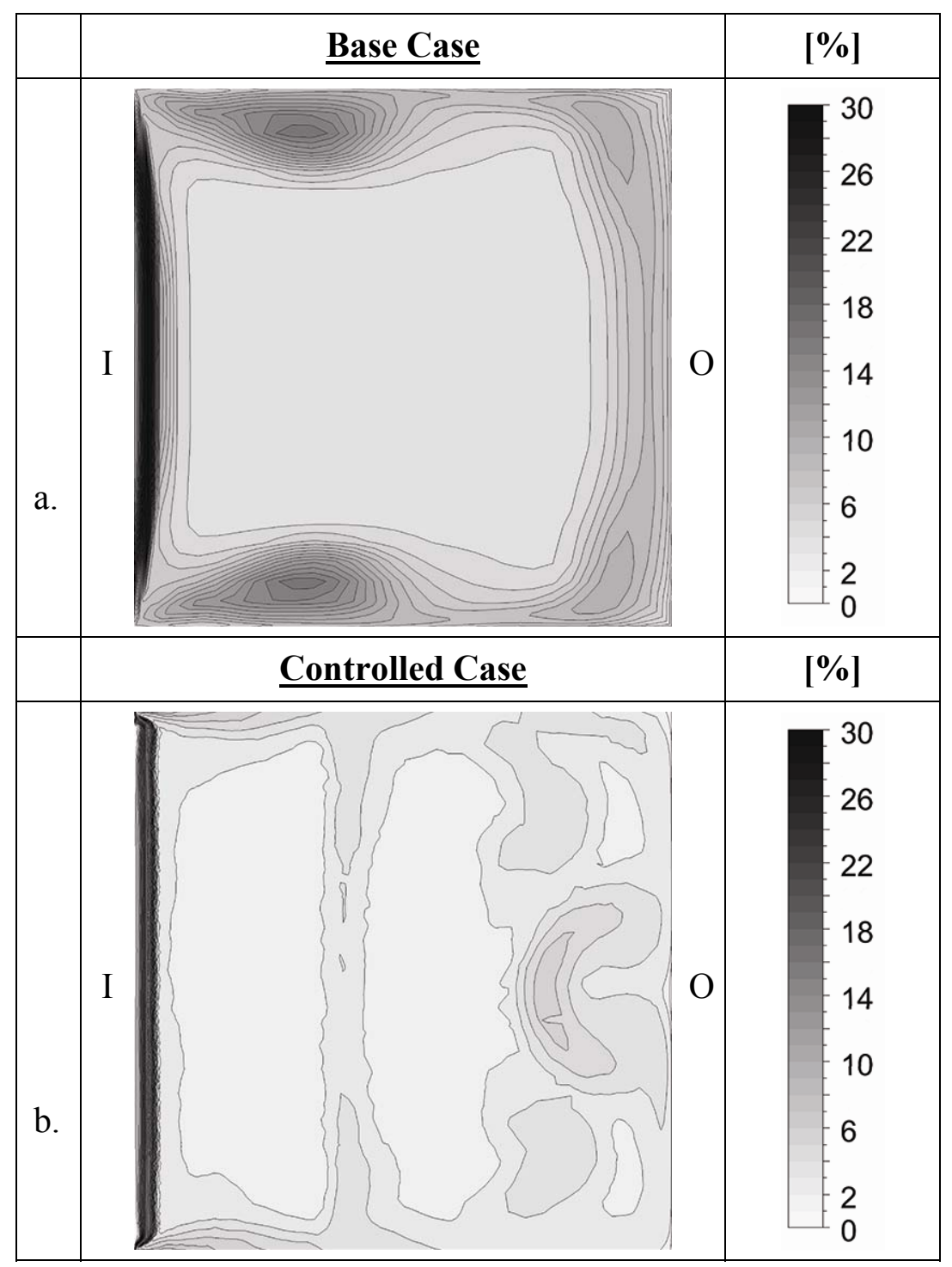

Figure 5.14 The contours of constant turbulence intensity levels at $\theta=90^{\circ}$ are shown in (a) for the base model and in (b) for the controlled case. 
Figure 5.15 shows the turbulence intensity values at the 120 -degree plane. Base case has highly turbulent regions where high vortex zones are dominated the flow. At this plane, base model has $28.3 \%$ maximum and $5.2 \%$ average turbulence intensity values. Maximum and average turbulence intensities show 5.7\% and 5.8\% decline after the implementation of the flow control airfoils into the bend section.

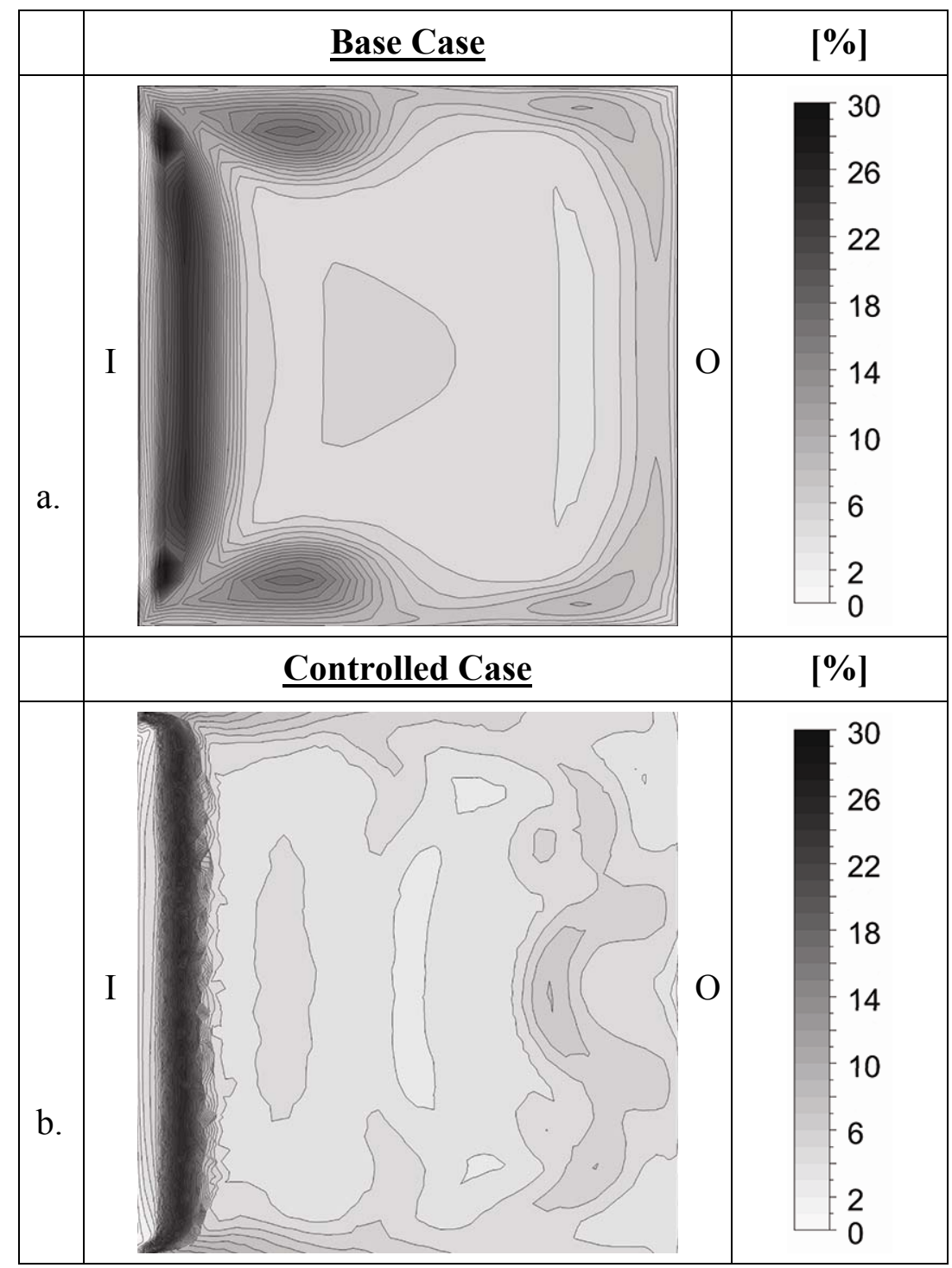

Figure 5.15 The contours of constant turbulence intensity levels at $\theta=120^{\circ}$ are shown in (a) for the base model and in (b) for the controlled case. 
At the 150-degree plane, maximum turbulence intensity location moves to the inner side of the plane. Two turbulent vortex regions are formed in either side of the midplane. Maximum turbulent intensity value is $27.1 \%$ for the base case and this value drops off to $23.5 \%$ with the elimination of the Dean vortices by airfoils. Average turbulent intensity value also decreases from $6.7 \%$ to $5.9 \%$ at the 150 -degree plane.

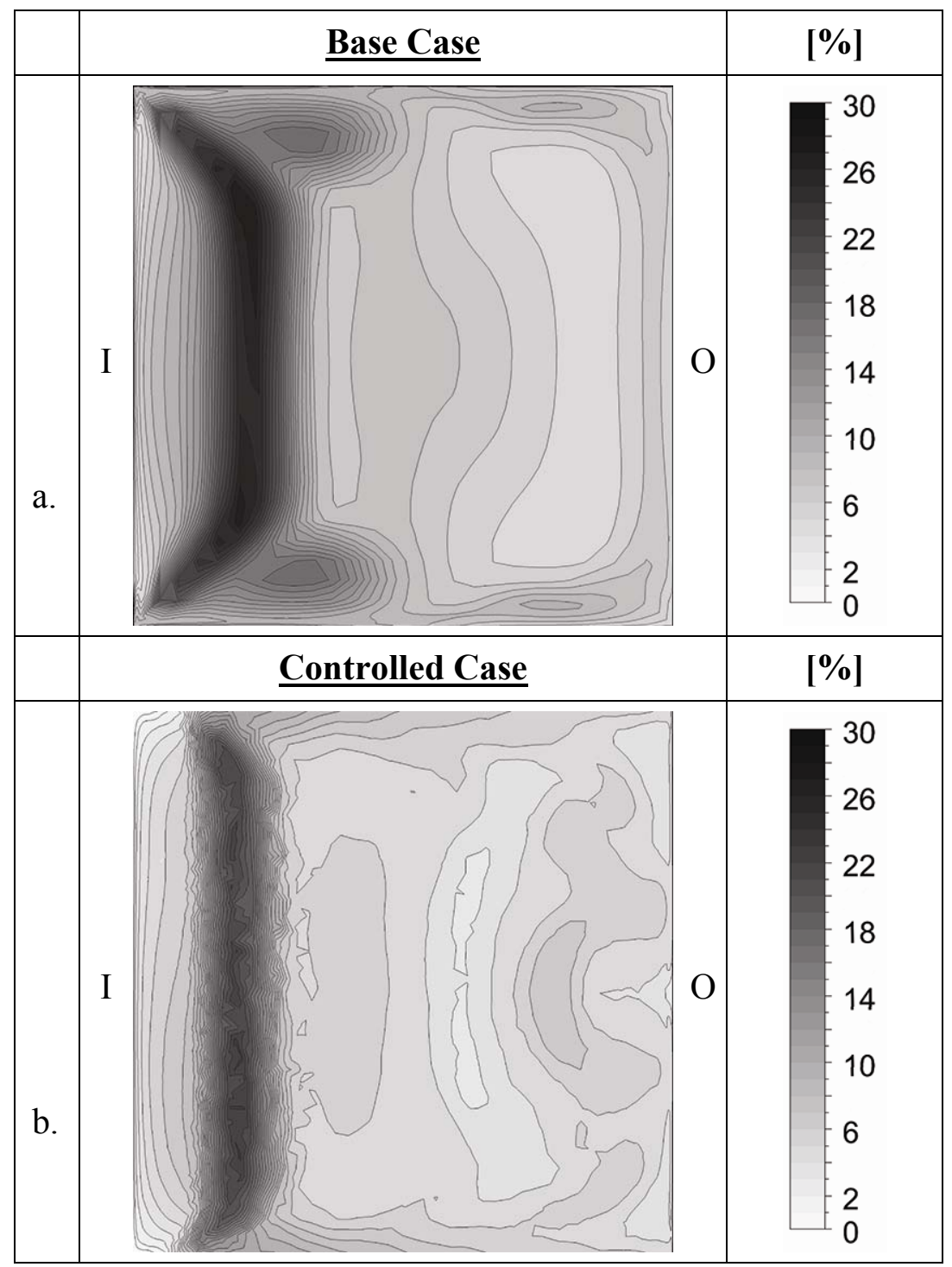

Figure 5.16 The contours of constant turbulence intensity levels at $\theta=150^{\circ}$ are shown in (a) for the base model and in (b) for the controlled case. 
At the 180-degree plane, turbulence intensity contours, which is shown in Figure 5.17, show coherence with the vorticity contours. Maximum turbulence intensity regions occur near the Dean vortex zones which are shown in streamlines. Base model has $29.1 \%$ maximum and $8.1 \%$ average turbulence intensity values. Flow control applied inside the bend removes the vortex zones and decreases maximum and average turbulence intensity values to $21.2 \%$ and $7.0 \%$, respectively.

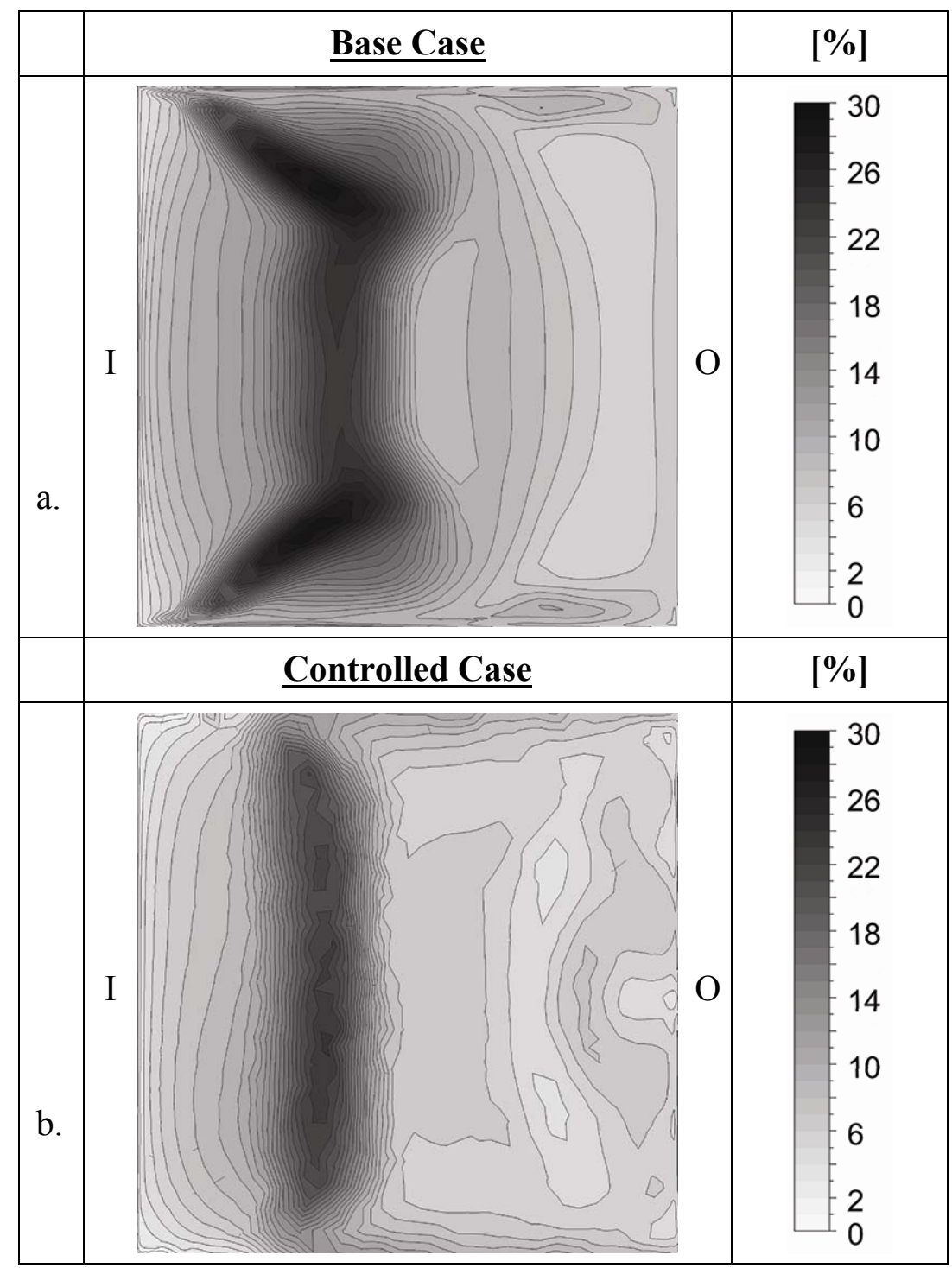

Figure 5.17 The contours of constant turbulence intensity levels at $\theta=180^{\circ}$ are shown in (a) for the base model and in (b) for the controlled case. 
Maximum and average turbulent intensity values for different bend angles, which are discussed in this section, are summarized in Table 5.3. In this table the first column shows the bend sections inside the bend, the second and third columns show the results for the base and flow controlled models, respectively. The last column, which is shown in gray shading, shows the difference of the turbulence intensity values of the base and controlled cases in percentage.

Table 5.3 The maximum and average turbulence intensity levels of the base model and the controlled case

\begin{tabular}{|c|c|c|c|}
\hline \multicolumn{5}{|c|}{ Maximum Turbulence Intensities } \\
\hline Plane & Base Model & Model with Airfoil & \% change \\
\hline 90 & 30.2 & 17.5 & $\mathbf{- 4 2 . 1}$ \\
\hline 120 & 28.3 & 26.7 & $\mathbf{- 5 . 7}$ \\
\hline 150 & 27.1 & 23.5 & $\mathbf{- 1 3 . 3}$ \\
\hline 180 & 29.1 & 21.2 & $\mathbf{- 2 7 . 1}$ \\
\hline & Average Turbulence Intensities & \\
\hline Plane & Base Model & Model with Airfoil & \% change \\
\hline 90 & 6.5 & 5.9 & $\mathbf{- 9 . 2}$ \\
\hline 120 & 5.2 & 4.9 & $\mathbf{- 5 . 8}$ \\
\hline 150 & 6.7 & 5.9 & $\mathbf{- 1 1 . 9}$ \\
\hline 180 & 8.1 & 7.0 & $\mathbf{- 1 3 . 6}$ \\
\hline
\end{tabular}




\section{CHAPTER 6}

\section{CONCLUSION AND FUTURE WORKS}

\subsection{Summary and Conclusion}

Turbulent flow passing through square sectioned U-bend with a curvature $R_{c} / D=0.65$ is studied in this work using computational fluid dynamic modeling. The simulations are performed with six different turbulence models: the standard k- $\varepsilon$, the k- $\varepsilon$ Realizable, the k- $\varepsilon$ RNG, the k- $\omega$ SST, the Reynolds Stress Model (RSM) and the Scale-Adaptive Simulation Model (SAS). The aims of the study are to develop numerical model, which accurately predicts the flow inside the bend, to compare the performances of different turbulence models, to propose optimum numerical approach for such bends, and to regulate the flow structure inside the bend using efficient control techniques. For the validation of the numerical models, the velocity profiles and separation point information from experimental results of Cheah et al. [11] are used.

The results show that the flow inside a U-bend is three-dimensional and highly complex. The following conclusions can be drawn from the present study;

- According to the velocity profiles obtained from computations, the k- $\omega$ SST, the Reynolds Stress Model (RSM) and the Scale-Adaptive Simulation Model (SAS) predictions are quite accurate when considering the Cheah et al.'s experimental results [11].

- In addition, considering the previous simulation results in the literature for the same test case, an improvement is witnessed in the present study.

- Location of separation points in the bend is best captured by k- $\omega$ SST model. In order to propose the optimum numerical approach, computation time is 
also considered along with the accuracy of the solutions. The k- $\omega$ SST turbulence model is selected as the optimum numerical approach for this application.

Furthermore, an efficient solution to eliminate Dean vortices and to reduce turbulence levels in U-bends is proposed. The flow control technique consists of two airfoils located on 45-degree plane of the bend. The streamlines, contours of constant turbulence intensity and vorticity levels of the base and controlled cases are compared. Airfoils, located inside the bend, significantly deteriorate the Dean vortices, which result in significant reduction of maximum and average turbulence intensity levels in all planes at a range between $5.7 \%$ and $42.1 \%$. A similar trend is witnessed for the plane average vorticity values.

Considering the aforementioned effects of control technique using airfoils inside the bend, it can be concluded that the flow control strategy is quite successful in eliminating Dean Vortices, reduction in turbulence intensity values, and increasing the flow uniformity inside the duct. It is expected that all these outcomes result in reduction in flow induced noise levels in the duct.

\subsection{Future Works}

With regard to future work, modeling and validation of the noise generation would be the next primary objective. ANSYS FLUENT has an Acoustics Module that is capable of predicting the aerodynamically generated noise. In addition, a test set-up can be used to measure the noise generated at different locations of the bend and can be compared with computer models for validation.

The flow control strategy presented in Chapter 5 consists of two airfoils located on the 45-degree plane. This is a static flow control technique, and based on this work it can be said that determination and application of a dynamic flow control strategy should be the next step in order to obtain lower turbulence intensity values inside the bend. 
Moreover, different bend shapes that is being used in the Heating, Ventilating and Air Conditioning (HVAC) systems can also be investigated for the formation of Dean vortices and generation of high levels of turbulence. 


\section{REFERENCES}

[1] F. Ducret, "Studies of Sound Generation and Propagation in Flow Ducts," The Royal Institute of Technology (KTH), 2006.

[2] T. Marks, "Explicit Formulas for the Calculation of Regenerated Noise in Ducts," in The 33rd International Congress and Exposition on Noise Control Engineering, 2004.

[3] O. V. Garcia, "Determination of the Correlation between Turbulence Intensity and Acoustic Noise Level - Two Clockwise - Turning Rotors Case," Lodz University of Technology, 2012.

[4] S. R. Ryherd and L. M. Wang, "Measuring Sound Power in Ducted Heating, Ventilating, and Air-Conditioning (HVAC) Systems for Use in Verifying Acoustical Prediction Methods," Build. Integr. Solut., pp. 1-5, Mar. 2006.

[5] A. Kalpakli and R. Örlü, "Turbulent Pipe Flow Downstream a 90 Pipe Bend With and Without Superimposed Swirl," Int. J. Heat Fluid Flow, vol. 41, pp. 103-111, Jun. 2013.

[6] M. Rowe, "Measurements and Computations of Flow in Pipe Bends," J. Fluid Mech., vol. 43, no. 4, pp. 771-783, 1970.

[7] J. Azzola, J. A. C. Humphrey, H. Iacovides, and B. E. Launder, "Developing Turbulent Flow in a U-Bend of Circular Cross-Section: Measurement and Computation," Journal of Fluids Engineering, vol. 108. pp. 214-221, 1986. 
[8] M. Anwer, R. M. C. So, and Y. G. Lai, "Perturbation by and Recovery from Bend Curvature of a Fully Developed Turbulent Pipe Flow," J. Phys. Fluids $A$, vol. 1, no. 8, pp. 1387-1397, 1989.

[9] K. Sudo, M. Sumida, and H. Hibara, "Experimental Investigation on Turbulent Flow in a Square-Sectioned 90-Degree Bend," Exp. Fluids, vol. 30, no. 3, pp. 246-252, Mar. 2001.

[10] S. M. Chang, J. A. C. Humphrey, and A. Modavi, "Turbulent Flow in a Strongly Curved U-bend and Downstream Tangent of Square Cross-Sections," Physicochem. Hydrodyn., vol. 4, no. 3, pp. 243-269, 1983.

[11] S. C. Cheah, H. Iacovides, D. C. Jackson, H. Ji, and B. E. Launder, "LDA Investigation of the Flow Development Through Rotating U-Ducts," $J$. Turbomach., vol. 118, pp. 590-596, 1996.

[12] Y.-D. Choi, H. Iacovides, and B. E. Launder, "Numerical Computation of Turbulent Flow in a Square Cross-Sectioned $180^{\circ}$ Bend," ASME J. Fluids Eng., vol. 111, pp. 59-68, 1989.

[13] H. Iacovides, B. . Launder, P. A. Loizou, and H. H. Zhao, "Turbulent Boundary-Layer Development Around a Square- Sectioned U-Bend : Measurements and Computation," ASME J. Fluids Eng., vol. 112, pp. 409$415,1990$.

[14] C. Münch and O. Métais, "Large eddy simulations in curved square ducts: variation of the curvature radius," J. Turbul., vol. 8, no. 28, pp. 1-18, Jan. 2007.

[15] K. Suga, "Predicting turbulence and heat transfer in 3-D curved ducts by nearwall second moment closures," Int. J. Heat Mass Transf., vol. 46, no. 1, pp. 161-173, Jan. 2003. 
[16] B. Djebedjian, M. S. Mohamed, and A. Elsayed, "Numerical Studies of Curvature Effect on Turbulent Flows in $180^{\circ}$ Curved Ducts," in 6th International Engineering Conference, 2008, pp. 347-373.

[17] P. Batten, T. J. Craft, M. A. Leschziner, and H. Loyau, "Reynolds-StressTransport Modeling for Compressible Aerodynamics Applications," AIAA J., vol. 37 , no. 7 , pp. $785-797,1999$.

[18] B. E. Launder and D. B. Spalding, Lectures in Mathematical Models of Turbulence. London: Academic Press, 1972, p. 176.

[19] V. Yakhot and S. a. Orszag, "Renormalization Group Analysis of Turbulence. I. Basic Theory,” J. Sci. Comput., vol. 1, no. 1, pp. 3-51, 1986.

[20] T.-H. Shih, W. W. Liou, A. Shabbir, Z. Yang, and J. Zhu, "A New k-e Eddy Viscosity Model for High Reynolds Number Turbulent Flows," Comput. Fluids, vol. 24, no. 3, pp. 227-238, 1995.

[21] F. R. Menter, "Two-Equation Eddy-Viscosity Turbulence Models for Engineering Applications," AIAA J., vol. 32, no. 8, pp. 1598-1605, Aug. 1994.

[22] B. E. Launder, G. J. Reece, and W. Rodi, "Progress in the Development of a Reynolds-Stress Turbulence Closure," J. Fluid Mech., vol. 68, no. 03, p. 537, Mar. 2006.

[23] F. Lien and M. Leschziner, "Assessment of Turbulent Transport Models Including Non-Linear RNG Eddy-Viscosity Formulation and Second-Moment Closure," Comput. Fluids, vol. 23, no. 8, pp. 983-1004, Nov. 1994.

[24] B. E. Launder, "Second-Moment Closure and Its Use in Modeling Turbulent Industrial Flows," Int. J. Numer. Methods Fluids, vol. 9, pp. 963-985, 1989. 
[25] C. G. Speziale, S. Sarkar, and T. B. Gatski, "Modelling the Pressure-Strain Correlation of Turbulence:An Invariant Dynamical Systems Approach,” J. Fluid Mech., vol. 227, pp. 245-272, 1991.

[26] D. C. Wilcox, Turbulence Modeling for CFD, Third. DCW Industries, 2006, p. 522.

[27] F. R. Menter and Y. Egorov, "The Scale-Adaptive Simulation Method for Unsteady Turbulent Flow Predictions. Part 1: Theory and Model Description," Flow, Turbul. Combust., vol. 85, no. 1, pp. 113-138, Jun. 2010.

[28] D. Flórez-Orrego, W. Arias, D. López, and H. Velásquez, "Experimental and CFD Study of a Single Phase Cone-Shaped Helical Coiled Heat Exchanger: An Empirical Correlation," in Proceedings of ECOS 2012 - The 25th International Conference on Efficiency, Cost, Optimization, Simulation and Environmental Impact of Energy Systems, 2012, pp. 375-394.

[29] K. Rup and P. Sarna, "Analysis of Turbulent Flow through a Square-Sectioned Duct with Installed 90-Degree Elbow," Flow Meas. Instrum., vol. 22, no. 5, pp. 383-391, Oct. 2011.

[30] M. M. Enayet, M. M. Gibson, A. Taylor, and M. Yianneskis, "Laser-Doppler Measurements of Laminar and Turbulent Flow in a Pipe Bend," Int. J. Heat Fluid Flow, vol. 3, pp. 213-219, 1982.

[31] K. Sudo, M. Sumida, and H. Hibara, "Experimental Investigation on Turbulent Flow in a Circular-Sectioned 90-Degree Bend," Exp. Fluids, vol. 25, pp. 42-49, 1998.

[32] K. Sudo, M. Sumida, and H. Hibara, "Experimental Investigation on Turbulent Flow in a Circular-Sectioned 180-Degree Bend," Exp. Fluids, vol. 28, pp. 51-57, 2000. 
[33] J. Anderson, "Airfoils, Wings, and Other Aerodynamic Shapes," in Introduction to Flight, Seventh., McGraw-Hill Education, 2013, p. 944.

[34] M. Selig, J. J. Guglielmo, A. P. Broeren, and P. Giguere, Summary of LowSpeed Airfoil Data Summary of Low-Speed Airfoil Data, vol. 1. Virginia Beach: SoarTech Publications, 1995, p. 315.

[35] F. Sadlo, R. Peikert, and E. Parkinson, "Vorticity Based Flow Analysis and Visualization for Pelton Turbine Design Optimization," in IEEE Visualization, 2004, pp. 179-186. 